\title{
The Nexus City
}

Researching connectivity between networks and flows of urban food, energy, and water

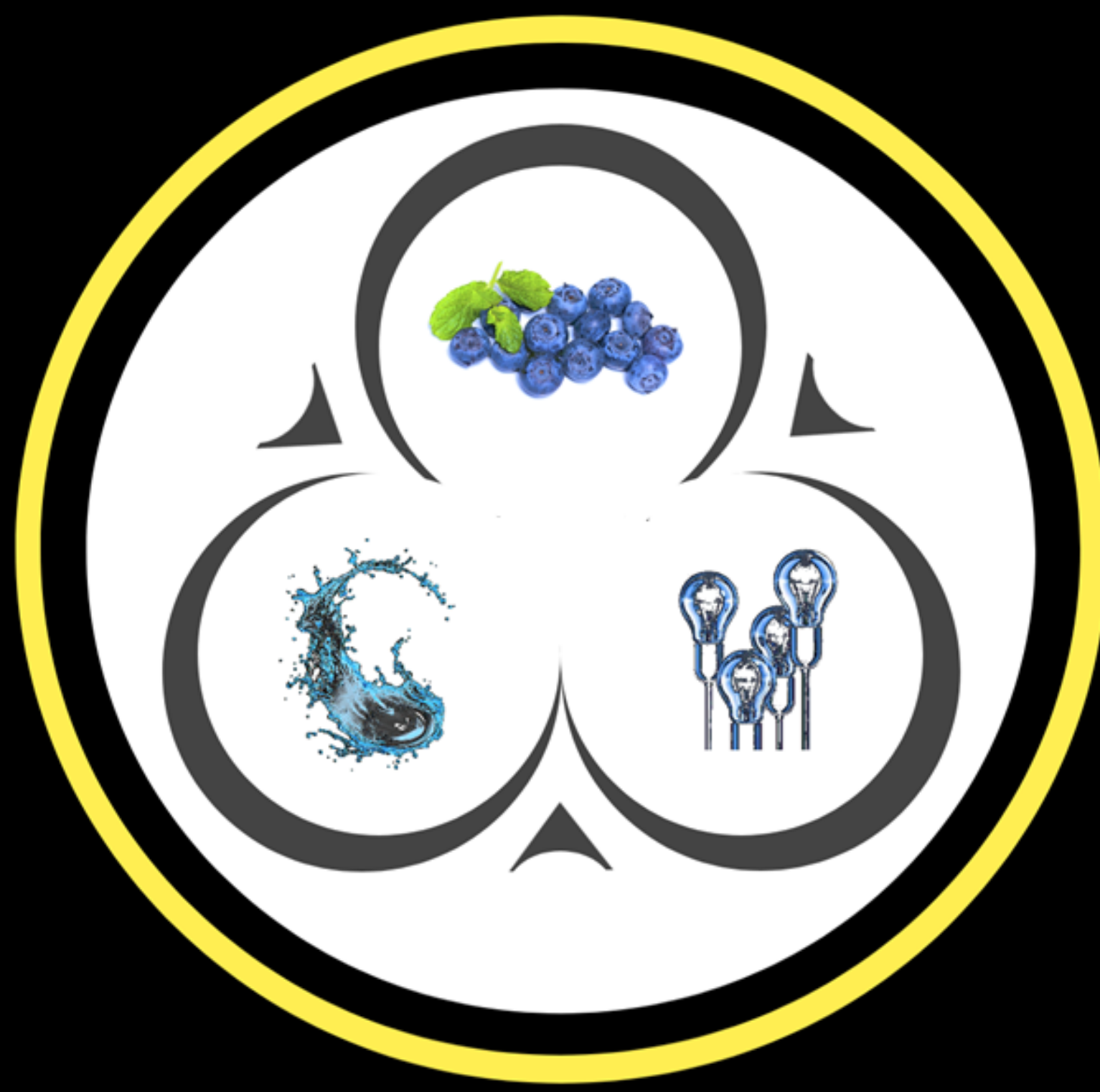

Moises Covarrubias 


\section{Propositions}

1. Connecting different resource systems into a nexus approach requires an interface for actors to govern resource connectivity. (this thesis)

2. Network-power dynamics block the urban sustainable development of water, energy, and food resources.

(this thesis)

3. Access to sustainable local food is key to increasing food sovereignty as a human right.

4. Similar to governing resource systems, the world of scientific publishing is constrained by networked and networking power dynamics.

5. Scholarship Ph.D.'s. are in a more vulnerable position compared to Ph.D.'s. that are employed.

6. Science deserves liberation in a world of academic busyness.

Propositions belonging to the $\mathrm{PhD}$ thesis, entitled

The Nexus City: Researching connectivity between networks and flows of urban food, energy, and water

Moises Covarrubias Perez

Wageningen, November $5^{\text {th }}, 2020$ 


\section{The Nexus City:}

Researching connectivity between networks and flows of urban food, energy, and water 


\section{Thesis committee}

\section{Promotors}

Prof. Dr Gert Spaargaren

Environmental Policy Group

Wageningen University

\section{Co-promotor}

Dr Ingrid Boas

Environmental Policy Group

Wageningen University

This research was conducted under the auspices of the WIMEK-SENSE research school 


\section{The Nexus City: \\ Researching connectivity between networks and flows of urban \\ food, energy, and water}

Moises Covarrubias

Thesis

Submitted in fulfilment of the requirement for the degree of doctor at Wageningen University

by the authority of the Rector Magnificus,

Prof. Dr A. P. J. Mol

In the presence of the

Thesis Committee appointed by the Academic Board

To be defended in public

On November $5^{\text {th }}, 2020$

At 11:00 in the Aula 
Moises Covarrubias

The Nexus City: Researching connectivity between networks and flows of urban food, energy, and water

PhD thesis, Wageningen University, Wageningen, NL (2020) With references and summaries in English

ISBN: ISBN: 978-94-6395-499-0

DOI: https://doi.org/10.18174/529198 



\section{Acknowledgements}

To my first love, my mother, my star that shines in the sky! The inspiration of every single day!

To all my close friends for following me everywhere, through every single dimension, from hell to heaven!

To my Family

To my father, for all the wisdom

To CONACYT

To all the participants that made this research possible (mainly to all of those persons that taught me to do research 'amb seny i rauxa' [with diligence and passion].

Thanks to all the special people who supported me in the foreign legion.

To my Co-promotor, Promotor, and the ENP.

Thank you (all) for the friendship! 


\section{Contents}

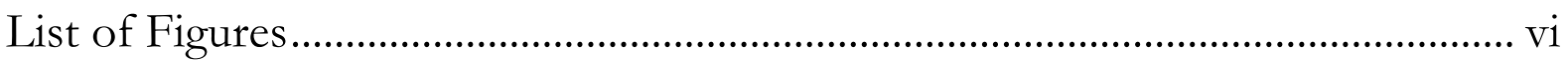

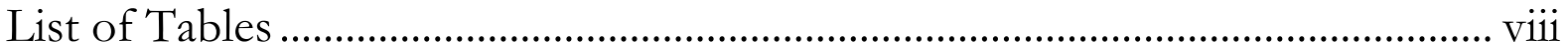

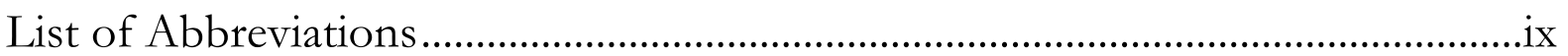

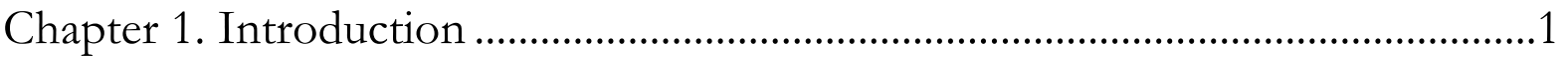

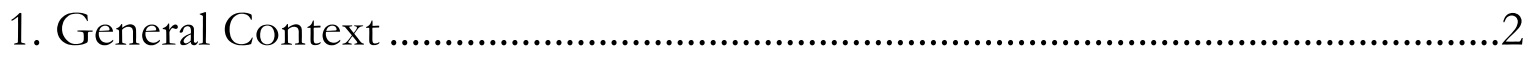

1.1. Introducing the Nexus City: the search for resources connectivity........2

1.2. A Brief Historical Overview of Resources Provisioning in Cities: from a sectorial toward a nexus approach.......................................................................

1.3. The Nexus Approach and its Relevance for Urban Sustainability

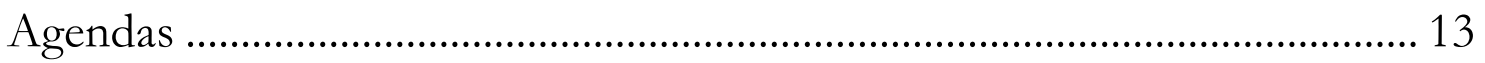

2. Conceptual Framework: towards a governance of the urban nexus ........... 21

3. Research Objectives and Questions .................................................................. 25

4. Research Methodology: tracing connectivity .................................................... 26

4.1. The Study Cases ......................................................................................... 26

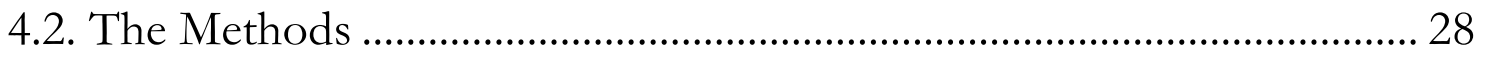

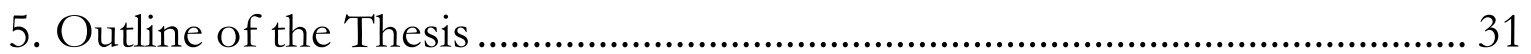

Chapter 2. The Nexus Between Water, Energy and Food in Cities: Towards Conceptualising Socio-Material Interconnections .................................................... 37

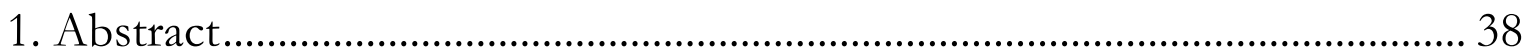

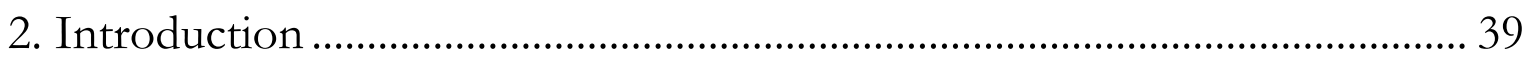

3. The Urban Nexus: connecting material and social flows............................... 41 
4. Conceptualising the Urban Nexus................................................................... 46

4.1. Material Flows of WEF Provisioning........................................................ 46

4.2. Social Flows of WEF Provisioning.............................................................. 48

4.3. The Urban Nexus of WEF Provisioning: analysing socio-material

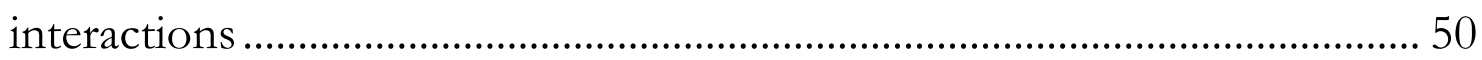

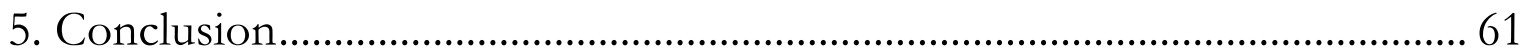

Chapter 3. Network Governance and the Urban Nexus of Water, Energy, and

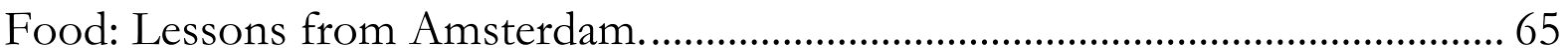

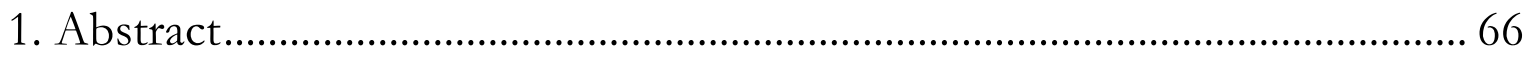

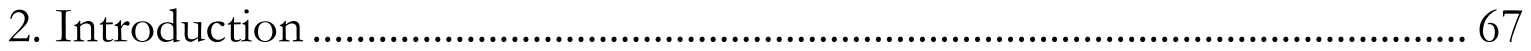

3. A Network and Flow Perspective to the Urban Nexus ................................... 71

3.1. Characterising Networks: structure and function................................... 72

3.2. Power in Networks: power dynamics in WEF networks ....................... 75

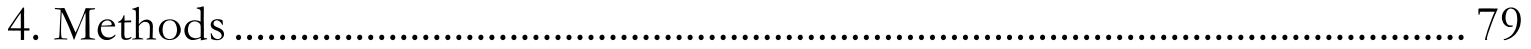

5. Results and Discussions: lessons from Water, Energy, and Food configurations in Amsterdam ................................................................................ 82

5.1. Food-Energy Nexus: entrepreneurs on the road of de-carbonising the

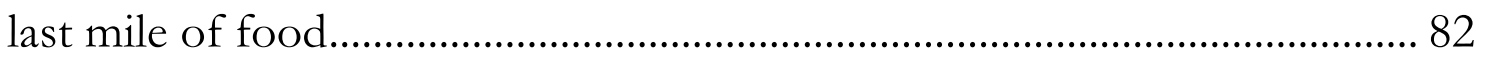

5.2. Water-Energy Nexus: wastewater to energy in Buiksloterham ............ 87

5.3. Water-Energy-Food Nexus: recovering nutrients from wastewater

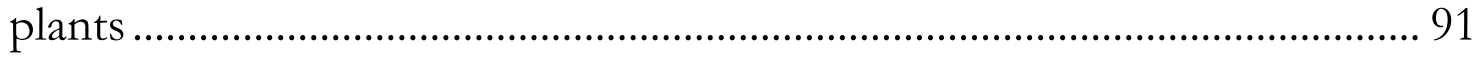

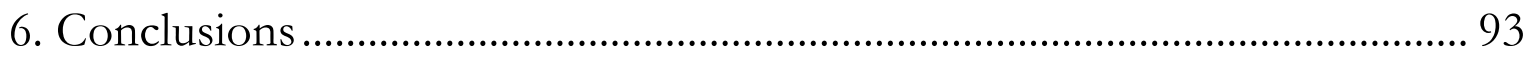


Chapter 4: The making of a Sustainable Food City in Barcelona: Insights from the Water, Energy and Food Urban Nexus.

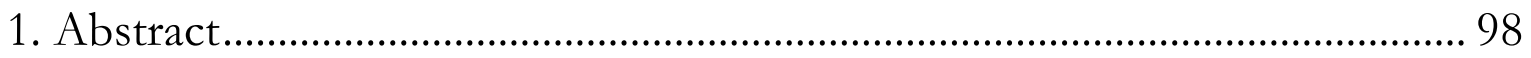

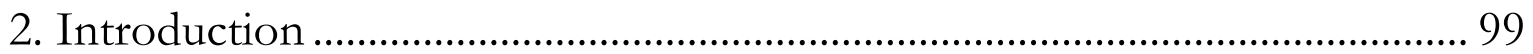

3. Background: a WEF urban nexus perspective in cities ................................ 102

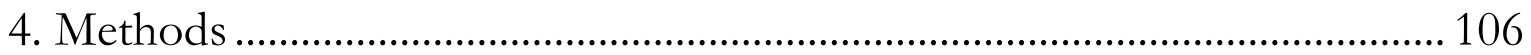

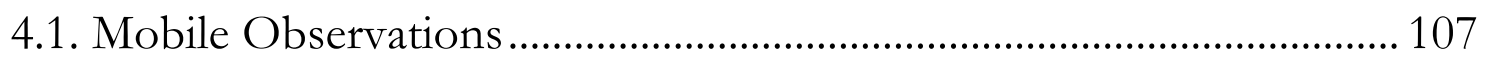

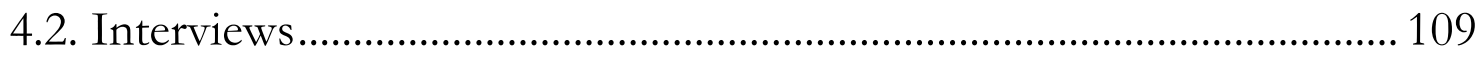

5. The Making of a Sustainable Food City in Barcelona .................................... 111

5.1. Background: food markets and flows in Barcelona................................ 111

5.2. Toward Reconnecting and Reconfiguring the Proximity of Food .... 113

5.3. Food Proximity Flows Provisioning and its WEF Urban Nexus

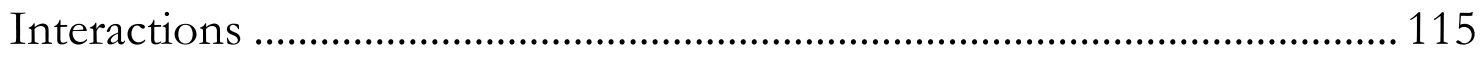

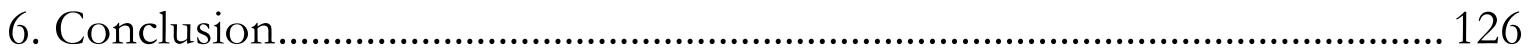

Chapter 5. Emerging Food Distribution Networks in the Last Mile, Amsterdam: Water, Energy and Food Urban Nexus Governance............................................. 129

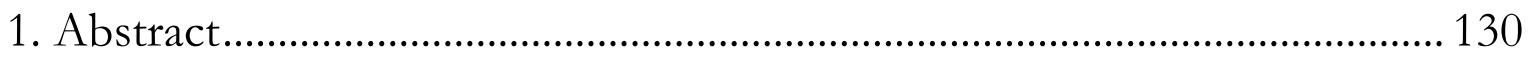

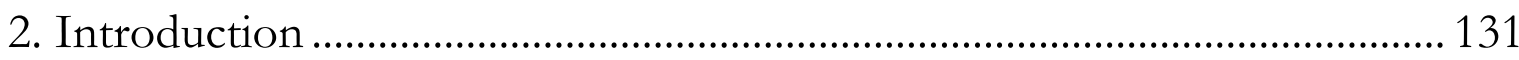

3. Movement of Food in the Last Mile ............................................................. 133

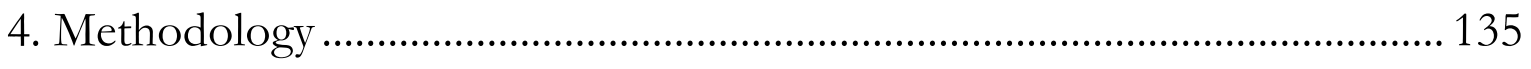

4.1. Moving with the Patterns of Food Through the Last Mile.................. 135

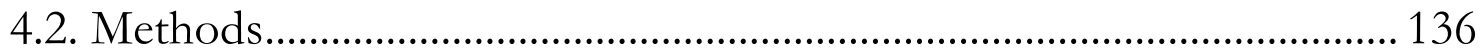


5. The Last Mile of Food in Amsterdam: unpacking dynamics of movement 139

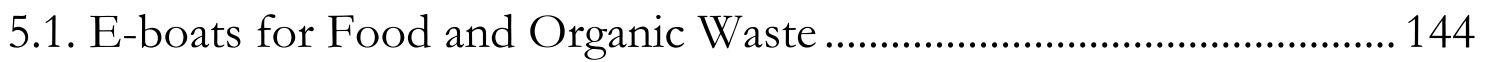

5.2. E-bikes and E-carts ............................................................................... 150

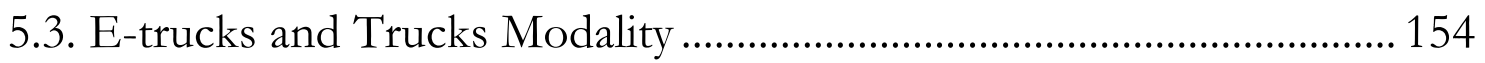

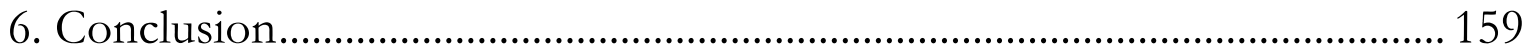

Chapter 6. Conclusions: Conceptual Approaches for the Making of the Nexus City 163

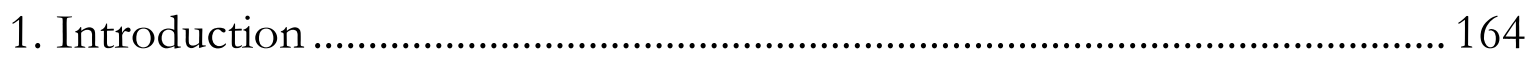

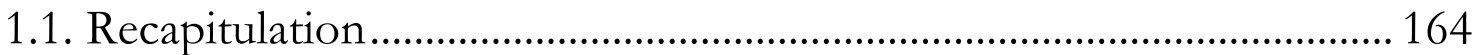

1.2. Summary: a conceptual vocabulary for resource connectivity governance 165

2. Theoretical Reflections ............................................................................... 171

2.1. Unravelling the Making of the Urban Nexus ......................................... 172

2.2. The Role of Two Groups of Actors in the Building Up of the Nexus Interface: switchers \& programmers, and incumbents.................................... 175

2.3. Interfaces at Work: nexus tools and strategies as developed and used by key social actors 181

2.4. Cities as Leverage Points for Global Sustainability of Resource Flows 193

3. Methodological Reflections ......................................................................... 195

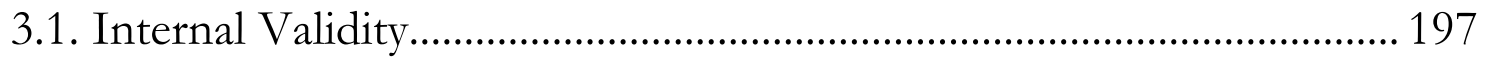

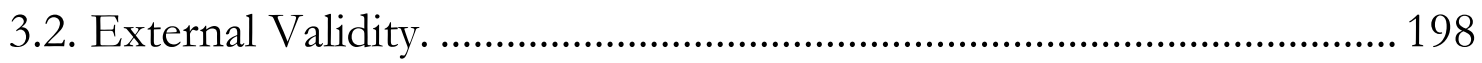


4. Further Research in the Nexus Agenda........................................................ 198

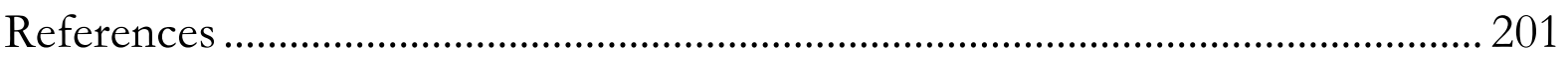

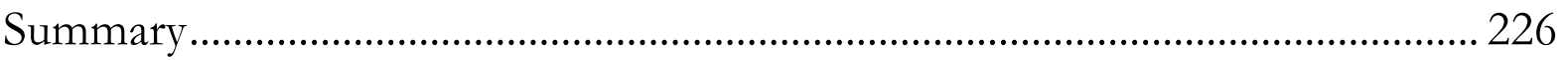

WIMEK SENSE Education Certificate................................................................ 229

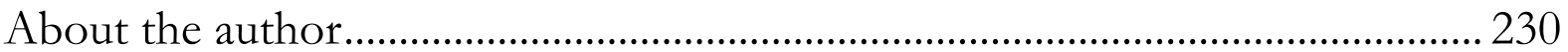




\section{List of Figures}

Figure 1: Environmental flows in the nexus........................................................ 50

Figure 2: The nexus governance network …………………………………........ 56

Figure 3: Characterising networks - structure....................................................... 73

Figure 4: Networks function - values and goals as programmed into the networks

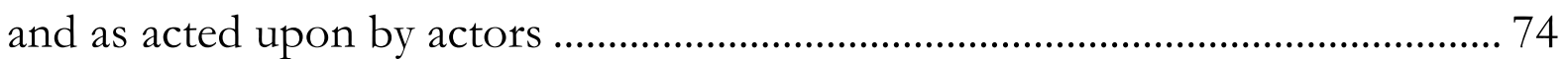

Figure 5: Interactions of networks characterisation allowing for connecting and

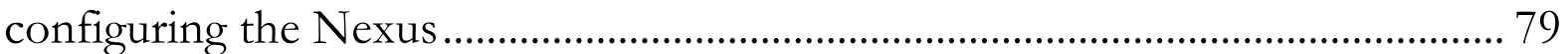

Figure 6: Proximity food flows and processes in Barcelona …………………..... 108

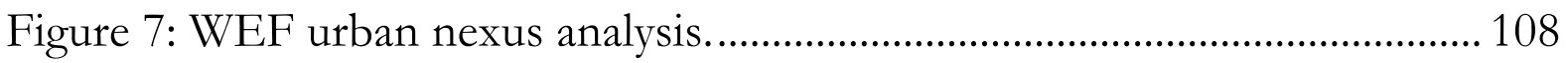

Figure 8: Map of Barcelona city .................................................................................. 111

Figure 9: Mercat galvany ................................................................................. 118

Figure 10: Distribution of food municipal markets through the Barcelona's districts

Figure 11: Map of food municipal markets throughout the city of Barcelona 120

Figure 12: Mapping of bike lanes in Amsterdam ................................................. 140

Figure 13: Mapping of water canals in Amsterdam............................................. 140

Figure 14: Mapping of the Food Centre Amsterdam and the Horeca sector .. 141

Figure 15: E-boat anchored at the FCA .............................................................. 144

Figure 16: Multi-modal transfer between vehicles.............................................. 147

Figure 17: Restaurants as obstacles to logistics via water ...................................... 149

Figure 18: E-boat collecting waste containers from a restaurant ........................ 149

Figure 19: Food distribution by e-bikes ............................................................ 150

Figure 20: E-bakkie distributing food to restaurants............................................ 151

Figure 21: E-truck at the Food Centre Amsterdam ............................................... 155 
Figure 22: E-trucks encountering pedestrians and sidewalks............................... 157

Figure 23: E-trucks parking on sidewalks ............................................................ 157

Figure 24: E-trucks competing for parking spots .............................................. 157 


\section{List of Tables}

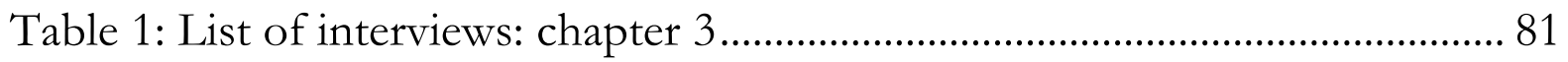

Table 2: List of interviews: chapter 4................................................................. 110

Table 3: List of interviews: chapter 5................................................................ 138 


\section{List of Abbreviations}

Abbreviation

AAA

AEB

CAAB

$\mathrm{CNG}$

$\mathrm{CO}_{2}$

C40

FAO

FCA

FICO

HORECA

ICLEI

IMMB

LDV

LED

MM

NGOs

MFA

MUFPP

PV

RUAF

SDGs

SES

\section{Definition}

Agenda Amsterdam Autoluw

Waste-to-Energy company in Amsterdam

Food Centre Bologna

Compressed Natural Gas

Carbon Dioxide

Cities Climate Leadership Group

Food and Agriculture Organisation

Food Centre Amsterdam

Italian Farming Company

Hotels-Restaurants-Cafes

Local Governments for Sustainability

Institute of Municipal Markets of Barcelona

Light Duty Vehicle

Light Emitting Diode

Mokum Mariteam

Non-Governmental Organisations

Material Flows Analysis

Milan Urban Food Policy Pact

Photovoltaic

Urban Agriculture and Food Systems

Sustainable Development Goals

Socio-Ecological Systems 
SFSCs

UN

UNDP

UNU

WE

WEF

WHO
Shorth Food Supply Chains

United Nations

United Nations Development Program

United Nations University FLORES

Water and Energy

Water-Energy-Food

World Health Organization 
Chapter 1. Introduction

\section{Chapter 1. Introduction}

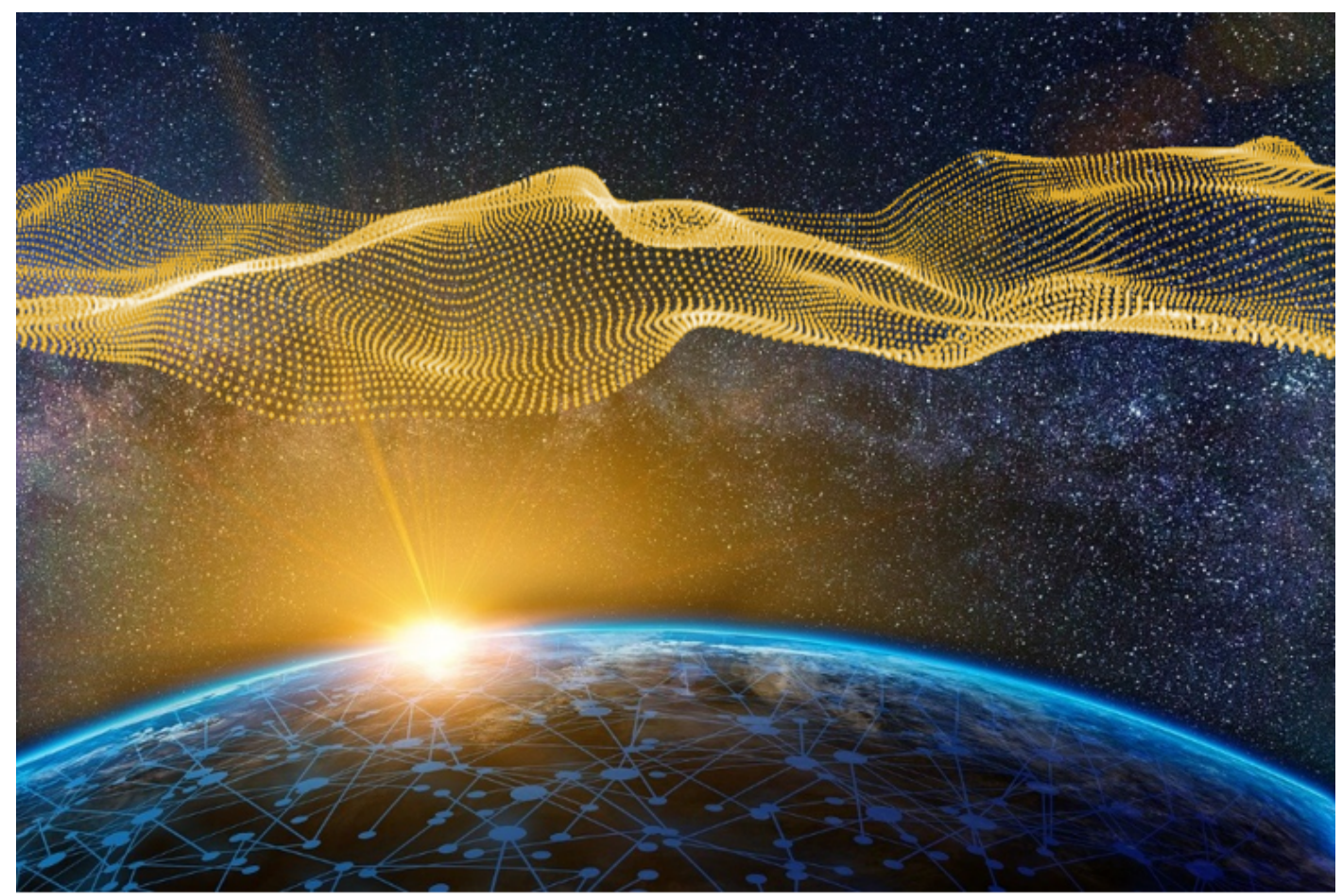

Image Source: https-pixabay.comillustrationsnetwork-earth-block-chain-globe-3885328 


\section{General Context}

\subsection{Introducing the Nexus City: the search for resources connectivity}

Cities are important platforms to push forward sustainable development agendas. To meet global sustainable development goals (SDGs), cities seek to further develop urban environmental space and to improve patterns of provisioning citizens with natural resources. Relevant issues on the urban sustainability agenda are; meeting climate goals as defined by the Paris Agreement (United Nations, 2015), improving the provisioning of water, energy and food, and the development of urban planning, transport, and information systems. Cities have become key actors in environmental governance in the form of hubs for innovation, commercial activities, culture, science, and socio-economic development (European Commission, 2011; B. Evans, 2005).

At the same time, cities are also hubs that concentrate people and the resources needed to sustain urban life. This makes urban sustainable development a challenging task. Today, over 55\% of people live in cities, globally. In Europe, $74 \%$ of people live in cities. Worldwide, the urban population is projected to rise up to $68 \%$ by 2050 (United Nations, 2018). High urban population densities place high demands on natural resources use, needed to sustain life in cities (Satterthwaite, 2010). Feeding cities with natural resources creates sustainability challenges to facilitate and organise resource provision and use in cities (Satterthwaite, 2010), whilst ensuring sustainable production and consumption of resources.

The concentration of resources and people in urban spatial and infrastructural settings can, however, also bring about opportunities for redirecting the provision 
of resources toward more sustainable patterns of resource production and consumption (Satterthwaite, 2010). In the last decades, cities have gained recognition as key actors to redirect, more sustainably, systems of resource consumption and production. In this light, the SDGs, inter-alia, refer to cities as key places to further integrate policies and practices on resource use efficiency. For instance, in the making of sustainable cities (SDG 11), cities cross-connect with other SDGs that have a stake in the sustainable provisioning of resources in the urban setting. Improving sustainable consumption and production of resources (SDG 12) also requires integrated policies and approaches to guaranty resource efficiency on urban scales (SDG 11). Furthermore, cities have a role in promoting more sustainable food production systems (SDG 2), while at the same time building up systems that can provide more sustainable management of water (SDG 6) and, more access to sustainable energy (SDG 7) (UNDP, 2016).

The New Urban Agenda (United Nations, 2017) is an instrument to help cities achieve these aims. The goal is to re-address the way societal actors plan, develop, govern, and manage cities while reorganising their resource systems. The SDGs and the New Urban Agenda are linked in many respects, such as through their shared focus on the provision of food, water, and energy. The New Urban Agenda as such also provides cities with a roadmap of technical elements and means of implementation for achieving the SDGs.

Generally speaking, city authorities, other urban actors, and organisations are committed to translating the urban sustainability agendas into new social practices of resource provision and consumption. In doing so, many cities have organised themselves with the help of global networks (e.g. ICLEI, C40, CITIES 100 or 
MUFPP) looking to share and adopt specific (best) practices in order to become more sustainable habitats for their urban populations. The Milan Urban Food Policy Pact (MUFPP) serves as one example of how cities seek to strengthen their role in sustainability using, for instance, food as a leverage point (Milan Urban Food Policy Pact, 2015). Through the Milan Pact, urban agendas (e.g. New Urban Agenda), are being linked with relevant (UN) bodies (e.g. FAO, UN-Habitat, or WHO) with the help of existing urban networks (e.g. Eurocities WG Food, ICLEI-RUAF CITYFOOD, and C40 Food Systems Network). The Milan Pact aims to address the specific needs of different cities worldwide in terms of providing more sustainable food. It has also placed a particular emphasis on European cities. When discussing food provision and consumption in cities, it is relevant to also look at other, related urban systems and infrastructures for the provision and use of energy, water, or mobility (to mention some examples) since they co-shape and influence the food provisioning systems and networks (Van Vliet et al., 2005). Taken together, these provisioning networks are key sociomaterial assets and constitutive parts of cities in modernity (Graham \& Marvin, 2001).

In the context of these urban challenges and rising opportunities to work towards urban sustainable development, this thesis studies the interconnections between water, energy and food resources and how their provisioning for consumption, as well as their governance, takes shape on an urban scale. This is from here on referred to as the urban nexus of water, energy, and food (WEF). WEF are part of socio-material urban networks that are increasingly recognised for their important roles in contributing to both local urban and global sustainability agendas. The assumption is that improving the governance of socio-material 
urban networks involved in the provision of water, energy, and food (WEF) brings along a range of (new) opportunities for making urban resource provision and uses more sustainable. Cities use their socio-material provisioning networks as veins to feed the urban system (Moss \& Marvin, 2001). Cities process and configure the sourcing, movement, use, and disposal of natural resource flows for provisioning resource services to people via socio-material systems (Graham \& Marvin, 2001). In doing so, cities obtain natural resources, primarily, from sources outside of their physical boundaries. Supplying cities with resources has direct consequences not only on the urban scale where resource usage is concentrated the most (e.g. air and water pollution); but also on regional, national and global scales where resources are extracted, produced, and transported from (e.g. deforestation because of intensification of global food systems) (Heard et al., 2017; P. Zhang et al., 2019). At any such scale, providing resources for urban areas comes at the cost of environmental trade-offs. These trade-offs have consequences on the different scales and processes of socio-material provisioning systems.

Providing resources for urban areas comes furthermore at the cost of interrelated trade-offs between different socio-material provisioning systems. It is widely accepted among scientists and policymakers that provisioning one resource system has implications for other resource systems (Kurian, 2017), such as the interconnections between water, energy and food. Understanding sustainability implications of impacts between systems from singular resource provisioning, implies '.... ho holistic understanding of un-intended consequences of policies, technologies and practices' around urban resource provisioning 'that seeks to describe the complexity and non-linearity of human-environment interactions' 
(Kurian, 2017, p.97). In the governance of urban provisioning systems, the interconnection between formerly 'separate' systems (of WEF) is being regarded as an important and feasible way to improve the overall sustainability performances of urban infrastructures and networks. In this regard, governing urban socio-material systems is no longer an issue of governing one specific resource or system at a time. Instead, it is a task of governing the connectivity and integration of resources systems by shedding light on the possible synergies or trade-offs that might exist between different resources (C. Zhang et al., 2018). This is well-known in literature as nexus-thinking and it is one of the latest concepts being explored as a way to improve sustainability of resources provisioning (Boas et al., 2016; Howarth \& Monasterolo, 2016; Kurian, 2017; Kurian \& Ardakanian, 2015).

Governing resource systems as an interconnected nexus requires further insight with regard to the unravelling, understanding, and steering the points of (dis)connectivity between resources and systems. Unravelling the connectivity of WEF is a task that can be examined at different levels of intervention. For example, connectivity can be analysed and understood either at the resource-toresource level, resource provision level or the system integration level (C. Zhang et al., 2018). The resource-to-resource level refers to the interdependency between resources. For example, in accounting for the volume of water needed to grow food in agriculture. The resource provision level refers to the availability of WEF supply to guarantee an urban resource system be provisioned. For instance, reliable energy supply to properly run the food distribution system in a city (e.g. fuels and cold chains to support food transport). Finally, to obtain a more holistic understanding of the different socio-material provisioning systems 
and their unintended consequences in the overall WEF policy and decisionmaking, a level of analysis that unravels and informs at the level of system integration is required. This thesis takes the latter approach.

In this context, this research provides the following main contributions: It develops a socio-material networks and flows framework to analyse connectivity and integration of WEF. This is the core contribution of the dissertation, with one particular set of interconnections (WEF) being explored in both more theoretical and empirical detail. Specifically, it contributes to shedding light on two identified knowledge gaps. 1) Contributing with sharper and clearer concepts, methodologies, and tools to identify connectivity of resources to inform both scientific debate and policy and decision-making for further WEF urban nexus governance; and 2) a focus on food as one of the dimensions in the context of the WEF nexus that still deserves to be addressed at the city level, as further elaborated through this thesis.

\subsection{A Brief Historical Overview of Resources Provisioning in Cities: from a sectorial toward a nexus approach}

\section{Water and energy developments in the city}

The socio-material systems that enable the urban provision and use of either food, water, or energy are configurations that have for long been shaped by societies. For instance, providing water and energy (WE) services in cities in a safe and secure way is nowadays regarded as an essential characteristic of contemporary and modern urban life, at least in the Global North (Van Vliet et al., 2005). Nevertheless, WE resource systems have gone through a long history of development. This is the case in most cities in the Global North, in which WE 
provisioning systems have been already well established from the 19th century onward (Van Vliet et al., 2005). Indeed, by the 1940s in virtually all cities in the Global North, WE networks of provisioning were already well developed and deployed (Graham \& Marvin, 2001). Nowadays in the Global North, the security and safety of WE provisioning can be more or less taken for granted as compared to many cities in the Global South for which these dimensions of provisioning are still values and goals to be accomplished (Van Vliet et al., 2011).

Such advancements, in Northern cities, have been achieved in part because of the standardisation of the technical, economic, and social dimensions of infrastructures of provisioning (Graham \& Marvin, 2001; Smil, 2019). At first, WE socio-material systems of provisioning aimed to deliver standardised, nondifferentiated, essential, and universal services to users (Graham \& Marvin, 2001). Indeed, most of the history of modern urbanism, in the Global North, can be understood as a series of attempts to 'roll out' the deployment of standardised WE networks in cities (Graham \& Marvin, 2001).

After the standardisation of WE provisioning systems, in the 1990's, a wave of technological innovation further triggered the development of these resources systems. Technological innovations around WE systems aimed to push forward economies of scale: large-scale systems, mass consumption and reliable and inexpensive supply of resource provisioning (Agnoletti \& Serneri, 2014; CrowMiller et al., 2017; Michael Hodson \& Marvin, 2017; Smil, 2010, 2019).

Modernisation of WE systems also brought innovations around the governance of resource provisioning. Over the last decades, WE provisioning systems are 
often framed by a political economy of privatised and free markets. Such modes of governance have increasingly allowed different societal actors (such as public, private and community actors) to play a role in reshaping provisioning systems into more horizontal and complex dynamics as compared to older modes of stateled organisation (Van Vliet et al., 2005).

To date, cities are still in the process of further developing their WE systems, especially from a sustainable development point of view. Cities incorporate new governance approaches that consider a number of issues that go beyond the standardisation and safety of provisioning only. In this light, we witness more efforts toward the differentiation of resource services (e.g. green energy and decentralised energy systems), the redefinition of the role of consumers in utilities provision (e.g. co-production), enabling demand-side management approaches (e.g. flatting peaks in energy consumption by shifting demand in terms of time and place of consumption), or recovering materials through circular management of resources (Van Vliet et al., 2005).

Through the last decades, the development of WE provisioning systems has reached a certain level of maturity. Such improvements made possible that societies of today are able to deliver reliable (in terms of security and safety), differentiated and efficient resource services to different categories of consumers (see discussions in (Magagna et al., 2019). Against this background, it comes as no surprise that most of the efforts of contemporary cities and city authorities tend to be focused on improving in particular the sustainability dimensions of urban resource provisioning. 


\section{Food developments in the city}

Providing food systems in cities, safely and securely, is also nowadays regarded as an essential characteristic of contemporary and modern urban life in cities in the Global North. Nevertheless, food advancements have also gone through a long history of development. Markets as food distribution points have been key puzzles in food systems. In Europe, markets have been important buying and selling points since the times of ancient Greece, Rome, and Constantinople (Costa et al., 2015). Since early times of these civilizations, foods were sourced from the proximity of cities, from regions nearby cities, but also many other places around the Mediterranean shore, and beyond. Markets have exercised a key socioeconomic role for cities as places where foods, among other products, are exchanged and delivered to city inhabitants.

From the medieval times, in Western Europe, markets gained a prominent role as places of trade in which city authorities took over the control of food security, food safety, and food taxation (Brand et al., 2019). The appearance of the state, by the end of the Middle Ages, is one of the critical game-changers for food in the city and the role of cities on food 'policy'. This phenomenon helped states, from the 16th century and until approximately 19th century, to replace the authority of cities by assuming a major role in food production and distribution (Brand et al., 2019).

Fast-forwarding to the 19th century, food went through a hygiene revolution. Rapid urbanisation brought about, largely in European cities, health concerns deriving from food and waterborne diseases and epidemics (e.g. typhoid, tuberculosis, pneumonia, and cholera). Such concerns triggered a general 
separation between cities and nature. Particularly, these events pushed forward the separation of cities from the food world by sending out of cities most of the possible hazards or nuisances for citizens (Brand et al., 2019).

In the 20th century, the Second World War was a critical point of development for food in Europe. The war reinforced the role of states as regulators and procurers of food supply (e.g. border controls for food imports) (Costa et al., 2015). The end of WWII also brought a major turn in the history of food. In the 1960s, supermarkets rapidly took over food retailing in Europe, and by the 1990s these controlled the vast majority of food sales (Spaargaren et al., 2012). Supermarkets also came with innovations and advances in food technologies related to production, storage, standardisation, and transport which facilitated long and organised supply chains. What is remarkable about the introduction and take off of supermarkets, is the effect of those on the way societies organise supply chains. Global and large-scale retailers have gained a high influence on where our food comes from, how it is transported, and how societies consume food (see discussions in Spaargaren et al., 2012).

More recently, by the end of the 90s, the adoption of the World Trade Organization (WTO) agreements marked another era in the domain of food policy in Europe (Costa et al., 2015). The turn from a localised and controlled food provisioning system into a global and liberalised food system has brought a reconfiguration of food provisioning dynamics. Nowadays, different societal actors from different geographical scales, interplay in the shaping of food systems. In Europe, these actors interact with each other through social dynamics that 
reflect more horizontal network configurations in which the state, private and community sectors shape food systems.

What characterises the food system in Europe today, is that food has gained high levels of security, safety, standardisation, and a large variety of choices. Nevertheless, food systems are also lately characterised by their balance of power toward retailers (mainly supermarkets) and catering services providers. This comes with a loss of power from the side of farmers and food markets (Spaargaren et al., 2012), and with a loss of control, either by cities or states, on where food is produced or consumed. Distances between places of production (global and local scales) and places of consumption (local scale) have increased while at the same time there is a call to regain more localised food production and consumption. These concerns come all together with further environmental pressures not only for cities in the globe, but for nature and society in general (e.g. food-miles, food-print, $\mathrm{CO}_{2}$ emissions, or water stress) (Spaargaren et al., 2012).

\section{Where do we stand now in terms of Water, Energy, and Food developments in the city?}

Resource systems (either water, energy, or food) are the key to further develop cities as more sustainable habitats. How cities can best organise further improvements of their resource systems have received increasing political attention during the last decades. The Local Agenda 21 in 1992 and the City Summit in 1996 are some of the key precedents of the current political discourse around governing sustainability of resources in cities. The Local Agenda 21 is one of the first calls appointing cities around the world to develop their own local 
sustainability agendas. The general message of the Local Agenda 21 is to work toward re-thinking patterns of resource consumption, inter alia. More recently, in 2015, the Sustainable Development Goals (SDGs) brought an overarching agenda of 17 goals that together should guide actors and organisations around the world in organising a more sustainable interaction between planet, profit, and people. The SDGs agenda is dedicated to improving gender equality, poverty, economic growth, and climate change. This global agenda also put forward specific goals for improving resource provisioning such as water, energy, and food (J. Evans et al., 2016; Michael Hodson \& Marvin, 2017; Hopwood \& Mellor, 2007; UNDP, 2015; United Nations, 1992). The SDGs mark an important next step in thinking about the sustainable governance of resource provision and use in cities, noteworthy for urban food in relation to for example climate targets. This focus on climate targets was of course provoked as well by the Paris Agreement in 2015. Paris brought along the first legally binding arrangement for connecting agriculture and food with environmental politics and governance in a specific way (United Nations, 2015). It does however not make any specific call for cities to address the climate-agriculture-food interaction but instead, it makes the call for states to work in that regard. In general terms, what characterises efforts taken by cities, in the last decades, is that those efforts often approach WEF resources provisioning by addressing one particular resource at a time.

\subsection{The Nexus Approach and its Relevance for Urban Sustainability Agendas}

When governing WEF in the city, policy actors often tend to focus on involving either water, energy or food experts only (Hoff, 2011). For example, in everyday practices of governance and decision-making in matters of urban food, experts in water and energy and policymakers are excluded or simply forgotten, while others 
that might have a stake in developing more integrated urban policies are not included in the process. This situation is referred to as governing in silos or silothinking (see discussions in B. Evans, 2005; World Bank, 2007). In literature, this stands for a one-dimensional and sectorial approach in which policy and decisionmakers do not reflect on the cross-sectorial connections that exist between different departments, sectors, or natural resources (see discussions in B. Evans, 2005; World Bank, 2007). Moving from silo-based resource governance towards a more integrated, 'nexus-based' approach means moving beyond exclusive, sector-based forms of governance and decision making.

To make such a switch over from silo to nexus-based policy making, the first step is to understand how silos emerged and why they seem so persistent. Domains or fields like energy, water, waste and mobility are governed through specific institutions, social and power dynamics, key actors and organisations, infrastructures and technologies. The silos have a history themselves and without knowing this history, efforts to develop nexus thinking and action are difficult to organise. After understanding silos, the second step is to identify promising points or elements in the silo-systems which can be instrumental for opening up the silos, to start developing inter-connections between strategies of resource provisioning originating from different systems. In stages, it becomes possible to consider interrelated sustainability implications in urban provisioning of water, energy, and food (Howarth \& Monasterolo, 2016; Kurian, 2017; Kurian \& Ardakanian, 2015). This approach of thinking of interrelations, interdependencies and mutual influences has become known in the social science literature as the 'urban nexus'. It stands out as the most widely used concept pushing forward more integrative thinking across different resource systems. 
The urban nexus concept gained particular attention in both science and politics after the Bonn 2011 Conference titled "The Water, Energy and Food Security Nexus Solutions for the Green Economy". The main message of the conference highlights that:

In our interconnected world, sectoral "silos" are no longer acceptable ways to approach our targets, because solutions based only on one sector or discipline will unavoidably affect other sectors, whether by design or accident. Nowhere are the interconnections more evident, and critical, than in the water, energy and food sectors, because each is not only connected to, but is also dependent on, the others.' (Hoff, 2011).

How, and whether or not, water, energy, and food (WEF) resources are being connected, either by design or by coincidence, is shaped by (specific) contexts that relate to different values and goals (e.g. security or safety), research directions, geographical and political realities, spatial scales of practice, and resources settings, among others.

Nexus literature so far has discussed two main perspectives to look at connectivity of resources: security and sustainability. The 'security' nexus (Beck \& Villarroel Walker, 2013) highlights the fact that the vitality of WEF resources depends on the connectivity of each resource with others with respect to their provisioning being guaranteed. For example, (Chirisa \& Bandauko, 2015) study African cities and the effects of climate change on increasing temperatures and its impacts on water scarcity (and energy) and food production. The United Nations University (UNU) through its Nexus Observatory also provides examples of security 
nexuses by analysing the risks and opportunities for Sub-Saharan cities as being affected by droughts which affect the security of energy, water, and food systems. Security dimensions of the WEF nexus are also shown to exist at the micro level of everyday cooking-practices in informal settlements in Kampala (Mguni et al., in press). In this context, energy poverty is shown to be the weakest link in the WEF nexus. Energy poverty translates to unsafe water consumption (lack of boiled drinking water) and unsafe food preparation (Mguni et al., in press). Guta et al., (2017) and P. Zhang et al., (2019 also identify the security implications of energy shortages on water and food security in cities around Brazil, the Russian Federation, South Africa, India, China, Ethiopia, Ecuador, and Nepal. What these examples portray, in general, is a context-specific nexus that relates to security constrains of water resources and its implications for food, energy and water provision due to droughts. Nexus dis- or misconnections between food, water, and energy, both at the micro and institutionalised system scales, have direct consequences for conditions of access to resources, and as such affect people's vulnerability and access to basic human needs.

The second perspective is about the 'sustainability' nexus. Whilst many cities in the Global South still struggle with attaining WEF safety or security, most cities in the Global North already benefit from secure, well-functioning WEF systems. In this geo-political context, nexus literature and research has been approached, more often, from the perspective of efficiency and sustainability in resources provisioning. One of the main goals of this 'sustainability' nexus perspective is to identify the sustainability or resource-efficiency synergies and trade-offs in WEF provisioning and resource systems (see e.g. in Vogt et al., 2014). 
Next to being focused mainly on security issues and sustainability issues, nexus literature so far has largely explored three research directions. In the review by (P. Zhang et al., 2019) on nexus for urban sustainability, the authors identify three research directions as the 1) interpreting of the concept, 2) developing of tools for quantification synergies and trade-offs, and 3) showcasing of empirical cases. With respect to interpreting and defining the nexus concept, the nexus is conceived by most authors as the examination of connections and disconnections between WEF resources through the research and policy lens of resources security, efficiency, and sustainability in the way discussed above. In the development of modelling and quantification tools (e.g. resources footprint or Life Cycle Assessment), the main goal is to advance systematic assessment tools that can quantify trade-offs and synergies between WEF resource production and consumption. By quantifying the impact of synergies and trade-offs for policy makers, it is shown why a focus on nexus governance is relevant in the first place. The third research direction, showing and investigating specific empirical examples, has mainly focused on implications of nexus governance in resource provision from different scales, from the global and national into regional and city levels (P. Zhang et al., 2019).

As regards to the latter issue of scale, nexus literature until now has mainly studied the connectivity of WEF at either the international, national or regional scales (see e.g. in Bazilian et al., 2011; Chen \& Chen, 2016; Daher \& Mohtar, 2015; Endo et al., 2015; Howells et al., 2013; Nair et al., 2014; Smajgl et al., 2016; Tevar et al., 2016). The urban scale, instead, has received limited attention, although this has increased in the past decade (for recent calls see Artioli et al., 2017; Covarrubias, 2018; Covarrubias et al., 2019; C. Zhang et al., 2018). To fill this knowledge gap, 
this thesis argues for an in-depth analysis and understanding of the ways in which WEF resources connect and relate to each other in the specific context of cities and their specific modes of governing resource provision to urban populations.

Providing urban WEF also relates to the different upstream geographical scales where the different processes of resource provisioning take place. For example, providing WEF flows, at the city level, intimately relates to the regional, national, and global scales where these resources are transported, produced and extracted from. For city authorities, their relationship to these flows is different for either water, energy or food, because of the different geographic scales of each flow at play at the urban level, and because of the division of governance responsibilities for each of these flows take place at different geographical scales.

In this sense, the dimension of scale can be shown to be rather complex and different from resource to resource (WEF). For example, water systems are often governed at the city and regional levels (where most of the time water bodies are located). Water systems are also often governed by state-like bodies at national levels. With regard to energy systems, their urban governance also relates to regional, national, and global governance contexts (e.g. urban regulation on electricity load within a context of global energy markets). For food, such an interscale system for governance has more obstructed boundaries and linkages (Oosterveer, 2005). For instance, in food governance, the global and national levels are less interconnected to the urban level, as compared to energy and water. Food is an urban resource mainly produced at the regional, national, and global scales. Food is also often regulated and governed at the national or global levels (e.g. global food markets or national level agricultural-food policies). This 
indicates the connection between urban governance of food and the global governance of food is rather complex and still misconnected.

A final remark about the nexus literature regards its focus on particular resource settings. The socio-material systems involved in the governance and provision of water and energy have by far received most attention in the nexus literature (Endo et al., 2015; Fan et al., 2019; Kenway, Lant, \& Priestley, 2011; Kenway, Lant, Priestley, et al., 2011; Nair et al., 2014; Yumkella \& Yillia, 2015). Food provision and consumption, and the sustainability of urban food systems has been generally overlooked, at least in Europe (Morgan, 2009). This is partly because urban food provision and governance have been regarded as a rural asset, resulting in a ruralurban divide of food provision and consumption (Sonnino, 2009).

In this thesis, it is argued that in order to address urban sustainability from a more integrated manner, food is one of the dimensions that deserves to be addressed at the city level (Morgan, 2009; Sonnino, 2009) and from a WEF nexus perspective. In this regard, cities and city authorities are key actors to address not only food, but resources policy and decision-making in general, across their different geographical scales and their interconnectivity (Artioli et al., 2017; Barber, 2013; B. Evans, 2005; Isenhour et al., 2015; Sonnino, 2016; Sonnino et al., 2019; World Bank, 2007). Nevertheless, efforts by cities often fail to specify their goals for an integrated, systemic, and cross-scale governance of urban WEF systems (Sonnino et al., 2019).

Governing WEF in cities might take two streams of governance that deserve a clear distinction. There are cities taking the role of urban governance of WEF 
provisioning systems, or cities governing the nexus of WEF flows that exist in the context of the boundaries of the city. These two modes of governance are analytically distinct to one another. Whilst the first embarks on the separated (silo) governance of each resource system at the urban, the latter analyses the interconnectivity of WEF resources systems in the city context. In this sense, this research will elaborate on the governance of the WEF Urban Nexus, and its need to consider the forgotten puzzle of food (equally to water and energy) as one of the essential (global) flows part of the urban metabolism (see (Sonnino et al., 2019), and its connectivity with energy and water, in particular.

In sum, the nexus debate has recently received a boost of academic and political attention, as indicated through this introduction. Nevertheless, the nexus approach has been regarded as an obscure buzzword which still requires sharper and clearer concepts, methodologies, and tools to identify connectivity of resources to inform both scientific debate and policy and decision-making for further nexus governance (see discussions in (Cairns \& Krzywoszynska, 2016), especially from an urban perspective.. This research aims to further explore the connectivity of WEF at the urban level by developing and using 1) a conceptual framework to examine WEF streams organising through network systems of provisioning, 2) specific methodologies to trace and follow WEF and to reveal their connectivity points, and 3) specific concepts which help to illustrate the added value of nexus-analyses in urban settings. 


\section{Conceptual Framework: towards a governance of the urban nexus}

In supplying cities with services; resources are provided in the form of flows using networks of provisioning. Flows are the continuous stream of resources, ideas, information, policies, or any other form that moves along between two or more points (nodes) (Castells, 2009). This research uses this network and flows approach to help illuminate the key networks, flows, and actors in steering the provisioning of WEF flows in cities. This approach aims to shed light on the ways in which these networks and flows do or do not manage to produce more integrated forms of urban management, planning, and decision-making between WEF systems.

Flows are compound by two dimensions. These are: 1) material dimension (e.g. 1 litre of drinking water) and 2) social dimension (e.g. policies for drinking water provision) (Mol \& Spaargaren, 2006a; Moss \& Marvin, 2001). Material flows perspectives have already contributed to tracing, accounting, and analysing the material dimension of resource flows in feeding societies (see e.g. of Material Flow Analyses in (Hunt et al., 2014). Nevertheless, understanding resource flows also requires a complementary social dimension. A social dimension that focuses on the role of policies, institutional arrangements, networks, and social meanings of resource flows shaping provisioning (Guy et al., 2011; Mol \& Spaargaren, 2006a; Moss \& Marvin, 2001).

Different socio-material flows connect to each other, and form nodes. Nodes are central parts of networks. Nodes are important connectivity points where flows concentrate in higher densities, as compared to other connections in networks 
(Castells, 2009). Different inter-connected nodes give emergence to networks. In other words, flows are the streams of information and resources that circulate between and around the nodes, creating networks.

Networks are organisational structures that process, configure, and deliver flows to societies around the globe (Castells, 2009). Networks, when processing and configuring flows, give shape and meaning to how cities, for instance, consume water or energy. For example, global energy generation in feeding the globe or decentralised renewable energy services in loading cities with electricity.

Governance networks configure and connect flows around common values and goals that a network and its actors are aimed to achieve (Bouteligier, 2013; Castells, 2009). For example, we could think about water and waste networks aiming to re-use wastewater flows by recovering the energy stored in such flows. For this, and many other related examples, actors in networks can decide upon the values and goals that a network will pursue. In doing so, some actors stand out for having the capacity to link and influence different actors and different networks into common shared ambitions. According to Castells (2009), this refers to the capabilities of actors, switchers and programmers to both 1) influence the structure of networks and their interrelations, in terms of connecting actors and nodes, and for 2) (re)configuring the goals and values that are being pursued. These capabilities rest with groups of switchers and programmers exercising their network-making power, which is one power dynamics that stands out in reconnecting and re-programming networks (Castells, 2009). This networks and flows perspective is also suitable for studying the specific context of the Nexus, at the urban level, as it is about connectivity of socio-material resource flows, 
crossovers in social relationships, and converging dynamics in governance for sustainability.

Studying flows is to understand them through concepts as introduced above. Moreover, it is of crucial relevance to understand flows by their movement through networks. In doing so, this theoretical framework also borrows inspiration and insights from the theoretical strands of Mobilities. These are useful insights for exploring the complex dynamic of movement of flows and actors (Sheller, 2011), as in this case WEF systems. Similar to flows, mobilities, is a commonly used set of concepts and tools to actually trace and follow the movement of people (or actors) and flows (Urry, 2007). Mobilities is a strand of literature that builds upon networks and flows theory by shedding light on the actual content and meaning of movement between two points, for example between two nodes in a network (Cresswell, 2006). In particular, mobilities is a tool well aimed to help in providing answers to why and how flows and actors actually move, connect, and get configured in the shaping of governance networks (Boas et al., 2018; Urry, 2012).

The urban level is a crucial temporal and spatial hub in which resources are concentrated and delivered through provisioning systems to consumers. The city is a level where social space and social distance are both compressed. In this sense, the metabolism of flows and transactions in cities is of a denser manner, as in the case of urban WEF (Sheller \& Urry, 2006). In the particular case of cities, these are crucial spaces in which environmental flows are densely concentrated and configured in specific ways through governance networks that are organised primarily, not exclusively, at the city level. At the urban level, there are also 
switchers and programmers whose main task is to configure resource governance networks and reconnect WEF flows. These switchers and programmers have specific and specialised roles in governing the urban nexus of WEF flows. Switching and programming networks are the results of actions and decisions that push forward the emergence of the nexus of different networks. In the context of the urban nexus, whether or not WEF integration results relate to the intended capability to steer connectivity points: switches, by switchers and programmers for outperforming sectorial approaches and for working towards more integration of WEF networks. Urban switchers and programmers, among other governance actors in governing the urban nexus, are also challenged to live up with national and global dimensions of the resources they govern at the urban. In other words, cities under urban governance and the governance of the WEF urban nexus, also need to consider the links across the different scales in WEF resources provisioning.

This research suggests that further cross-connectivity of WEF resources toward a nexus fashion comes along with the reorganisation of the governance of resource systems in cities. How these nexus governance networks emerge, how they connect and (re)configure WEF flows and how such connections engage with synergies or discourage trade-offs (in the quest of sustainable outcomes) are questions that this research aims to answer with the guidance of the presented conceptual framework. 


\section{Research Objectives and Questions}

The Objective of this research is to generate knowledge on the urban nexus of WEF. To develop this objective, this research formulates a conceptual framework which aims to unpack the urban nexus of water, energy and food networks and flows (see Chapters 2 and 3). It aims to shed light on what the connectivity of resource flows is about, how it occurs, and what roles key actors in the governance of resource provisioning perform in relation to the nexus. The conceptual framework helps to examine specific forms of urban environmental nexuses in some empirical depth and detail, and to trace how networks of WEF connect in practice (see Chapters 3, 4, and 5). By reflecting the conceptual framework upon the empirical findings this research unravels new insights into the generation of urban nexus knowledge (see Chapter 6). This research is led by the following research questions:

1. What concepts can be used to unpack and trace the (un)sustainable connections between water, energy, and food networks and flows?

2. How do water, energy, and food networks organise and connect flows from a sustainable provisioning point of view, in cities?

3. What are the identifiable steering points for sustainable urban governance to further address the connectivity, challenges and opportunities, of networks and flows of water, energy, and food? 
Answering these questions opens new dimensions to better understand connectivity and to contextualise the urban nexus in a broader body of scientific literature around networks and flows theory. In the quest to apply such a conceptual framework and explore connectivity through empirical networks of WEF, this thesis proposes the following research methodology.

\section{Research Methodology: tracing connectivity}

\subsection{The Study Cases}

This thesis elaborates two in-depth case studies (Barcelona and Amsterdam, see Chapters 4 and 5) to explore urban nexuses practices, drawing on three small case study examples (Amsterdam, Bologna, and Reykjavik, see Chapter 2) to test the proposed conceptual framework of this thesis. In selecting the two cases, this research first looks at different rankings and indexes providing examples of urban resources sustainability in Europe. For example, The Sustainable City Index 2015 and 2018, the SDGs Index in 2019, C40 ranking, Cities 100, and the Lisbon Ranking, are examples of rankings and good practices measuring how cities are including SDGs in their urban development. Most developed European cities often come top of the overall rankings, when compared to other cities in different regions of the world. Cities such as Oslo, Stockholm, Helsinki, Frankfurt, London, Copenhagen, Amsterdam, Barcelona, and Rotterdam often lead the rankings.

The 2019 SDGs Index and Dashboards Report for European Cities (see (Lafortune et al., 2019) ranks the cities with the highest progress on attaining the SDGs. Most of these cities, according to the index, have built on their sustainable 
food production systems (SDG 2), their sustainable management of water (6) or, their access to sustainable energy (SDG 7). Despite the level of sustainability attained by leading cities, they still have significant and major challenges to further work on. For instance, they still need to work on major challenges to properly address climate change actions at the urban scale (SDG 13). Moreover, in the making of sustainable cities (SDG 11), they need further work to re-pattern sustainable consumption and production of resources (SDG 12), in a manner that looks forward to further integrate resource systems and their patterns of provisioning toward more nexuses practices.

Amsterdam and Barcelona are cities that stand out as examples of European cities in which sustainability practices around food and water and energy emerge, with some challenges remaining (see Good Practices in (Forster et al., 2015; Lafortune et al., 2019) and SDGs Index in Lafortune et al., 2019). These are cities that have taken a step forward in the sustainable management of water provisioning (SGD 6). Barcelona is a step ahead in pursuing more access to sustainable energy (SDG 7) compared to Amsterdam who is still facing major challenges to address such a resource system (see Lafortune et al., 2019). What these cities both have in common is that they are starting to invest on efforts to become more sustainable food cities (some challenges remain to attain SDG 2) while working on the related links to sustainable consumption and production (significant challenges remain to attain SDG 12) (Lafortune et al., 2019) Nevertheless, they are still challenged with adopting approaches that consider WEF systems as integrated puzzles to attain more sustainable cities. 
In shedding light on how cities further integrate the WEF puzzles to attain the SDGs, this research uses the case of food in the WEF urban nexus to further contribute to understanding sustainable urban food agendas. In this light, this work elaborates on the cases of Amsterdam and Barcelona. Barcelona stands out as a city that is nowadays playing a role in its net of modern food markets as places to distribute more sustainable food (see Good Practices in Forster et al., 2015). This thesis shows how the city is working on its network of food markets and the food of proximity those markets distribute as a way to further strengthen its position as Food City. In doing so, the city of Barcelona uses its different socio-material provisioning systems, to steer interventions in its proximity food system. In the case of Amsterdam, the city is working on experimenting with new ways to govern resource flows. Amsterdam then plays a role in its food system by reconnecting food flows with 1) energy and nutrients recovery, and 2) more sustainable options of food transport that consider water and energy connections.

\subsection{The Methods}

To better operationalise such a nexus conceptual framework (as introduced in the preceding sub-section), this research delineates a set of methods that enable a study of connectivity between resource networks and flows. Whilst most of the current methodologies to study resource governance in cities are siloed methodologies, this research offers a methodology that allows for the understanding of WEF networks and flows from their points of connection. In doing so, this research borrows insights from mobilities methodologies. These are useful methodologies to trace, draw, and follow the dynamic movement of flows and actors through networks (Sheller, 2011). Mobilities insights add value to the theory of networks and flows by tracing and understanding what the content of flows is about (Cresswell, 2006) and what the content of their 
connectivity is about. In doing so, this research traces and sheds light on 1) how WEF flows move, 2) who organises the movement of flows, 3) who decides on such movement, and 4) how those WEF flows actually interact one to each other.

To gather data on the connectivity dynamics of WEF networks and flows for the cases described above, this research employed the following Data Collection Methods:

\section{Mobile methods for following flows of water, energy, and food.}

Mobilities methodologies are useful tools that help to trace and capture the complex dynamic movement of flows as they happen in social life (Sheller, 2011). 'Moving with flows' (see Sheller, 2011; Sheller \& Urry, 2006) is one of the mobile methodologies used by this research. It allows the researcher to (re)trace and follow the movement of WEF flows while capturing how WEF flows are shaped by their social or material dimensions. Tracing flows not only sheds light on why and how flows move, but also on why and how flows connect and get configured through or between networks. Using this method, the researcher aimed to trace the WEF flows through their different processes of provision as studied in the city of Barcelona (see Chapter 4). This method offered the possibility to map the proximity of food flows and networks around food markets, in Barcelona. The researcher identified and traced the movement of food flows from agricultural areas in the proximity of Barcelona through its channels of wholesaling, and distribution via municipal food markets. While tracing food flows, the researcher placed particular attention on the embedded social dimensions shaping food provisioning through its processes while considering its water and energy implications. In the case of Amsterdam, moving with flows also happened while 
being mobile with such flows. In this regard, the researcher participated in the movement of flows. In other words, and as addressed in Chapter 5, in the case of Amsterdam the researcher got on board of the three e-transports studied (evehicles, e-bikes, and e-boats) and as such examined food flows taking shape in practice. The researcher learned the obstacles and advantages of each transport while being on the road on each type of transport, seeing in practice how both the wider social-material context shapes their operations.

\section{Expert interviews}

The researcher also conducted one round of Semi-Structured Experts' Interviews (Bogner et al., 2009) for each of the cases addressed in this thesis. The aim was to gather answers about the points of integration and interdependencies between the social dynamics, actors, and institutional arrangements of the networks and flows of WEF. This method was conducted for gathering data to elaborate on the portfolio cases in Chapter 3, but also for the two in-depth case studies in Chapters 4 and 5. Some of the themes aimed to explore through the interviews relate to levels of governance integration, levels of resource integration practices in food distribution, and levels of integrative policy and decision-making, among others. The respondents were sampled based on the expertise and knowledge they hold. First, a convenient sampling looking for accessible and knowledgeable participants was conducted. Second, the first participants contacted were snowballed in order to explore the networks of WEF and further respondents. And third, a saturation point was established. 


\section{Literature review}

Along the time carrying out this study, the researcher conducted a Literature Review which analysed governmental publications, policy documents, and scientific papers. This method supported on the elaboration of 1 ) the conceptual framework used for this research, 2) the elaboration of the desktop city-cases in Chapter 2, 3) the elaboration of the portfolio cases in Chapter 3, and 4) the sourcing of data to contextualise the two cases studied with their current level of urban sustainability development.

\section{Data analysis}

Most of the interviews conducted were recorded when the participants approved it and when the circumstances allowed for it. Thereafter, the content was analysed by using the software Atlas.ti and coding the data for its analysis. During the following of WEF flows, pictures were taken when it was allowed to and possible to do so. Also, fieldwork notes about the on the move interviews and observations were made. Secondary data was also analysed.

\section{Outline of the Thesis}

This thesis is structured as follows. The introduction in Chapter 1 provided an overview of the topic of this thesis, its research questions and objectives, theory, and the methodology pursued to conduct this research.

In Chapter 2 this research elaborates in greater depth, from a theoretical perspective, how the connectivity of WEF flows occurs. It aims to give answers to the set of theoretical research questions conducted in this thesis. This chapter 
argues that resource flows contain a social and a material dimension that interplay with one another in giving shape to resource provisioning systems and in connecting WEF. This chapter explains how nexus literature has mainly focused on understanding resource flows interactions from material-focused perspectives. It argues that material-focused methodologies need to be complemented with social flows analyses that enable researchers and practitioners to understand the daily practices, policies, ideologies, and networks shaping WEF provisioning. In doing so, this chapter aims to contribute to the theorising of the urban nexus. It offers a theoretical framework that helps to shed light on the socio-material interface of flows in shaping connections between WEF, and the actors facilitating these connections. Its main argument is that in the quest for understanding the WEF urban nexus, cities are crucial spaces in which environmental flows get configured and linked through governance networks. Some of the key actors to look at when identifying nexuses are switchers and programmers. These are actors that link and configure the socio-material flows of WEF facilitating the emergence of nexus governance networks. This is exemplified through examples from geothermal energy in Reykjavik, a food centre showcase in Bologna, and the case of the last mile of food in Amsterdam.

Chapter 3 further explores how these nexus governance networks emerge, and how they connect and (re)configure WEF flows. In this manner, this chapter aims to answer the second theoretical research question. It argues that the interaction of structures, functions, and power dynamics of networks plays a crucial role in (re)connecting and (re)configuring WEF in higher or lesser nexus outcomes. The authors offer a set of concepts to further elaborate on what urban nexus networks are about, how different networks connect and configure, and what the main 
actors are in connecting urban WEF networks. The authors apply this framework to the study of three examples in the city of Amsterdam. By means of these examples, the chapter shows the way in which these urban nexus networks program and connect around sustainability values and goals. This study found that one of the ways to connect WEF systems in Amsterdam is through experimental projects that allow for innovative connections between different societal sectors and resource systems. Experimental labs in Amsterdam are providing an initial and important step toward reconnecting the city into more innovative and sustainable ways. However, the studied projects still have to find their way in terms of becoming more prevailing modes for organising WEF provisioning in the future. WEF networks still have to cope with current and prevailing provisioning systems that impose a lock-in effect on infrastructures and organisational and economic factors that shape the ways in which WEF systems are formed. Nonetheless, the analysis of switchers and programmers provides lessons on the ways in which actors can re-shape the on-going provisioning systems (and its barriers) towards innovative reconfigurations of networks of provisioning. This chapter concludes that Amsterdam has managed to obtain a certain level of nexus dynamics in its existing water, energy, and food networks. The nexus in Amsterdam so far has materialised at a start-up and experimental level that proved feasible for trying out innovative approaches towards sustainability in interconnected flows of WEF.

Whilst Chapters 2 and 3 were more theoretical in focus, chapter 4 is more empirical and further applies the theoretical concepts introduced in earlier chapters. In Chapter 4 the authors study, empirically, how governance networks and flows emerge, connect, and organise around proximity food distribution in 
Barcelona. The chapter explains that cities adopt different strategies to become sustainable cities (e.g. Blue City, Renewable Energy City, etc.). In any of those strategies, Food in the City is an aspect of sustainability that has often been overlooked. The authors argue that Barcelona is one of the cities emerging as a Sustainable Food City. Barcelona is gaining sustainability by strengthening, promoting, greening, and using its network of municipal food markets and the proximity food these distribute. In this case, the authors analyse how and to what extent these food markets function as access points to more sustainable food and how these can contribute to making the city more sustainable. We discuss that the sustainability of proximity food is not just determined by distance (between places of production and access) but by the specific ways in which food flows relate to connections with energy-and-water flows. We conclude that in Barcelona, proximity is developed as a concept to improve and gain on food sustainability and it has been employed as a crucial element in the re-coding of the urban food network and its food flows. However, such code and coding still deserve further developments in closing physical and social distances, not only within the food network (through its processes) but between the WEF dimensions at and through every process of food provisioning in Barcelona.

In Chapter 4, the authors learned that the sustainability of proximity food is not just determined by distance but by the specific ways in which food flows relate to connections with energy-and-water flows. In this regard, Chapter 5 aims to unpack the content and meaning of what occurs in distributing food in the proximity. More specifically, it aims to unpack what occurs in the distance between points $A$ and B (wholesaling and access to food). In this chapter, the authors study the case of emergent e-transport alternatives distributing food in 
the last mile (electric boats, electric vehicles, and electric bikes). The authors study these transports under the context of the city's sustainability agenda to strive for emissions reductions, air quality improvements, carbon neutralisation, and less congested and more liveable city space for its citizenry. In doing so, the authors employ methodologies based on Mobilities as developed in Sociology to help to trace, follow, and to enable the researchers to actually be mobile with the transports under study. This methodological approach was useful to understand in-depth what and how the connectivity of WEF flows occurs in the last mile of food distribution in Amsterdam. This chapter focused on actually being on board of the transports studied and learning from the social actors involved in the actual movement of food between A to B. This analysis provided answers to how and why food moves and relates to water energy and organic waste through the food distribution network, and in what ways it is blocked and enabled. Via this analysis, the authors argued that a more sustainable last mile of food requires more than a shift toward greener modes of transport. It is also about the wider supporting urban infrastructure, including fuel shifts, alternative infrastructure provisioning (e.g. the use of canals as opposed to roads), and the socio-political infrastructure supporting or limiting the sustainable urban food transition (e.g. who supports or obstructs the transition).

The thesis concludes with Chapter $\mathbf{6}$ which draws the main conclusions of this thesis dissertation. 
Chapter 1. Introduction 


\section{Chapter 2. The Nexus Between Water, Energy}

\section{and Food in Cities: Towards Conceptualising}

\section{Socio-Material Interconnections}

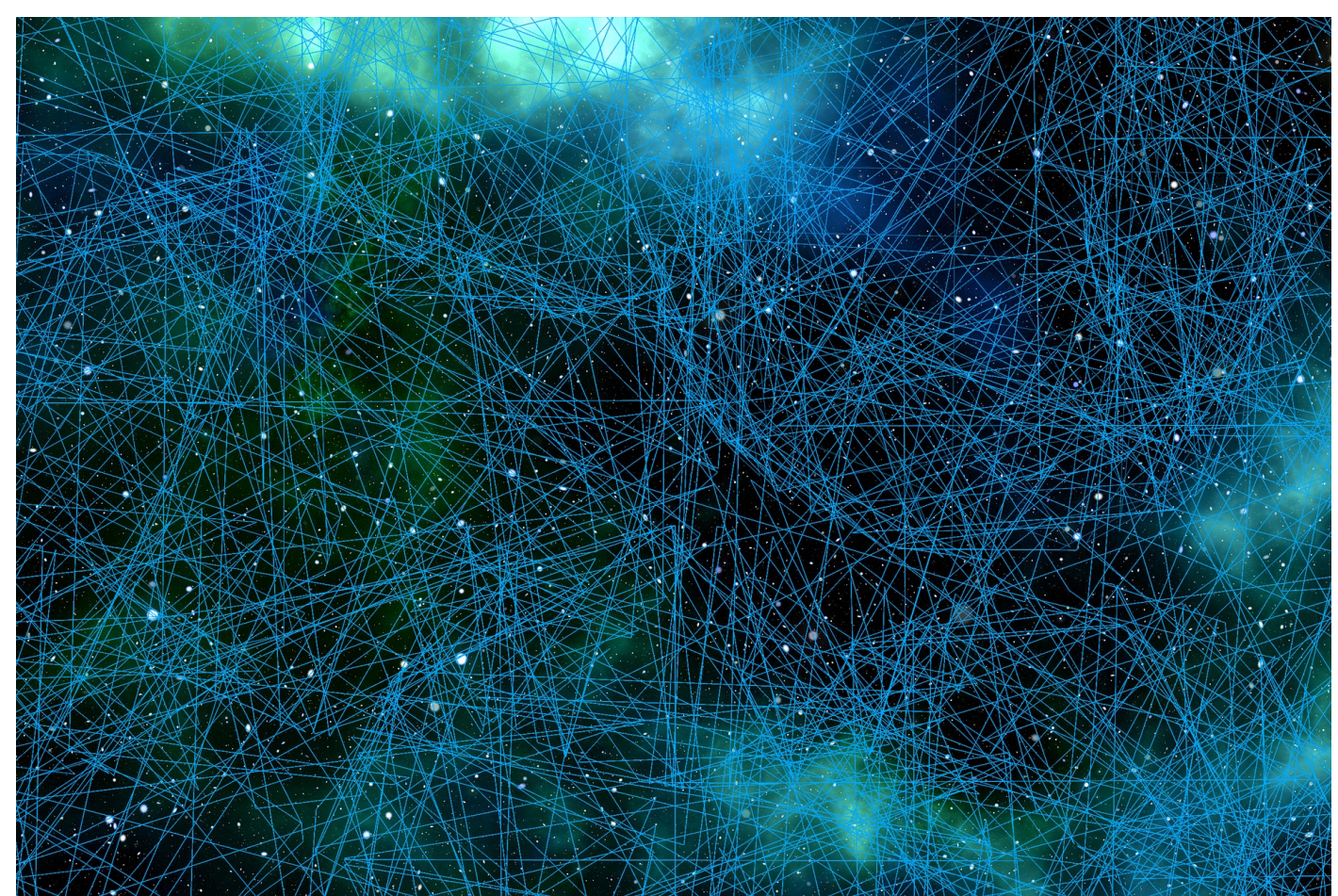

Image Source: https://pixabay.com/photos/system-web-network-connection-2660914/

This chapter has been published as: Covarrubias M (2018) The nexus between water, energy and food in cities: towards conceptualizing socio-material interconnections. Sustain Sci. doi: 10.1007/s11625-018-0591-0 
Chapter 2. The nexus between water, energy and food in cities

\section{Abstract}

Sustainable use and supply of natural resources dedicated to feeding urban life are becoming increasingly complex in a time of rapid urbanisation and climate change. Sustainable governance of Water-Energy-and-Food (WEF) requires innovative and cross-sectorial systems of provisioning. However, practitioners have often treated WEF as separate domains, while ignoring their interconnectedness. What is missing is an 'Urban Nexus' perspective, which assumes that Environmental Flows of WEF interact and relate to one another in achieving urban sustainable development. This paper contributes to theorising the Urban Nexus and to understand its emergence and governance from a more socio-material perspective. It offers a conceptual framework that helps to shed light on the social and material flows shaping connections between the sectors of WEF, and the actors facilitating these connections. The paper suggests that switchers and programmers link and configure the socio-material flows of WEF facilitating the emergence of Nexus Governance Networks and Nexus Programs. In doing so, the paper provides three examples of cities to test the conceptual framework by analysing their main challenges and examples around the Nexus. It demonstrates that material and social dimensions of WEF might not play an equal role in steering synergies or trade-offs, either material or social flows and their agents can be central in facilitating a nexus or in preventing it to take shape. The paper argues that material-focused methodologies need to be complemented with a social flows analysis that pays attention to the daily practice, policies, ideologies, networks or any kind of socio-cultural meaning shaping WEF provisioning.

Key words: Urban nexus; Environmental flows; Urban governance; Networks; Water-Energy-Food 
Chapter 2. The nexus between water, energy and food in cities

\section{Introduction}

Sustainable use and supply of natural resources are becoming increasingly complex in a time of rapid urbanisation and climate change (Childers et al., 2015; Hoff, 2011). Cities concentrate the largest share of the human population and they conglomerate people with the provision of services and goods for consumption (Hoff, 2011). Cities thus depend on larger quantities of resources, such as Water-Energy-and-Food (WEF), whilst at the same time, these resources become increasingly scarce (Vogt et al., 2014). The urban setting thus represents a challenge and opportunity for understanding and steering resources into more sustainable configurations (Vogt et al., 2014; Webb et al., 2018).

Effective and sustainable governance of WEF requires innovative and crosssectorial systems of provisioning. Systems that for instance address sustainable infrastructure operation beyond a single-systems-view, and towards understanding each system connectivity with other related systems, for example connections between WEF (Knoeri et al., 2016). However, urban planners have often treated resources such as WEF as separate domains, while ignoring their interconnectedness (see discussions in Hellegers et al., 2008; Hoff, 2011; Scott et al., 2011; Bazilian et al., 2011; Bizikova et al., 2013; Howells et al., 2013; Howells and Rogner, 2014). Therefore, what is missing is an 'Urban Nexus' approach, which assumes that socio-material flows interact and relate to one another in achieving urban sustainable development. By adopting this perspective, WEF sectors could benefit from having a more integrated and comprehensive understanding and decision-making process to avoid cross-sectorial trade-offs while promoting synergies and enhancing sustainable resources usage (Smajgl et al., 2016). 
Chapter 2. The nexus between water, energy and food in cities

The urban nexus approach, however, still needs to be operationalised and theorised. Most literature concentrates on the global, national or rural nexus but little attention has gone into how the nexus plays out in urban settings. The main objective of this paper is to add to the theorising of the urban nexus to understand its emergence and governance from a more socio-material perspective. It brings together materialistic flows literature focused on natural resources systems and infrastructures, with social flows literature focused on questions of the daily practice of provisioning, policy, discourse, power and (in)formal regulation; by balancing these two thoughts into a socio-material analysis. It does so by further conceptualising the socio-material interconnections between environmental flows that circulate in the city. Specifically, it offers a conceptual framework that helps to define and identify interconnections of the social and material flows shaping connections between the sectors of WEF, and the actors facilitating these connections. The paper suggests that material and social dimensions of WEF are not necessarily equal in creating synergies or trade-offs, either material flows or social flows and their agents can have a more prominent role in facilitating a nexus or in preventing it to take shape. In the urban context, this paper argues, it is in particular social interventions that lead the way towards more cross-sectorial provisioning of water, energy and food.

This chapter is structured as follows. Section 3 provides a background into the literature on the nexus with a focus on social and materialistic approaches and introduces their interconnections through engagement with socio-ecological systems (SES), environmental flows literature from sociology and literature on sustainable urban development. Section 4 offers a conceptualisation of an urban nexus approach from a socio-material perspective focused on WEF provisioning 
Chapter 2. The nexus between water, energy and food in cities

in cities. To build this approach, it brings together different strands of literature, including Material Flow Analysis, Environmental Flows and Castell's Network Society. This section furthermore illustrates these arguments through the use of examples on the nexus in European cities. Section 5 concludes.

\section{The Urban Nexus: connecting material and social flows}

The Nexus has emerged as a concept to improve sustainable usage of natural resources. The nexus stands for cross-sectorial decision and policy making, mostly in the domains of Water-Energy-Food (WEF) provisioning, to overcome trade-offs and to stimulate synergies in sustainable development. A key problem it seeks to overcome is working in silos (see discussion in United Nations 2014). For instance, policymakers focus on one sector at the time (e.g. energy) without accounting for how their respective policies negatively or positively affect other sectors (e.g. water). Indeed, when it comes to resources governance '...policy makers have continued to address and formulate policies in silos that do not guarantee simultaneous attainment of WEF security as well as environmental sustainability' (Bhaduri et al., 2015, p. 726). The governance of such resources attainment and its related infrastructure has often been underestimated or it has been as well difficult to address in practice (Knoeri et al., 2016).

Much literature has already addressed the question how a Nexus between WEF can be achieved. Most papers stress the lack of attention to the material connections between water, energy and food and provide new methodologies examining these connections (see e.g. Bazilian et al., 2011; Howells et al., 2013; Nair et al., 2014; Endo et al., 2015; Daher and Mohtar, 2015; Chen and Chen, 
Chapter 2. The nexus between water, energy and food in cities

2016; Smajgl et al., 2016; Tevar et al., 2016; Ramaswami et al., 2017). For instance, Bazilian et al., (2011) analyse the linkages of WEF for the case of ethanol production. They do so by tracing the industrial processes taken for producing ethanol and their relations with energy, water, land and climate. For example, they illustrate the water flows needed to irrigate land and the energy flows required for the production of ethanol. Alternatively, papers focus on the social side of the equation and discuss for instance how institutional coordination can help to establish a nexus between WEF (see e.g. Scott et al., 2011; Harvey, 2014; Foran, 2015; Bhaduri et al., 2015; Gain et al., 2015; Halbe et al., 2015; Biggs et al., 2015; Smajgl et al., 2016; Boas et al., 2016). But very few articles or literature strands examine both material and social dimensions when understanding or assessing the nexus of WEF. Meanwhile, material and social dimensions of sustainable development interact as the provisioning of services is not just dependent on the resource itself, the industrial processes and infrastructures at work, but also on the policies, daily practices, informal rules, discourses and actors at play. This becomes particularly crucial when considering the policy and decision-making of cities as socio-material systems (Webb et al., 2018). Cities represent the places in which actors, networks, infrastructures, and resource flows get connected in specific socio-material urban contexts (Hodson et al., 2012).

The interaction of social and material characteristics of sustainable development has featured in older discussions on Socio-ecological Systems (SES) literature, Environmental Flows, and sustainable urban development. SES literature (see Anderies et al., 2004; Ostrom, 2007; Janssen et al., 2007; McGinnis and Ostrom, 2014) posits a 'theory-neutral framework' to analyse the linkages and relations of an ecological (non-human, physical or material) system with one or more social 
Chapter 2. The nexus between water, energy and food in cities

systems (Anderies et al., 2004; McGinnis \& Ostrom, 2014; Ostrom, 2007). These scholars suggest that 'tiers' within the SES such as actors (e.g. producers or users) and governance systems (e.g. government and non-government organisations, monitoring rules, etc.) interact and connect with resources units (e.g. $\mathrm{m}^{3}$ water flows) and resource systems (e.g. water sector), and vice versa, into specific action situations (e.g. drinking water provisioning) (McGinnis \& Ostrom, 2014; Ostrom, 2007).

This paper does acknowledge, and align with, the core argument of addressing environmental problems/situations from a socio-material perspective as argued by the schools of thought of Ostrom and SES. Nevertheless, SES literature has been criticised for delivering a simplistic or reductionist perspective of its 'social' tiers. Such 'social tiers' proposition bypasses an adequate theorisation, operationalisation, and conceptualisation of its social dimension rather than proposing a more profound sociological based foundation for these tiers (Stojanovic et al., 2016). What is seen in practice is that such social tiers proposition in SES research relate more to economic or quantifiable units (e.g. employment, tourists number, population, etc.) or to less quantifiable components such as social learning and land use (see Stojanovic et al., 2016). Rather than focusing on the significance of social components such as the power, politics, social practices, networks dynamics, institutions, and dynamics that go along through material flows (Mol \& Spaargaren, 2006b); which have been neglected by the SES (Stojanovic et al., 2016). The framework this research aims for looks forward to capturing the dynamism of flows (perspective) moving along processes and networks shaping WEF provisioning; in this sense, flows are under the spotlight as the unit of analysis of this Nexus research framework. 
Chapter 2. The nexus between water, energy and food in cities

Environmental Flows address the interactions between social and material layers of flows (Mol \& Spaargaren, 2005, 2006a). Environmental Flows are more than material substances units or infrastructures and are also the social organisation that goes along with the flows in question (Mol \& Dieu, 2006; Mol \& Spaargaren, 2005, 2006a). For example, natural resources systems supply urban areas in the form of flows. Flows are the continuous stream of objects, materials, resource units, ideas or information, or any other form that moves along, at least, between two points. These can be either material flows (e.g. 1 litre of drinking water) or social flows (e.g. policies for drinking water provision). A material additions-andwithdrawals perspective is therefore insufficient. It needs to go further into a more sociology-based analysis of flows, which focuses on the role of policies, institutional arrangements, networks and social meanings shaping urban provisioning of resources (Guy et al., 2011; Mol \& Spaargaren, 2006a; Moss \& Marvin, 2001). Along these lines, Moss \& Marvin (2001) have also proposed a more socio-technical flows management of urban utilities. It goes beyond material approaches and examines social, technical, environmental, economic and institutional factors affecting the utility services in cities (Hodson et al., 2012; Moss \& Marvin, 2001). Their contribution is essential since flows management literature has invested on materialistic approaches rather than investigating the social factors shaping resources use and consumption (Binder, 2007a; Moss \& Marvin, 2001; Oosterveer, 2015; Urry, 2003).

Such a more socio-material informed flows analysis is, however, often ignored when analysing interconnections between WEF in cities. Only a few studies have addressed the Environmental Flows of WEF resources from a more balanced socio-material perspective (see Binder, 2007b; Scott et al., 2011; Pahl-Wostl et al., 
Chapter 2. The nexus between water, energy and food in cities

2013; Schiller et al., 2014). And when they do so they often do not adopt a nexus approach by studying only one resource flow at the time. For example, the literature review conducted by Binder (2007a) collects different social approaches that attempt to be coupled with material flows analyses. In this review, Binder (2007a) discusses and concludes that those approaches instead relate mostly to economic approaches such as microeconomics modelling for instance, which relate more to a single-system perspective. More recently, Binder et al., (2013) reviewed a larger diversity of socio-material approaches that address natural resources analyses including Natural Step, DPSIR Analysis, Earth Systems Analysis, Ecosystems Services, and others. When looking closer into their results of how such approaches address their social dimensions (e.g. social dynamics), those mainly reflect that the social dimension is not (adequately) conceptualised. Moreover, it is worth noting that Mol and Spaargaren (2006) discuss how those approaches continue to address flows only or primarily from physical or biological terms. Although those approaches do provide a step forward in providing methodologies for socio-material analyses and perspectives, what is missing is an approach that understands the social significance of different flows and the way these get configured through WEF networks and flows of provisioning. This research then posits Networks and Environmental Flows as a suitable analytical perspective for emphasising that the Nexus is about the connectivity of resources flows and their embedded social relationships around WEF.

The paper thus argues that the analysis of the urban nexus should not just focus on creating cross-sectorial synergies or identifying cross-sectorial trade-offs; but, also on bridging the material versus social divide that has for long characterised systems of urban provisioning. The paper argues so not only because cross- 
sectorial provisioning in cities includes both social and material dimensions, but also because understanding and explaining how the nexus unfolds in the first place requires attention to both its social and material dimensions. In the next section, the paper will outline this argument in more detail. It will demonstrate how cross-sectorial urban provisioning can emerge and takes shape from connections between material flows affecting the social organisation of provisioning, or the other way around, namely from new connections made by entrepreneurs leading to new visions and ideas (thus a change in social flows) leading to a different usage and circulation of material flows.

\section{Conceptualising the Urban Nexus}

Building on the above literature, this section seeks to conceptualise material and social interconnections into cross-sectorial provisioning of WEF in cities, in short, the urban nexus; including what it consists of, how it emerges and how its governance takes shape. The paper explains it in three steps, starting with 1) the material flows, followed by 2) the social flows, and finally 3) how these can come together as the urban nexus.

\subsection{Material Flows of WEF Provisioning}

Material flows are the continuous stream of natural resources extracted and moved along by infrastructures for the provisioning of services in the city. Natural resources enter, move around and leave the city, or are created and circulated continuously within the city, in the form of flows facilitated and directed by hardware (the infrastructures). The methodology of Material Flow Analysis (MFA) is one of the most established ways to trace such flows and their possible 
Chapter 2. The nexus between water, energy and food in cities

impacts on the environment. It is therefore used to examine the material interactions of WEF (see examples Bazilian et al., 2011), for instance, to trace the relations between urban wastewater flows and the energy that could be recovered from these flows.

Wallsten (2015) and Fischer-Kowalski (1998) discuss the origins of MFA, which they place at the study of industrial metabolism of materials and energy flows in cities. MFA studies the material composition of the resources on which a city relies and how these are processed. MFA is useful for investigating the physical activity of materials, for tracing how materials are allocated to feed cities and for tracing possible inefficiencies in their production systems (Wallsten, 2015). It does so by analysing the material flows going along through processes of extraction, production, consumption and disposal. In other words, the processes and flows needed to sustain urban provisioning of utilities (Fischer-Kowalski, 1998).

Tracing and analysing material flows through MFA are essential parts for understanding the urban nexus. First, this is to identify the origins of WEF resources, e.g. do they originate from within or nearby the city or do they come from abroad? Second, from this point of origin onwards, it can be examined how these resources are extracted, converted, transported and provided to consumers by infrastructures. This results in an overview of the urban metabolic processes taken for the provisioning of WEF, including how WEF are related to each other along the processes that WEF provisioning takes. Third, MFA gives insight into the environmental impacts of these material flows. 
Chapter 2. The nexus between water, energy and food in cities

Whilst giving insights into the origins, directions and consequences of material flows, MFA has struggled to provide relevant and understandable input for policy and decision-making (Binder, 2007b, 2007a). For example, as argued by (Binder, 2007b) understanding material flows per se does not provide sufficient feedback for policy-makers as to how the effects or relations of their policies affect the material flows. Also, MFA can be criticised as an analytical tool that quantifies materials in a summarised manner as it simplifies reality into inputs and outputs of resources within a determined system (Wallsten, 2015). These make difficult to actually implement findings from MFA into the sustainable upgrading of, for instance, the WEF domains (Binder, 2007b). Along these lines, Knoeri et al., (2016) argue for the need of understanding infrastructures (and any material flow) not only as material systems supplying resources but rather as a more socially balanced end-user centred infrastructure which addresses the consumption practices and needs of end-users for resources services. Therefore, the need to complement MFA with social approaches that help to understand resources in a more informative way for policy-making, for decision-making, and for scientific research (Binder, 2007b, 2007a; Guy et al., 2011; Moss \& Marvin, 2001; Oosterveer, 2015; Schiller, 2009; Urry, 2003).

\subsection{Social Flows of WEF Provisioning}

The provisioning of WEF is not just about material substances, physical objects, and infrastructures. It is also about social flows. Social flows can take the shape of ideas, ideologies, images, information, discourses, practices or policies (Appadurai, 1996, 2001) flowing through the different processes of resources provisioning. Castells (2010, p. 442:442) defines flows as "the expression of processes dominating our economic, political and social life". These social expressions (e.g. ideas or information, or governance systems) shape the 
Chapter 2. The nexus between water, energy and food in cities

continuous stream of physical substances (e.g. water, energy or food as resource units and systems) and their resources provisioning systems in cities (e.g. transmission of these resources via infrastructures). For example, regulations and social practices (as examples of social expressions of governance systems) shaping the uptake of domestic water-saving appliances that lower the flows of water flushes (a continuous stream of a physical substance).

Conducting a social flow analysis would go beyond the material aspects of flows and instead centre on the social organisation, actors, networks, policies, ideologies, discourses and any kind of socio-cultural meaning that goes along with the material flows of WEF (Guy et al., 2011; Mol \& Dieu, 2006; Mol \& Spaargaren, 2005, 2006b). For instance, in case of examining the provisioning of water, it means to not only examine the quantity and quality of drinking water or its provisioning infrastructure, but also the regulations shaping this provisioning. Or even a step further zooming-up into examining the social context explaining the lifestyles of individuals pursuing their daily life activities such as e.g. showering, cooking, or dwelling, or in other words, the Social Practices of being an end-user of water, energy and food (Spaargaren 2003; Knoeri et al., 2016). This provides a more holistic understanding of resource provisioning by examining (different aspects of) its social embedding and it explains how social processes shape resources provisioning.

Understanding the role of the social flows is crucial to obtain a full picture of how the provisioning of WEF works and for possibly steering these in a more sustainable manner. Ignoring the practice, policy and politics of the provisioning of WEF risks that technical solutions will not be implemented or have a different effect than anticipated. 


\subsection{The Urban Nexus of WEF Provisioning: analysing socio-material interactions}

The above steps discuss the material and social processes involved in the urban provisioning of water, energy and food, but do not yet show how this all comes together as a nexus approach. The urban nexus is about the interaction between WEF provisioning in cities consisting of socio-material flows (see Figure 1). This third step reflects on how this interaction takes shape or fails to take shape, and how this can be detected and understood.

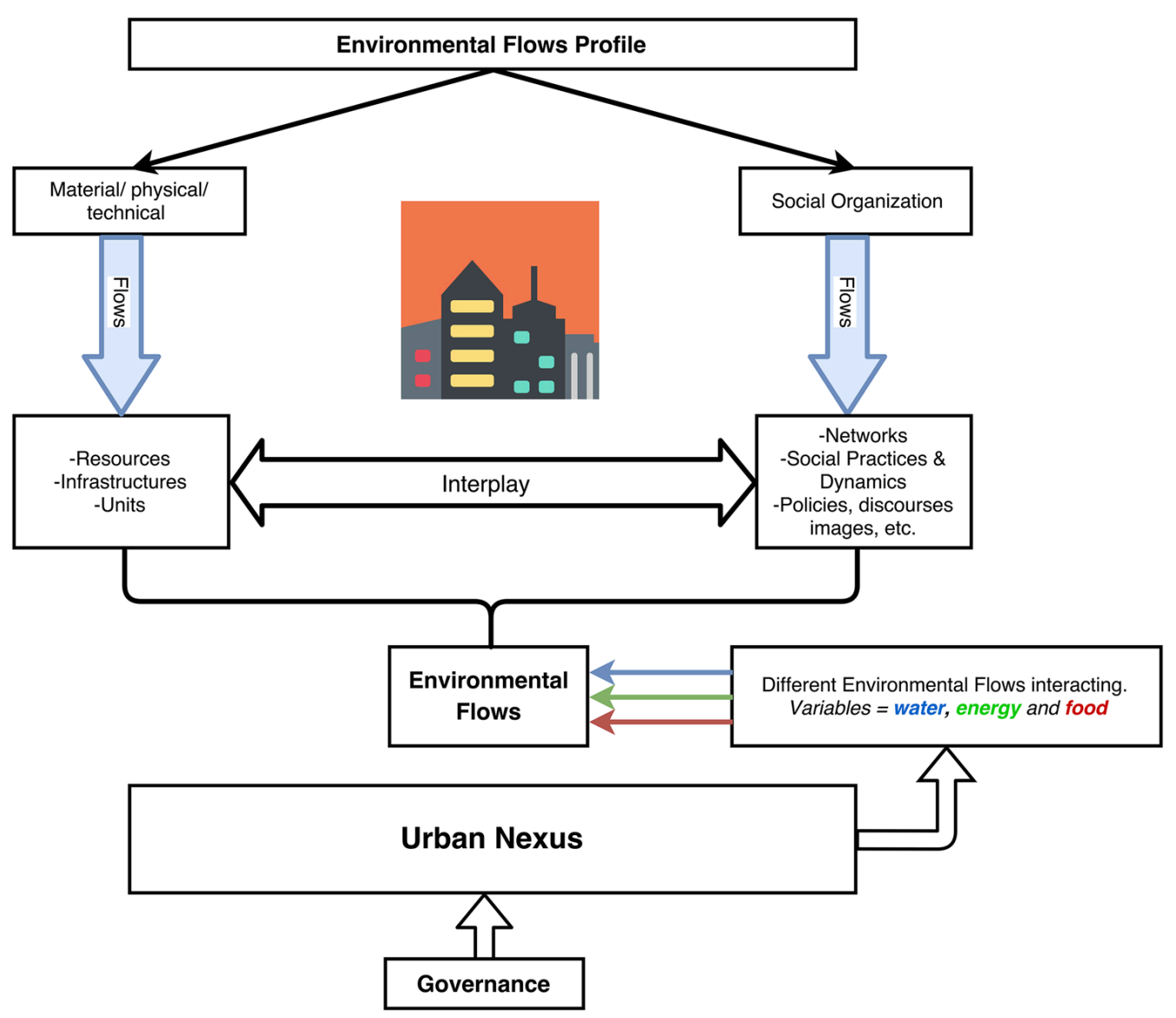

Figure 1: Environmental flows in the nexus

The paper argues that there are two ways in which material and social flows of WEF can come together and constitute a 'nexus'. The first is where the material 
flows are the main driver in creating a nexus between WEF provisioning in the city. In these instances, social flows will follow and organise themselves in such a way that they facilitate synergies between the provisioning of water, energy and food. To detect those, it is most effective to trace the interconnections of material flows of WEF and examine how they are or have become socially embedded. The second way in which a nexus can come about is when cross-sectorial linkages are more socially driven; the nexus is then a result of social interventions such as a new policy or strategy for the provisioning of energy to a certain neighbourhood requiring changes in infrastructures and the circulation of material flows. In this case, it is a network of actors, such as utility managers, municipalities, and entrepreneurs, that have the capability to link, configure and steer the material flows of WEF in a cross-sectorial manner through collaboration, policymaking, discourse or other social flows. In such instances, the analysis can start with tracing such actions and initiatives and how these (re)shape the (material) provisioning of WEF in the city. This paper will elaborate on both types below and illustrate them by means of examples of cross-sectorial provisioning of WEF in different European cities.

\section{Materially driven nexus}

First, a nexus between water, energy and food in the city can most simply be achieved in case material flows easily connect, or ideally have a natural connection. When materials, substances, physical objects, processes and infrastructures match, it is just a manner of effective planning and provisioning to achieve cross-sectorial management of natural resources. 
Chapter 2. The nexus between water, energy and food in cities

A good example of such a nexus is the case of Reykjavik. Reykjavik has benefited from the presence of geothermal activity due to its geographical location. Hot water, as a primary energy source, has historically powered Reykjavik mainly by using the heat and steam of water coming from geothermal reservoirs (C40 Cities, 2011; National Energy Authority, n.d.). The environmental flows of water and energy are thus synergistically interlinked in Reykjavik. Reykjavik Energy is the public utility company that produces and provides electricity and heating to the city (OR Orkuveita Reykjavikur, n.d.). To gather hot water (as primary energy source) this power generation company has built wells as infrastructures for its extraction (OR Orkuveita Reykjavikur, n.d.). After hot water is extracted, one of the first processes is the separation of steam from hot water. Then, each of these flow resources has a different use. Hot water can be directly provided as a service for heating spaces such as houses, and the steam is used as an input source to spin electric turbines for electricity generation. Once electricity is produced it is transmitted and distributed in the city, making electricity load available for domestic consumption (C40 Cities, 2011; National Energy Authority, n.d.). Whilst this nexus is mostly about the material connections between water and energy, there is also a link to food; yet outside the boundaries of the city. As argued by Iceland's National Energy Authority (National Energy Authority, n.d.): 'Apart from space heating, one of Iceland's oldest and most important usages of geothermal energy is for heating greenhouses. For years, naturally warm soil has been used for growing potatoes and other vegetables.' In this way the material flow connection between hot water and energy also links to the production of food, making geothermal energy a highly efficient and sustainable source relevant for all three resources constituting the nexus. 
Chapter 2. The nexus between water, energy and food in cities

In this example, it is thus the material conditions that are central to allow for a nexus between water, energy and food to emerge. It is even fair to say that for Reykjavik this nexus is almost a given and taken-for-granted context, which has shaped how utility provisioning is organised. As it is such a natural, relatively straightforward process, it also does not require a complex governance structure. Instead, there is one single organisational unit of production, the public utility company Reykjavik Energy, for generating hot water, heating and electricity. Such organisational structure is the result of a historical merge of different utility companies providing separately electricity and heating (both sourcing from hot water) (OR Orkuveita Reykjavikur, n.d.). Such merge is, in part, a result of the referred interlinked material conditions and the overlapping functions delivered by two different utility companies. Another element from the social flow that has been important in further developing the geothermal industry in Reykjavik (and Iceland) is the introduction of the Energy Fund back in the late 1960'. The introduction of such policy instrument has stimulated the exploration, drilling, and use of geothermal resources (C40 Cities, 2011).

It is important to note that finding a materially-driven nexus in an urban context is rare, especially if looking for connections between all three resources of water, energy and food. This research, therefore, struggled in finding other suitable examples. One reason may be that in the European urban context provisioning of WEF has already been highly planned and organised since the industrial revolution. Moreover, as argued by (Hodson et al., 2012, p. 796): 'Cities are actually gigantic networks of interlocked infrastructures that have been built over many years to manipulate vast and varied flows of resources that enter into, circulate within, and exit from them in support of human prosperity.' Thus, unless material flows have the space to naturally connect, or in case urban planners were 
aware of their interconnections decades ago and structured the infrastructural provisioning accordingly, a lack of cross-sectorial provisioning is deeply ingrained in the way cities function and operate. This brings us to the next point that in most instances, the urban nexus is socially driven, a result of concrete social interventions.

\section{Socially driven nexus}

When material settings do not simply allow for a nexus to take shape, usually social flows have a more important role to play. The nexus then becomes a result of a social intervention. Initiating and steering of environmental flows in a crosssectorial manner is dependent on the actors and new practices and ways of doing provisioning, and in that sense is inherently socially-driven. When successful, cross-sectorial actors and the associated practices, (informal) rules and regulations, will constitute a Nexus governance network. Sørensen \& Torfing suggest that a Governance Network stands for 'a stable articulation of mutually dependent, but operationally autonomous actors from state, market and civil society, who interact through conflicting ridden negotiations that take place within an institutionalised framework of rules, norms, shared knowledge and social imaginaries... and contribute to the production of public value in a broad sense of problem definitions, visions, ideas, plans...'(2009, p. 236). Similarly, the Nexus is a Governance Network in which actors from the WEF sectors are mutually dependent, interrelated but autonomous. This Nexus constellation includes actors from different sectors, and they interact in the quest for understanding and framing what Nexus problems (trade-offs) and opportunities (synergies) are for urban sustainable development. This Nexus constellation operates within an existing framework of policies, norms and shared knowledge, 
Chapter 2. The nexus between water, energy and food in cities

while at the same time adding new ideas, practices and regulation to align efforts towards the sustainable provisioning of WEF in the city.

Whether and how a nexus between WEF provisioning unfolds is in part a result of the structure of the Nexus governance network. This governance network consists of a set of interconnected nodes (which can be actors or central points of provisioning) which are characterised by their number of links, the density of connections and symmetry of communication among nodes (Castells, 2010). Consumers, producers, distributors, or regulators are examples of "actor" nodes in the network (e.g. of a network for drinking water distribution). Each of these nodes relates and each of them is dependent on one another for the effective provisioning of services. For instance, consumers depend on the supply of a service, while the producers respond to patterns of consumption and both of them depend on regulations set by different actors from different sectors (e.g. water and energy). From this example, one could argue that regulations from one sector (e.g. water) might affect more sectors (e.g. food) and these regulations can also affect the way a service or product (e.g. food) is provisioned and consumed. The more interconnections there are between the nodes, not just within one network but also between the networks of WEF, the more these governance networks become cross-sectorial and thus a Nexus governance network.

In the making of the Nexus Governance Network, actors from the WEF sectors contribute to its creation. This is the role of 'switchers' and 'programmers' from each system (WEF) exercising their 'network making power' to create a new network and to (re)program the values, rules, arenas, power and actors of this new network (Castells, 2009). For example, as illustrated in Figure 2, actor nodes 
(e.g. producers, utility managers, consumers or municipalities) from different sectors could play the role of switchers and reconnect a new network configuration by linking efforts, resources, meanings, decisions and information towards a more Nexus-thinking of the urban governance of WEF provisioning. And at the same time, these actors can be programmers by deciding on the rules and values that this Nexus governance network will pursue.

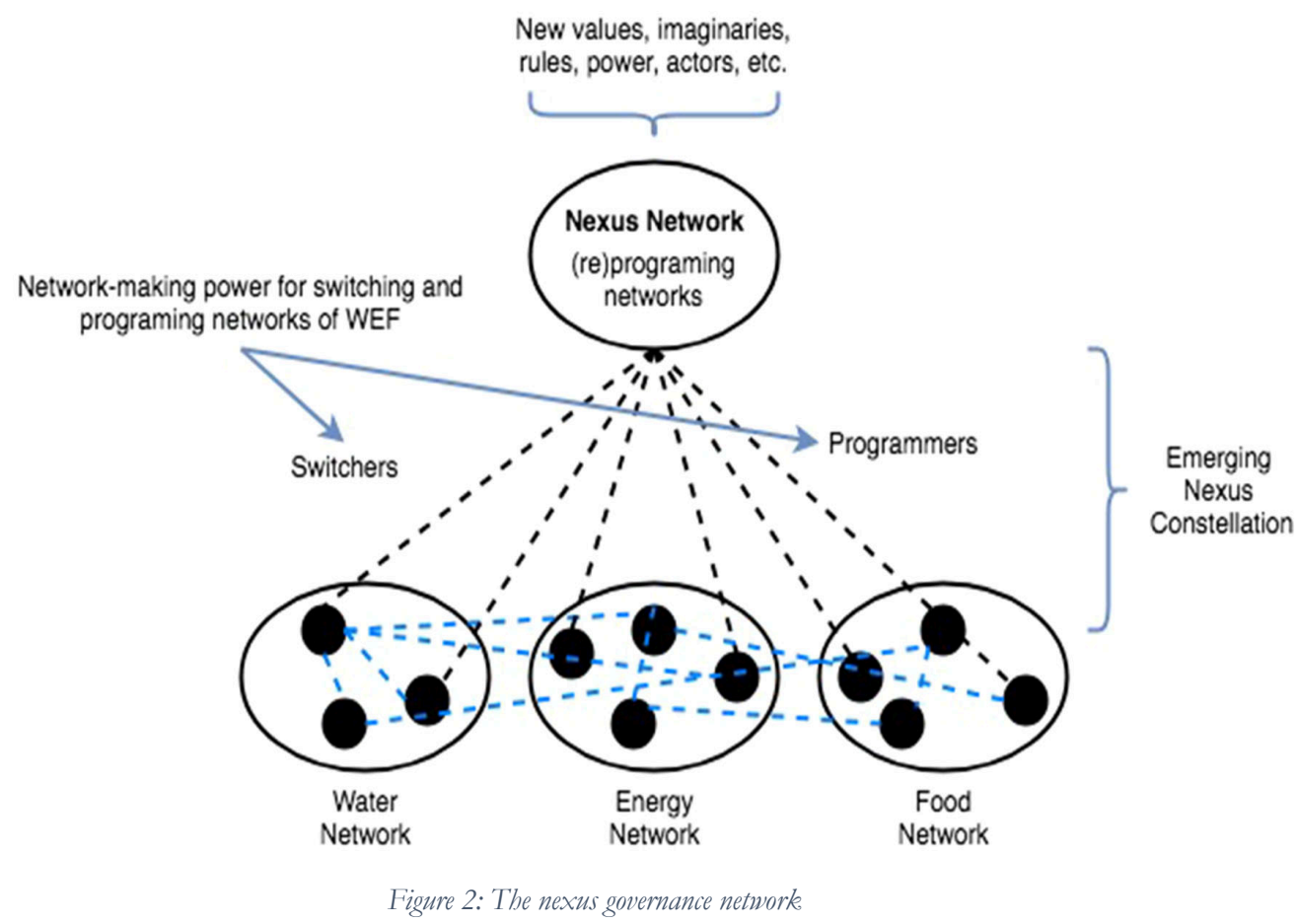

By establishing such Nexus governance networks, actors overcome silo-based decision and policy-making approaches. This can be an unintended outcome of more cross-sectorial collaboration. But in the current context where the nexus has become a highly popular concept in the domain of sustainable development (see e.g. World Bank, 2013; Vogt et al., 2014) some governance actors may take conscious and explicit steps to work on a more cross-sectorial level. This may include a systematic assessment of socio-material interconnections of WEF and a plan of action to pursue the breaking down of silos. Then, when switchers and 
Chapter 2. The nexus between water, energy and food in cities

programmers configure the Nexus (as a program) they bring a new configuration to the linked-up network(s) by changing imaginaries, rules, arenas, power relations, values, problem definition and framing, targets and actors. As a result, there is a new constellation of actors from the WEF sectors, which are linked in a cross-sectorial basis, aligning and mobilising resources, visions, policies and actors from different sectors.

To make it tangible how such nexus governance network emerges and operates, it is relevant to consider the example of sustainable provisioning of food in the city of Bologna. Bologna is well known for its culinary traditions and for its role as a food producer and distributor in Italy. Bologna has been working towards more sustainable and resilient options for the urban provisioning of food, by connecting it more effectively with the provisioning of water and energy (City of Bologna, 2016). Mutually dependent but operationally autonomous actors have emerged and collaborate across sectors by trying to integrate WEF policies and central points of provisioning into one food project. The Municipality of Bologna in cooperation with the Urban Centre Bologna, the Food Centre Bologna (CAAB), renewable energy companies, and food companies, have worked on a food project which tries to integrate in one site all the processes taken in a food supply system (including production, processing, wholesaling, distribution, consumption, and waste management) (CAAB, n.a.; FICO Eataly, 2015). These actors collaborate in creating an alternative to the conventional food supply system and in that manner act as switchers to create a new type of provisioning network. This alternative is the development of a food and agriculture park named FICO (Italian Farming Company). FICO aims to produce local food and to provide services such as catering, retailing, marketing, research and educational 
Chapter 2. The nexus between water, energy and food in cities

activities. And, it aims to reproduce the whole food production chain (CAAB, n.a.; FICO Eataly, 2015).

FICO links more than actors and policies and it also generates a new vision about how to manage material flows and new resources to accomplish that. This vision is about creating a synergetic nexus of WEF to become sustainable and selfsufficient. To materialise this, one of its partners 'CAAB' (CAAB is the food centre for logistics, warehousing and wholesales which shares facilities with FICO) has installed, on-site, 43,750 solar PV panels with a production capacity of up to $11,350,000 \mathrm{kWh}$ a year. The aim is to power the site's operations of both $\mathrm{CAAB}$ and FICO. The renewable energy surplus is aimed to power vehicles transporting people or goods coming in or out of FICO. With regard to water usage one of the strategies within the FICO project is to re-use wastewater and use rainwater to minimise the dependency from the conventional water supply service (Urban Centre Bologna, 2016). In this way, the FICO project is a perfect example of how agents of change set up and create a new governance network to provisioning food in a nexus way leading to a transformation in the use and circulation of material flows. It has done so not just by connecting efforts but also by acting as programmers to generate new visions and ideas about what urban provisioning of services should be like. FICO also resembles an intended linking of WEF into a Nexus governance network in which actors consciously tried to integrate WEF, processes and actors into a specific project.

An emerging nexus governance network does not have to be so well planned and neatly organised. In contrast, very often changes start bottom-up resulting in some change agents leading the way, not necessarily centrally organised but 
instead working from a networked set of entrepreneurs. Take the case of food provisioning in Amsterdam and its nexus with energy use. In contrast to the FICO project in Bologna, cross-sectorial efforts here are less intended and more fragmented. In this case, it started from bottom-up with entrepreneurs seeking opportunities and experimenting with innovative methods to make urban management more efficient and sustainable. In Amsterdam, a number of entrepreneurs have started food distribution services using normal bikes or electric bikes as opposed to using cars or trucks for delivery, making food distribution dependent on mobility systems that require no energy sources at all or cleaner energy sources. At the same time, it also reduces the congestion of cars, scooters and trucks in the city, thereby reducing levels of air pollution and $\mathrm{CO}_{2}$ emissions. These entrepreneurs thus stimulate nexus thinking as to how food distribution should look like by setting goals and operationalising them into new ways of distributing food and new sources to power this transport. These actors re-connect the food system with the energy system in a way that will help to decarbonise and de-congest distribution of food. It is not clear whether this is indeed also the intent of these actors. For instance, the primary objective of entrepreneurs such as Uber or Deliveroo may just be to create a new market of bike delivery in a city where bikes are actually much quicker than cars in reaching destinations, plus allowing a larger group of people to work as delivers as all you need is to own a bike. These innovations in delivery services are nonetheless increasingly being picked up by multiple actors, including by established players in the Amsterdam network of food provisioning such as the Food Centre Amsterdam which is the main distributor, warehouse and wholesaler in Amsterdam (Amsterdam Smart City, 2015). Thus whilst still a bottom-up, innovative and open development, a wider nexus governance network around the 
Chapter 2. The nexus between water, energy and food in cities

use of new mobility systems is gradually emerging including both entrepreneurs and established actor nodes, possibly in leading to a more rigorous application of these new delivery services and an expansion of its use from the food sector to other sectors of provisioning as well.

Whilst the above cases resemble positive storylines on the emergence of an urban nexus on WEF, it is more the exception than the rule. A nexus governance network does not easily unfold. In the quest of the nexus, there are many hurdles and complexities related to policy and decision-making to overcome. These may concern limitations resulting from administrative boundaries (city, regional or national scale); the scale of the management of WEF (municipal, regional or national) (Bhaduri et al., 2015; Biggs et al., 2015; Weitz et al., 2017); and disarticulation in the policy and decision-making (Gain et al., 2015). Actors in the quest of making the nexus thus constantly have to co-frame sustainability related goals, co-define problems, or contest perceptions with regard to effective policy making or even what a nexus governance of WEF is like. It is therefore also of interest to examine such cases, to understand why a nexus does not come about or fails to come about and how that can be explained through understanding how both material and social flows are historically organised in a city. For instance, Villamayor-Tomas et al., (2015) provide an example of how the allocation of wastewater use incentives for agricultural irrigation has triggered perverse incentives and outcomes. They address the case of the City of Braunschweig (Germany) in its attempt to link wastewater with food and energy. They explain the historical modernisation of the wastewater treatment management for addressing the synergy between a growing urban population producing larger quantities of wastewater with the agricultural needs of water for growing crops. Such synergetic agreements between the City, the Wastewater Association, and 
farmers (from the peri-urban area) provided a desired but temporal outcome. Factors such as the supply of affordable and sufficient wastewater to irrigate agriculture triggered then an increase in the growing of crops and in particular, for that case, the production of energy crops. Such events of synergies turned out to be a case of trade-offs, which brought the City and the Wastewater Association back to negotiations with farmers to coordinate their cropping plans and their irrigation schedules in order to stop the exceeding water intake from groundwater sources. The authors then argue that the main institutional challenge for the nexus in this case was to coordinate goals and values around food cultivation, energy supply (and the event of energy crops cultivation and energy production) and (waste)water consumption (for irrigating crops and energy crops) across sectors and policies (see Villamayor-Tomas et al., 2015). Competition of goals and visions towards the management of WEF could also then result in poor integration of the Nexus of WEF as seen in this example and further argued in Binder, (2007b); Scott et al., (2011); and Gain et al., (2015).

Whether a nexus between WEF provisioning is materially or socially driven, in the end, both material and social dimensions constitute the urban nexus. Crosssectorial governance of WEF in cities, or a lack thereof, cannot be understood without identifying and analysing both social and material dimensions of utility provisioning.

\section{Conclusion}

This paper contributed to the debate of the theorisation of the urban nexus by outlining a conceptual framework that helps to identify interconnections between 
Chapter 2. The nexus between water, energy and food in cities

different systems of provisioning, WEF, and between the social and material flows shaping these connections. Whilst Material Flow Analysis (MFA) provides a crucial overview of the metabolic processes that constitute the urban provisioning of WEF and their interrelations, it does not show how these processes are socially embedded. The paper, therefore, argued that materialfocused methodologies, such as MFA, need to be complemented with a social flows analysis that pays attention to the socio-cultural meaning shaping WEF provisioning. It subsequently argued that either material or social flows could be central in driving the creation of the nexus, with the material flows affecting the social organisation of cross-sectorial WEF provisioning or vice-versa. In the quest for understanding the urban nexus of WEF, cities are crucial places in which environmental flows get configured and linked through governance networks. Cities are nodes where cross-sectorial actors, resources, infrastructures, policies and utility services come together for the provisioning of water, energy and food.

Whilst this paper made a start in conceptualising how material and social flows interplay in the nexus of WEF provisioning, there are limitations to this study as well. For one, the paper only focused on the nexus within the boundaries of the city. Further research can elaborate on studying the nexus at different scales or administrative boundaries, for instance by understanding how WEF flows in the rural hinterland interact with urban provisioning and vice-versa. Similarly, more research needs to address in-depth issues of overlapping accountability and faculties as barriers and opportunities to further gain on Nexus Governance knowledge. As well, further research can develop this conceptual framework for the study of different components of the social (e.g. discourses, social practices, or power dynamics through WEF networks) and material (e.g. disposal processes) 
Chapter 2. The nexus between water, energy and food in cities

flows, or it might be applied as well to different natural resources (e.g. waste, nutrients or minerals). 
Chapter 2. The nexus between water, energy and food in cities 
Chapter 3. Network governance and the urban nexus of water, energy and food

\title{
Chapter 3. Network Governance and the Urban
}

\author{
Nexus of Water, Energy, and Food: Lessons
}

\section{from Amsterdam.}

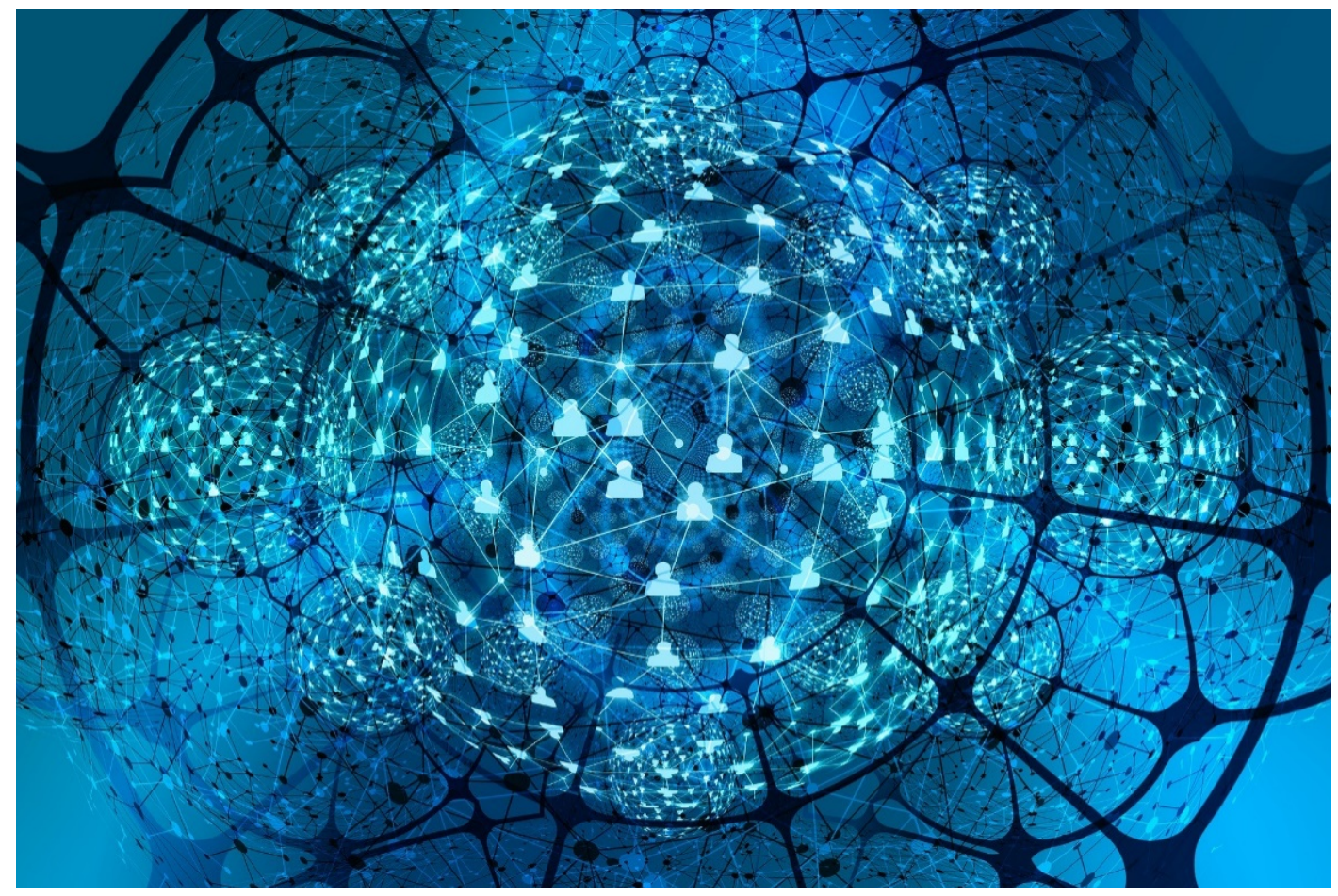

Image Source: httpspixabay.comillustrationssystem-web-news-personal-figures-5292534

This chapter has been published as: Covarrubias, M., Spaargaren, G. \& Boas, I. Network governance and the Urban Nexus of water, energy, and food: lessons from Amsterdam. Energy Sustain Soc 9, 14 (2019) doi:10.1186/s13705-019-0196-1 
Chapter 3. Network governance and the urban nexus of water, energy and food

\section{Abstract}

Background: Silo-thinking stands for one-dimensional and sectorial policy and decision-making in which natural resources managers do not reflect on interrelations between different sectors involved in the management of resources. Nexus-thinking stands out as a way of breaking down silos by identifying and understanding the interconnectedness of multiple resource flows within a determined spatial and temporal context, as in our case study of the flows of water, energy, and food (WEF) in the city of Amsterdam. To further the conceptualisation and analysis of the Urban Nexus, this research introduces the theoretical perspective of networks and flows as developed in sociology by Manuel Castells. It offers a set of concepts to analyse how networks of WEF integrate or fail to do so, what the main actors are in connecting and configuring WEF networks, and how they interact. Method: We analyse how the structure and function, and power dynamics of networks play out in the WEF Nexus. We use the city of Amsterdam as a case study because this city offers examples of how networks of provisioning are being integrated in innovate ways. Results: Amsterdam managed to realise a certain level of nexus dynamics in its existing WEF networks. The nexus in Amsterdam so far has materialised at a start-up or experimental level which proved feasible for trying out innovative approaches towards sustainability in interconnected flows of WEF. Conclusions: However, the studied projects still have to find their way in terms of becoming more prevailing modes for organising water, energy, and food provisioning in the future.

Keywords: Urban Nexus, Governance, Networks and Flows, Water-EnergyFood. 
Chapter 3. Network governance and the urban nexus of water, energy and food

\section{Introduction}

Within natural resources management, silo-thinking stands for one-dimensional and sectorial decision-making in which the involved actors do not reflect on the cross-sectorial linkages or interrelations between different scales in the management of natural resources. It hinders informational exchange and collaboration, concerning synergies and trade-offs between different resources systems, e.g. water, energy, and food, which are often approached as single and independent sectors (Hoff, 2011). Such lack of cross-sectorial management has been discussed through different concepts, such as integrated water resource management, environmental policy integration, earth system governance, etcetera (Allouche et al., 2015; Boas et al., 2016; Cairns \& Krzywoszynska, 2016; Wichelns, 2017). The concept of the nexus is the latest one seeking to push forward a crosssectorial agenda, focused on the domains of water, energy, and food. Nexus thinking is about breaking down silos; it emerges as a way of thinking to identify and understand the interconnectedness of multiple resource flows within a particular spatial and temporal context, for instance the flows of water, energy and food in a city. The nexus approach then is a form of systems thinking which focuses on the inter-linkages between natural resources and the ways in which the linkages are or could be managed and steered into more sustainable and integrated configurations (Vogt et al., 2014).

In this paper we focus on the urban dimension of the nexus. In the field of WEF management 'many cities in the world still rely on outdated modes of planning notwithstanding that planning is central to achieving sustainable urban development' (UN Habitat, 2017, p. 121). Cities are thus challenged to develop innovative modes of governing and planning for the sustainable provisioning of 
Chapter 3. Network governance and the urban nexus of water, energy and food

WEF; modes of planning that no longer address WEF as single, independent and isolated flows, infrastructures and systems. What the nexus approach suggests is that sustainability improvements in one domain (e.g. water) are intimately related to the sustainability gains or losses in other domains (e.g. energy and food). Such cross-sectorial modes of steering and planning of material flows in the city represent an approach to governance that we refer to as the 'Urban Nexus'. Cities are the places where a critical mass of actors, networks, infrastructures, and resource flows come together with high density (Hodson et al., 2012) and under the responsibility of designated authorities operating at city level.

In scientific literature, the study of the nexus has already advanced on researching connectivity of WEF resources at global, national and regional scales (Bazilian et al., 2011; Endo et al., 2015; Howells et al., 2013; Nair et al., 2014). Yet, comparatively the urban scale has received less attention (C. Zhang et al., 2018), although it is a rapidly emerging field of research (see Artioli et al., 2017; Chan, 2015; Keilmann-Gondhalekar \& Ramsauer, 2017). Clearly, the urban domain and the WEF nexus taking shape at city levels is not independent from global, regional and national scales. Cities source WEF resources, through networks of provisioning, from places out of their territorial boundaries where resources are extracted, produced, and transported from (Villarroel Walker et al., 2014). Yet, it is the urban scale where connections between resources and users are concentrated the most and where global flows (such as WEF) intersect (Sassen, 2005). The urban is also a key site of innovation and experimentation (Bulkeley \& Castán Broto, 2013a; Castán Broto \& Bulkeley, 2013), also in the field of the nexus. This article therefore further zooms in on the urban dimension of the 
Chapter 3. Network governance and the urban nexus of water, energy and food

WEF nexus to get a better sense of this emergent form of governance (Artioli et al., 2017).

To further the analysis of the urban nexus, this research introduces the theoretical perspective of 'networks and flows' as developed in sociology by Manuel Castells and as applied within environmental studies by (Mol \& Spaargaren, 2006a; Spaargaren, 2003), amongst others. Whilst most studies on the nexus adopt a quantitative methodology focused on the material flows involved (Chen \& Chen, 2016; Howells et al., 2013; Leung Pah Hang et al., 2016; Mannan et al., 2018; Martinez-Hernandez et al., 2017; Menegaki \& Tiwari, 2018; Smajgl et al., 2016; Tevar et al., 2016; C. Zhang et al., 2018), few authors examine the socio-political processes which help to explain the emergence or failure of nexus governance in the city (Artioli et al., 2017; Covarrubias, 2018). Those that do examine sociopolitical questions in the provision of WEF often use a critical discursive or political economy perspective to reveal dimensions of power and inequality in nexus governance (Allouche et al., 2015). We argue that a network approach is particularly suitable when considering how complex socio-technical systems interact and overlap in the provisioning of WEF in a more integrated and sustainable way. Such an approach emphasises how WEF networks overlap with respect to their operational structures, their functions, their material flows, and their dynamics of end-use and provision. Studying existing empirical WEF networks can be interesting both for their synergies and the prevention of side effects as for the conflicts and new forms of competition for authority they represent. 
Chapter 3. Network governance and the urban nexus of water, energy and food

The study focuses on Amsterdam. This urban area provides an example of innovation and integration of its provisioning networks for WEF. Amsterdam strives to become a sustainable and carbon neutral city. It aims to reduce by $75 \%$ its $\mathrm{CO}_{2}$ emissions by 2040 (compared to 1990) (Gemeente Amsterdam, 2011). To attain these goals Amsterdam aims to: increase its renewable energy production and consumption, become a more circular city by recovering energy and nutrients from waste and wastewater flows (AEB Amsterdam, 2014; Gemeente Amsterdam, 2015), and further promote the use of bikes as medium of transport of goods (Gemeente Amsterdam, n.d.) (among other measures). As a way to trigger the accomplishment of these goals, Amsterdam aims to become an urban laboratory to facilitate innovation around its provisioning systems (Gemeente Amsterdam, 2009). A number of projects have already been explored for their contribution to urban nexus thinking and governance within WEF domains (Amsterdam Smart City, n.d.; Van Wilden et al., 2016). We analyse to what extent some of the projects make use of and benefit from concepts and dynamics as put forward by the networks and flows perspective to urban nexus (Covarrubias, 2018). In this way, we are better able to discuss the conditions for the projects to become more mainstream. We show how values, power, and structural factors condition the adoption of an urban nexus approach by managers, operators, and practitioners of WEF networks. We seek to demonstrate how new groups of actors, referred to as the switchers and programmers of WEF networks, play a crucial role in building WEF connections and in reconfiguring existing systems of provision of energy, water and food.

The chapter elaborates as follows. Section 3 presents the theoretical framework based on insights from the sociology of networks and flows as developed by 
Chapter 3. Network governance and the urban nexus of water, energy and food

Manuel Castells. This framework is used to structure the empirical findings. Section 4 introduces the methods used to conduct this research. Section 5 presents the cases studied and then it discusses the empirical findings through the lens of the sociology of networks and flows. Section 6 provides some conclusions on the potential of the urban nexus of WEF.

\section{A Network and Flow Perspective to the Urban Nexus}

The hierarchical organisation of social life is increasingly being replaced by new forms of network governance (Kuindersma et al., 2012); a development Castells has termed the emerging 'network society'. Also, in the case of WEF provisioning, new network dynamics replace the organisational logics of hierarchical and sectorial units of provisioning. Network governance refers to horizontal shifts in the social organisation of cities and societies. Traditional forms of state-led governance are being replaced by new forms of network governance in which public, private, and community actors co-shape policy and decision making processes (Arts \& Tatenhove, 2004). In network governance, the boundaries between the spheres of public, private, and community sectors have become blurred and permeable (Bush et al., 2015; Kuindersma et al., 2012). This has direct consequences for the ways in which power is enacted in networks of WEF. In the network society, power is no longer exercised by one central actor dominating other social actors. Societies have become organised in terms of multiple and dynamic horizontal flows resulting in heterogeneous power relations and forms of distributed power that are more fuzzy, fluent and indeterminate (Castells, 2009). 
Chapter 3. Network governance and the urban nexus of water, energy and food

In this section, we further explain the central concepts of Castells' network society and discuss how these are or can be made relevant to study to the Urban Nexus of WEF. The networks and flows perspective is particularly suitable for studying the Urban Nexus as it is about connectivity of resource flows, crossovers in social relationships, and converging dynamics in governance for sustainability. We use this network and flow approach to help illuminate what the key networks are in steering the provisioning of WEF, and in what ways these networks do or do not manage to produce outcomes of more integrated forms of management, planning, and decision-making. In particular, the network concept will be used to study how WEF networks integrate or fail to do so.

To characterise social networks, we first look into its structure and function: what do networks and their interrelations look like, and what are their main aims or functionalities. These basic questions are answered to be able to then analyse the dynamics of power and social change involved in the governance of WEF as networks.

\subsection{Characterising Networks: structure and function}

A network is an organisational structure that results out of a set of inter-connected nodes (Castells, 2009); nodes are made up by all possible components of the network (e.g. actors, processes, policies, etc.). Networks are structures that process and configure flows (Castells, 2009); flows are the streams of information and resources that circulate between and around the nodes that constitute networks (Castells, 2009). In this vein, we suggest that the scope of a network indicates how extended the networks are and what the variety of flows and actors in the network is about (see an illustration in Figure 3). For instance, in the food sector the scope can be urban agriculture projects and practitioners that self- 
Chapter 3. Network governance and the urban nexus of water, energy and food generate food within an urban setting, or it can refer to the global food system that produces food to markets around the world. Nodes are connected by flows (Castells, 2009); how nodes operate more or less central in the network and how different nodes can be connected in more tight or loose manners refer to connectivity of networks (see an illustration in Figure 3). For example, the structure of an urban agriculture network is determined by how it connects (or not) nodes of farmers markets, supermarkets and local or global food providers. Networks are furthermore characterised as dense in terms of the frequency, in terms of the time-space dynamics, and the 'robustness' of their flows and connecting nodes (see an illustration in Figure 3). For instance, the networks for the provision of urban water, energy and food are connected not only through social actors but as well through the energy and nutrients flows (e.g. heat, or phosphorus, nitrogen and potassium) that come along with wastewaters in the city. The scope and density of these connections tells us something about the options for recovering energy and nutrients and their application as fertilisers in food production. WEF networks are considered densely connected when a myriad of actors, flows, resources, and projects, critical mass, connect or overlap to actually recover and apply those energy and nutrients into food farming, for instance.

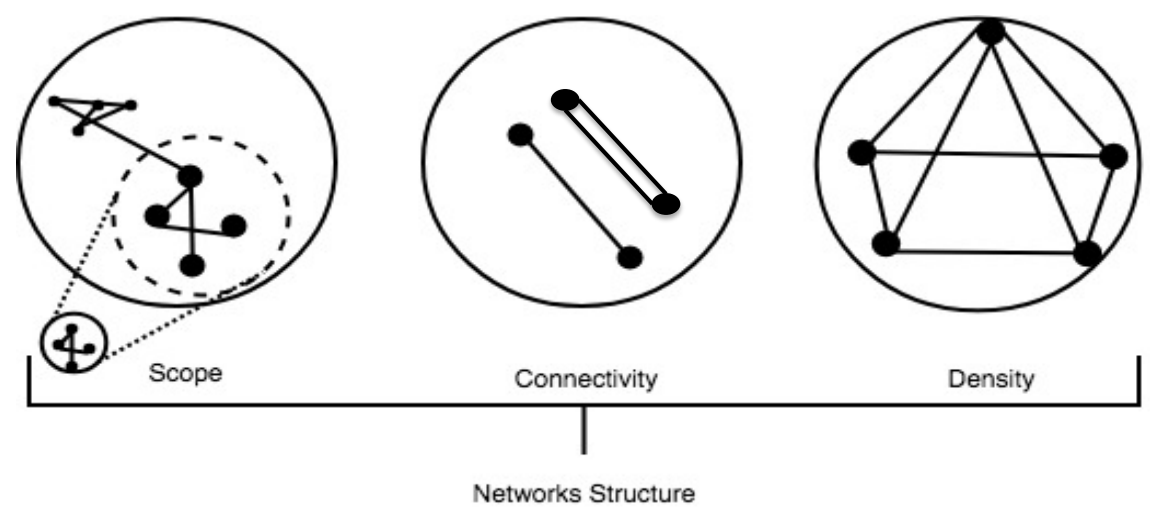

Figure 3: Characterising networks - structure 
Chapter 3. Network governance and the urban nexus of water, energy and food

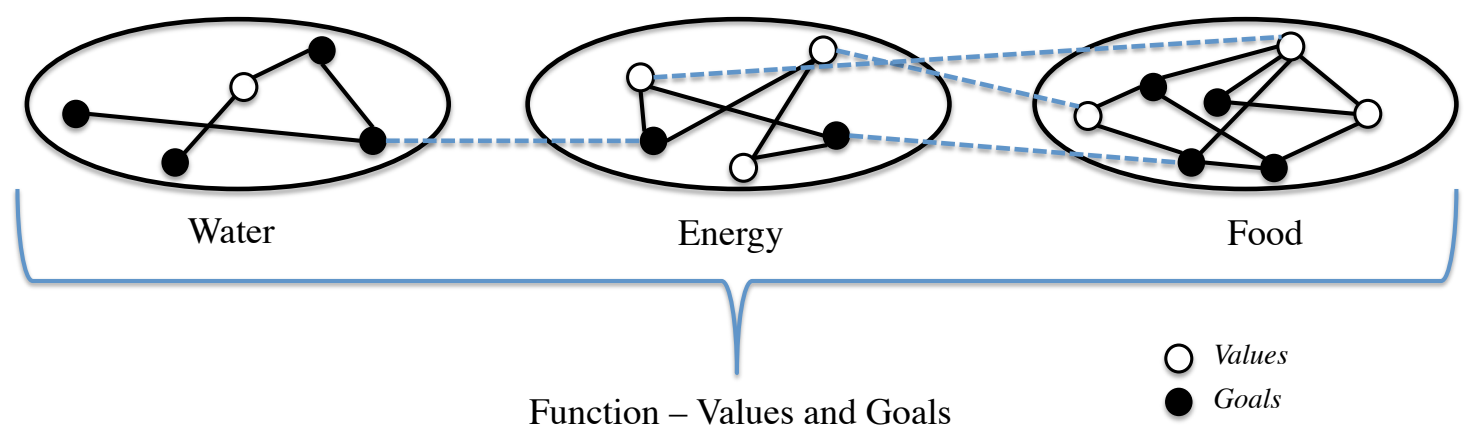

Figure 4: Networks function - values and goals as programmed into the networks and as acted upon by actors

The function of a network refers to the set of values and goals that the network is aimed to achieve. Networks result from the interactions of social actors pursuing common values and goals (see an illustration in Figure 4); those guide actors into the creating, organising, and the (re)configuring of networks. We then posit to use the concept of function to refer to values and goals of networks as inscribed in their functioning towards the realisation of its interests. This function is laid down in the 'code' of the network (e.g. the program). The meaning and function of nodes connecting flows depend on the functions that the network(s) is programmed with (Castells, 2009). For example, in the context of governance strategies for urban climate neutrality, networks and flows of WEF interact with each other based on unifying goals (e.g. $\mathrm{CO}_{2}$ emissions reduction goals) for neutralising the anthropogenic impact of cities in their commitment towards sustainability, values. Functions are not only inscribed into the network via network programs. The values and goals represented by the network program are being acted upon by network actors e.g. utility managers, regulators, consumers, NGOs, etc. 
Chapter 3. Network governance and the urban nexus of water, energy and food

In short, to examine and understand the urban nexus of WEF networks, it is important to consider their goals, values, actors, nodes and flows, and to analyse how these social and material components of networks are involved in successful or failed integration in the context of the urban WEF nexus.

Next to functional and structural factors, power dynamics play a crucial role in allowing for a nexus of WEF networks to come about and for shaping the level and the kind of integration within the relevant networks.

\subsection{Power in Networks: power dynamics in WEF networks}

Dynamics of power inform the possibilities for social change towards more integration or collaboration between WEF networks. Power dynamics, in contemporary networks, deserve special attention since these represent new dynamics of change when compared to older organisational forms (e.g. state organised WEF provisioning after The Second World War). According to Castells (Castells, 2009), power in networks comes in four dimensions. Next to networked power, as the most classical form of old and concentrated power in networks, there are three more power dynamics in networks that deserve analytical attention. In the context of the WEF nexus, whether or not and how networks emerge across WEF sectors is shaped by the 1) networked power, 2) network power, 3) networking power, and the 4) network-making power exercised by switchers and programmers (in terminology of Castells, 2009).

1. Networked Power relates to 1) the actors dominating the processes of decision and policy making; 2) the sectors competing for dominance in the nexus debate; 3) the WEF sectors competing to determine what the standard approaches are to tackle common 
Chapter 3. Network governance and the urban nexus of water, energy and food

urban challenges (e.g. climate neutrality roadmaps or measures); and 4) the actors that actually establish rules for inclusion and exclusion, and the execution of those standards. Although this is the oldest form of power in Castells' categorisation, it should not be ignored that in some contexts this form of power still plays a role in networks dynamics. Indeed, in the context of Europe most of the utility systems have gone through liberalisation schemes in which the state is not the only societal actor dominating the sphere of resources provisioning. Instead, more societal actors play a role in modern organisational networks (e.g. WEF). What networked power in this context refers to is the actual concentration or accumulation of power by particular actors within networks and their influence on the decision and policymaking of WEF provisioning.

2. Networks are programmed with rules to be followed by individuals and actors. These rules relate to Network Power (Castells, 2009). This relational capacity of power implies that coordination between actors or networks relates to the imposition of rules or standards that determine the inclusion of individuals, actors, and networks into (the nexus of) networks. For example, in the context of water-energy nexus, integrating decision-making or synergies between these two sectors might be conditioned by exclusivity rights from each sector that do not actually allow for one sector to intervene or participate in the other one. For instance, some water companies are restricted to produce and 
Chapter 3. Network governance and the urban nexus of water, energy and food distribute energy because of exclusivity rights (rules) granted to the latest, and vice versa.

3. Once the rules or standards governing networks are determined, Networking Power (Castells, 2009) plays out as a gatekeeping capability towards any individual aiming to join a network. Networking power thus stands for the capability of certain actors for actually including or excluding individuals or organisations from networks (e.g. excluding tourism sectors from the Nexus of WEF, or by restricting the nexus and its political attention exclusively within WEF sectors). Inclusion and exclusion are based particularly on the extent to which the scope, values, goals or interests of the incoming party matches, or are compatible, with those of the actors already included in the host network(s). In giving shape to networks, dynamics of power play out far beyond the imposition of rules and the exercising of gatekeeping capabilities. Power is also a matter of concentration and allocation of such relational capacity held by particular actors and networks. Distribution of power is then the capacity of concentrating influence by one or some actors and networks over the rest of actors or networks.

4. Network-making power refers to the capabilities of actors in networks to both influence the structure of networks and their interrelations in terms of connecting actors and nodes, and the 
Chapter 3. Network governance and the urban nexus of water, energy and food functions of networks in terms of (re)configuring the goals and values that are being pursued. These capabilities rest with groups of switchers and programmers of networks (Castells, 2009). For instance, programmers from WEF networks (towards the nexus of networks) could install as a network program a goal for more integrated decision-making protocols between WEF sectors (nexus-thinking) in which actors aim to enhance possible synergies and reduce potential trade-offs among these WEF resources systems. Then, switchers emerging in the nexus of networks are the actors that link up other actors, resources, and flows from (WEF) networks for pursuing a program of more integrated management or decision and policymaking of WEF.

Integration of WEF networks is in one hand an outcome of unintended actions or practices held by actors from different networks, which results in either higher or lower overlapping of networks. Integration of networks is also the result of intended actions and decisions that push forward the nexus of different networks to come about. In the latest assumption, integration results from the intended capability to control connectivity points, switches, for outperforming sectorial approaches and for working towards the emergence of the nexus of networks. We thus argued that the interaction of structures, functions, and power dynamics of networks play a crucial role in (re)connecting and (re)configuring WEF in higher or lesser nexus outcomes (see Figure 5). 
Chapter 3. Network governance and the urban nexus of water, energy and food

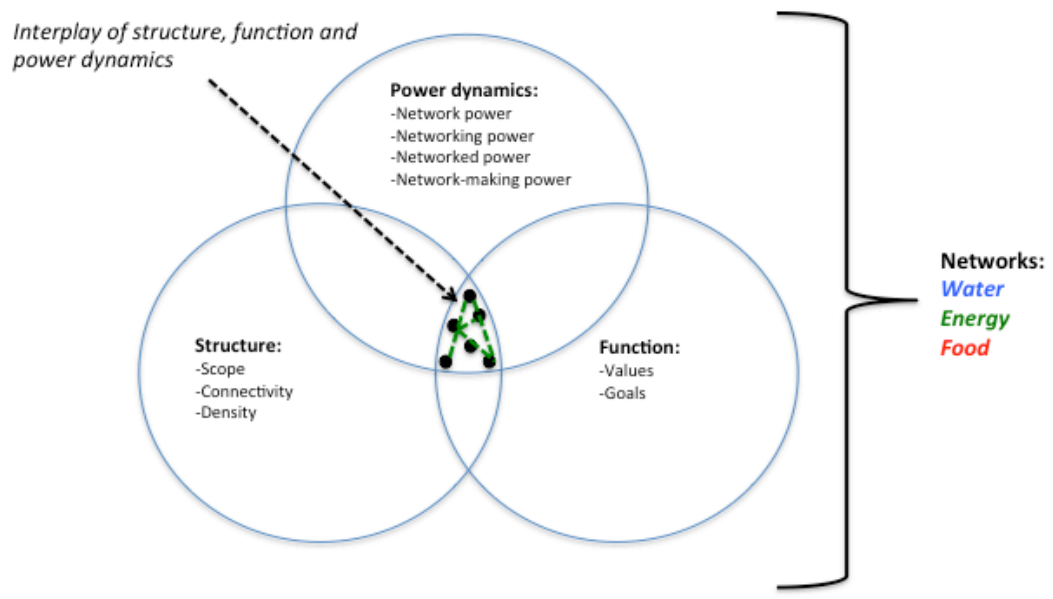

Figure 5: Interactions of networks characterisation allowing for connecting and configuring the Nexus

\section{Methods}

By means of the case of Amsterdam, we examine how networks of WEF provisioning connect, or struggle to connect, towards more sustainable configurations. We conducted: 1) a document and literature review and 2) one round of semi-structured experts' interviews during April and May 2017. The documents review analysed recent governmental publications, policy documents, and publications addressing water, energy or food provisioning sectors in Amsterdam. The interviews ( $\mathrm{n}=14)$ held face-to-face with different managers, operators, and practitioners of the WEF networks, aimed to gather answers about the points of integration between the different networks and the social dynamics between actors and networks from WEF domains. First, we employed a convenient sampling looking for knowledgeable and accessible participants. 
Chapter 3. Network governance and the urban nexus of water, energy and food

Second, we employed a snowball sampling method in order to explore WEF networks and to explore further respondents, until we established a data saturation point. Table 1 shows the list of organisations approached for the expert's interviews, the societal sector they belong to, and the provisioning sectors they work on or address. Table 1 also shows the number of interview held which is used in Section IV to refer to the results obtained and their source of data. We corroborated the information gathered from interviewees by asking different interviewees for the same information. All interviews were recorded and transcribed as soon as possible.

The cases were selected based on examples that do not only show stories of success but rather cases that show the complexity of relational dynamics between sectors of WEF towards nexus configurations. In this vein, we aim to show cases that are rich in portraying the barriers, challenges and triggers in the emerging of the Nexus. Based on this, we selected and zoomed in on three instances in the WEF sector in Amsterdam, where a nexus is actively emerging in different ways. These are 1) decarbonising practices in the last mile of food distribution; 2) wastewater and energy links in Buiksloterham; and 3) the recovery of nutrients from wastewater plants. Each of these sub-cases mirror different ways in which network structures and functions, and power dynamics, promote or constrain the emergence of the nexus. 
Chapter 3. Network governance and the urban nexus of water, energy and food

Table 1: List of interviews: chapter 3

Interview

Number

\begin{tabular}{|c|c|c|c|c|}
\hline 1 & $\begin{array}{l}\text { University of Amsterdam - } \\
\text { Smart Mobility \& Logistics }\end{array}$ & $\begin{array}{l}\text { May 30, } \\
2017\end{array}$ & Research & Food \\
\hline 2 & $\begin{array}{c}\text { Wageningen University \& } \\
\text { Research Centre } \\
\text { Urban - rural relations in } \\
\text { Agriculture }\end{array}$ & $\begin{array}{c}\text { May 23, } \\
2017\end{array}$ & Research & Food \\
\hline 3 & $\begin{array}{l}\text { University of Amsterdam - } \\
\text { Food Logistics }\end{array}$ & $\begin{array}{l}\text { May 30, } \\
2017\end{array}$ & Research & Food \\
\hline 4 & $\begin{array}{l}\text { Food Distributor in the 'last } \\
\text { mile' }\end{array}$ & June 2, 2017 & Private & Food \\
\hline 5 & $\begin{array}{l}\text { Alliander (Energy Grid } \\
\text { Operator Company) }\end{array}$ & $\begin{array}{c}\text { May } 10, \\
2017\end{array}$ & Private & Energy \\
\hline 6 & $\begin{array}{l}\text { MABS Consultancy } \\
\text { Company) }\end{array}$ & $\begin{array}{c}\text { May 11, } \\
2017\end{array}$ & Consultancy & $\begin{array}{l}\text { Energy and } \\
\text { Food }\end{array}$ \\
\hline 7 & AEB (Waste to Energy & $\begin{array}{c}\text { May 31, } \\
2017\end{array}$ & Private & Energy \\
\hline 8 & $\begin{array}{l}\text { Urban Farming expert and } \\
\text { practitioner }\end{array}$ & $\begin{array}{l}\text { May 24, } \\
2017\end{array}$ & Community & Food \\
\hline 9 & $\begin{array}{c}\text { Waternet (Water Network } \\
\text { Company) }\end{array}$ & $\begin{array}{c}\text { May } 10, \\
2017\end{array}$ & Public & Water \\
\hline 10 & Waternet & $\begin{array}{l}\text { May 16, } \\
2017\end{array}$ & Public & Water \\
\hline 11 & Waternet & $\begin{array}{c}\text { May 09, } \\
2017\end{array}$ & Public & Water \\
\hline 12 & $\begin{array}{l}\text { Amsterdam Rainproof } \\
\text { (initiative by Waternet) }\end{array}$ & $\begin{array}{c}\text { May 19, } \\
2017\end{array}$ & Public & $\begin{array}{l}\text { Water, } \\
\text { Energy and } \\
\text { Food }\end{array}$ \\
\hline 13 & $\begin{array}{c}\text { Amsterdam Rooftop } \\
\text { Solutions by Amsterdam } \\
\text { Municipality }\end{array}$ & $\begin{array}{c}\text { May 16, } \\
2017\end{array}$ & Public & $\begin{array}{l}\text { Water, } \\
\text { Energy and } \\
\text { Food }\end{array}$ \\
\hline 14 & $\begin{array}{l}\text { Urban Planning Department } \\
\text { of the City of Amsterdam }\end{array}$ & $\begin{array}{l}\text { May 29, } \\
2017\end{array}$ & Public & $\begin{array}{l}\text { Water, } \\
\text { Energy and } \\
\text { Food }\end{array}$ \\
\hline
\end{tabular}

Societal

Date Sector

Domains

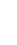


Chapter 3. Network governance and the urban nexus of water, energy and food

\section{Results and Discussions: lessons from Water, Energy, and Food configurations in Amsterdam}

In this section we examine three nexus projects running in Amsterdam. We put particular attention on how WEF networks are being integrated in innovate ways or struggling to integrate further. We highlight what the main actors are in connecting and configuring WEF networks, the structures and functions of WEF networks, and how these interact through power dynamics. Each of the examples spotlights its attention on the concepts that better help to explain the unfolding or hurdles of more integrated management, planning, decision-making, and collaboration between WEF networks.

\subsection{Food-Energy Nexus: entrepreneurs on the road of de-carbonising the last mile of food}

Interrelations between WEF emerge from different actors pursuing similar values and goals (e.g. sustainable development or carbon neutrality). Nevertheless, a nexus of energy and food does not always come about as a straightforward process of function alignment. The case of entrepreneurs decarbonising the last mile of food distribution in Amsterdam provides a fruitful example of how network power, in the form of food standards, and networked power, encountered in supermarkets, do not easily allow food distribution entrepreneurs, switchers \& programmers, to create a nexus between (renewable) energy and food distribution.

When it comes to powering food processes, energy and food networks densely connect to fossil fuels, but to non-renewable energy sources in a lesser extent (Interviews 1-3, see Table 1). In the last mile of food distribution in Amsterdam, 
Chapter 3. Network governance and the urban nexus of water, energy and food entrepreneurial services scope to deliver food from wholesalers to food services providers (hotels, restaurants and cafes) by employing electric and conventional bikes (Interviews 1-3). Those services aim to deliver a more sustainable and local option for connecting food processes, connecting wholesaling with distribution and food access. This connection aims to replace the dominant practice of moving food in the city from A to B by means of CNG and diesel by gradually shifting towards the employment of electric means of transport or human-energy based transport (Interviews 1, 3-5). Despite of such efforts and the contribution of these services to the $\mathrm{CO}_{2}$ reduction targets of Amsterdam, the share of those initiatives reflects more as a start-up level when compared to conventional (fossil fuels based) food distribution.

That ambition has been driven by the aim to deliver energy efficiency, affordable food, and local and sustainable food distribution in Amsterdam (Interviews 1, 4, 6)(Amsterdam Smart City, 2015; Foodlogica, 2015). These ambitions closely relate with the values pursued by the energy sector, which seeks to push forward on energy efficiency, sustainability, ensuring cooperation with different societal actors, and shifting from fossil fuels to renewable energy sources for energy provisioning (Interviews 5, 7). For example, sustainability is a value that overlaps between energy and food networks. Food and its goals overlap with the energy sector, for instance, when it comes to support a local and sustainable food system (Interview 4). It aims to sustainably distribute food as efficient as possible in terms of timing, quantity, frequency, and price as compared to the conventional food system (based on fossil fuels and longer distances of sourcing) (Interviews 1, 3, 8). This implies that not only food distribution needs to grow in energy efficiency with regard to its timing, frequency, and quantity of deliveries between 
Chapter 3. Network governance and the urban nexus of water, energy and food

wholesalers and retailers or food services providers. It is also of high importance that such energy-food connection comes in a way that a transition to sustainable energy generation and load actually embeds and powers the transport distributing food. Although values from these networks present similarities, it is important to recall it would for the food sector be difficult to accomplish its energy neutrality visions without connecting with decarbonising transition processes supported by the energy sector, and vice versa.

Although both networks hold similar values and goals to work towards to, those come along with power dynamics that play out through energy and food networks. Examining power relations, helps to better understand why emerging projects such as e-bikes distributors experience constrains when trying to connect with more prevailing forms of provisioning. Dynamics of network power best help to explain this case by referring to the interplay between the rules of supermarkets and food services providers. Supermarkets, for instance, partially set the standards of what products are sold in the city, what size, and packaging or its specific requirements (e.g. frozen cargo or food safety standards); but also how frequently supermarkets have to get restored by food processors, wholesaler and distributors (Interviews 1, 3, 4). These standards play out as the inclusion conditions and rules to satisfy by producers, processors and distributors of food. For e-bikers those standards still represent a capacity challenge (in terms of size, distance and timing) in order to get included into the food distributors of supermarkets. Another factor playing a role in such inclusion conditions relate to the large logistics planned by supermarkets which make difficult for other individuals to get included into these planned logistics. These standards also relate to the energy network in terms of what energy can actually power food distribution and how. 
Chapter 3. Network governance and the urban nexus of water, energy and food

In other words, what energy and type of transport is able to deliver the same efficiency, timing and frequency that supermarkets demand. Modes of distribution such as e-bikes have had difficulties for collaborating with other actors in the food network, specifically with supermarkets, because of the standards of inclusion established by these retailers.

These standards play out differently when considering the relationship between food distributors and different food receptors. For instance, standards play out differently in the relationship between e-distributors and the Horeca (HotelsRestaurants-Cafes). In this context, those standards, in terms of the size, distances, and timing of cargo, are more compatible with the delivering capabilities of e-bikes as such sector demands more localised distribution and food sourcing, shorter distances, and lighter cargo capacity (Interviews 4, 6, 8).

Standards play out as the conditions for the inclusion or exclusion of actors from this particular nexus project. Those standards then relate to the actual exercising of networking power. From the view of the supermarkets the standards are actually not including distributors such as e-bikers as opposed to food services providers (Horeca) who reflect more inclusive dynamics towards e-bikes distributors.

The inclusion rules that play out through networks is in part related to the allocation or distribution of power. Networked power is evidenced in the capability of supermarkets and food services providers over the energy implications of food distribution. Supermarkets are actors that have control on what, how, and when to consume; and those influence the whole food supply 
Chapter 3. Network governance and the urban nexus of water, energy and food chain (Interviews 1, 2, 3). For instance, supermarkets in Amsterdam can influence the supply chain on the side of distributors, wholesalers, processors and producers (Interview 3). Then, the standards that supermarkets exert in the supply chain influence the energy inputs required for provisioning food in the city. This, in turn, translates into the dominance of the fossil fuels-based logistics, via retailing, through the food supply chain.

In the relation between e-bikers and food services providers (Horeca), networked power plays out differently when compared to supermarkets. Contrary to supermarkets, the power of the Horeca sector is rather fragmented; it does not concentrate the same critical mass of networked power as supermarkets do. The Horeca is conformed to by over 5000 establishments; and most of them have their own ownership, management, logistics, providers, and operations (Interviews 1, 3, 6). This has a dual effect. On one hand, a myriad of establishments with their own logistics translates into myriad of services providers distributing food in Amsterdam employing different types of transport which might be seen as inefficient logistics (Interviews 1,3). On the other hand, its fragmented networked power opens the opportunity to alternative food distribution providers for competing and gaining a share in supplying food distribution services to this market segment (Interview 4).

Despite the hurdles discussed around network and networked power, initiatives of ebikes distributors are breaking through into the last mile of food in Amsterdam. They do so by exercising their network-making power through their role of switchers and programmers. These initiatives challenge the dominant fossil fuels based last mile by reconfiguring it with more sustainable practices of distribution. 
Chapter 3. Network governance and the urban nexus of water, energy and food

These initiatives emerge as switchers connecting with other actors (e.g. Horeca and urban farmers) that share a mindset alike towards 'good food' and 'a clean last mile of food' (Interviews 4, 8).

What outstands in this project is the role of switchers and programmers that, despite of the standards and power held by supermarkets, constitute new functions, structures (e.g. scope), and aim to re-arrange power dynamics between energy and food networks. This case showed that despite of the dominance of fossil fuels usage in food transport plus the discussed power dynamics, switchers and programmers gradually gain position in the food system towards its decarbonisation. They do so via projects of action in which actors with similar structures and functions align and open the space for new practices of distribution and new setting up of actors.

\subsection{Water-Energy Nexus: wastewater to energy in Buiksloterham}

Buiksloterham is a former industrial area located in Amsterdam which has recently been used as an experimental living lab to test innovative urban solutions. In this area, Waternet, the water company responsible for all the water cycle in Amsterdam, runs an experimental project that consists of a decentralised water treatment plant to recover nutrients and energy from wastewater flows (Interviews 5, 9-11)(DELVA Landscape Architects, 2014). This project is the outcome of cross-sectorial dynamics of problem framing, collaboration, and decision-making in which actors such as the municipality, the urban planning department, AEB (waste-to-energy plant), Waternet, and housing corporations (in total close to 24 different parties) gathered their interests, visions, and goals (Interviews 5, 9-11). The outcome of this project is to produce biogas and heat (Interviews 9, 10, 11, 12) and by doing that this project exemplifies a re- 
Chapter 3. Network governance and the urban nexus of water, energy and food connection between, and re-configuration of, water-energy networks. Particularly, it connects Waternet and AEB (waste-to-energy company). We shed light on 1) competing structures and network power dynamics, 2) the deregulation of switches between networks, and 3) the roles of switchers and programmers linking and programming water and energy into the project in Buiksloterham.

Water and energy networks have similar functions and competing structures. Waternet is driven by values that aim to deliver sustainability and decentralisation of the water treatment processes while guaranteeing safety of water provisioning as its core value (Waternet, 2018). The way the water company operationalises its values is by closing water cycles and re-using materials (Van Der Hoek et al., 2013), and by working toward climate, carbon and energy neutrality (Interviews $5,7,9-11)$. Those values and goals are similar to the ones the city of Amsterdam (toward 2040) (Gemeente Amsterdam, 2011, 2015) and the energy sector pursue. The energy sector in Amsterdam targets to gain in sustainability, $\mathrm{CO}_{2}$ neutrality (city-level), and shifting from fossil fuels to renewable energy sources for energy supply (Interviews 5, 7). Sustainability, for example, is a value that overlaps in energy neutrality visionaries from both networks when 1) the water sector aims for decarbonising its processes, and 2) the energy sector envisions shifting toward renewable energy provision. What these visionaries have in common is a shift in the energy inputs for powering the two sectors. For both sectors, the accomplishment of such goals closely depends on 1) the deployment of more renewable energy sources and 2) powering water and energy processes with renewable and recovered energy (Interviews 7, 9-11). This project reflects the ambitions and efforts in Amsterdam to re-connect water and energy into more sustainable configurations. 
Chapter 3. Network governance and the urban nexus of water, energy and food

Although water and energy networks overlap in their functions, these also experience competing structures and conflicting network power dynamics. Waternet provides all the processes related to the water cycle. This enables the water company with the control (and the accountability) to establish the rules of inclusion into this network. Its bylaws grant Waternet with the competences and accountability for provisioning water to Amsterdam. Leaving out, for instance, innovators (from outside of the water company) to play a role within this network (Interviews 6, 9-11). Instead, the energy network has a more diverse constellation of actors that interplay in the establishment of its rules of inclusion (e.g. generators, transmission managers, distributors, and co-producers are all different actors). This results in organisational rules and operational competences competing between water and energy networks. Waternet overlaps its operations with the energy network (mainly producers and distributors) competences when recovering, and consequently producing, energy from wastewater flows. Waternet is restricted to produce and distribute energy (heating) since these processes are the competence of energy producers and operators (Interviews 9-11). In the same way, the scope of the energy network does not allow energy companies to intervene on water provisioning. Therefore, structures and rules from networks (such as competences and bylaws) determine the inclusion and exclusion of other actors into the discussed networks.

In this experimental project, water and energy networks are opening up their structures (primarily their scopes) to actually collaborate instead of excluding each other. This is reflected in the experimental status granted to the project; which functions as a permission to try out innovation or in other words an opening of scopes. 
Chapter 3. Network governance and the urban nexus of water, energy and food

This is explained by the networking-making power exercised primarily by the Municipality of Amsterdam, Waternet, and AEB in their roles as switchers and programmers. Through setting up experimental projects, based on a permission to try out innovation, they actually re-connect and re-program the way those networks normally work. What they do is to attenuate rules, regulations, barriers, bureaucracy or bottlenecks that may interfere with carrying out innovations (Interviews 5, 9-11, 13, 14). In other words, those constrains are de-regulated to allow for experimentation and innovation. Consequently, their exclusivity competences written in their structures and rules open and create a space and time for experimentation.

This project is in part also possible because the Municipality of Amsterdam is a shareholder in both companies, Waternet and AEB. In this way the municipality functions as one of the switchers that re-connect, via this project, water and energy in an innovative manner to support the city ambitions. This has facilitated cooperation between these networks by means of a common working agenda, research, and projects to work towards to (Interviews 5, 9-11). AEB and Waternet scopes are examples of switches from the water and energy networks allowing for water-energy reconfigurations and reconnections to emerge.

This example showed the case of de-regulation of switches (scopes) between two competing networks claiming the applicability of their own competences. It showed how critical switches, such as rules and competences, can create a connection between different actors and networks into the emergence and configuration of a specific nexus project. In this case, the structures of networks adapt as a result of more flexibility for both networks to experiment with 
Chapter 3. Network governance and the urban nexus of water, energy and food wastewater and energy. Nevertheless, in this case, the de-regulation of switches does not yet result in a more conventional way of provisioning energy and water systems at the city level. Instead, it rather resembles an experimental momentum.

\subsection{Water-Energy-Food Nexus: recovering nutrients from wastewater plants}

As discussed in the last example, structure characteristics of networks are a key puzzle in connecting different networks towards more nexus-oriented configurations. Similarly, compatibility of functions between interacting networks and their embedded network power dynamics play a crucial role for the nexus of networks to come about. To illustrate these concepts further, we provide an example of an experimental project in Amsterdam that links Water-Energy-Food networks.

Waternet is a water company that runs a decentralised wastewater pilot project in Buiksloterham. Decentralised wastewater systems facilitate the option to recover and close energy and nutrients cycles (Mijatovic, 2017). In Buiksloterham, Waternet separates streams of wastewater into grey and black wastewater flows (Mijatovic, 2017). This project links the processes of wastewater treatment and nutrients recovery, mainly Nitrogen and Phosphorus, for their possible applications on fertilisers and proteins (for feed) production (Interviews 911)(CityZen Smart City, 2017). In connection with the WEF nexus, this project powers its processes with the energy surplus load from the waste-to-energy-plant (AEB) (Interviews 5, 9-11). Wastewater does not only represent a key source of energy and nutrients, but it also represents a source of micro-pollutants (e.g. pathogens, hormones and medicine residues) that can trigger diseases in humans (DELVA Landscape Architects, 2016; FAO, 2017). This concern is reflected in 
Chapter 3. Network governance and the urban nexus of water, energy and food the competing values safeguarding different priorities. On the one hand, those values pursue more resources circularity and sustainable development (Circle Economy et al., 2016; DELVA Landscape Architects, 2014; Mijatovic, 2016, 2017, July 17), versus water safety for water users on the other hand (Interviews 9-11) (Reinstra, 2018).

Waternet contributes to the city ambitions to become an urban laboratory. It experiments with phosphorous recovery from grey water treatment and its further connection in agriculture. Experimenting with this linkage has provided for Waternet with circularity, economical and operational feasibility results. Despite of the feasibility tests, taking experimental projects into more prevailing and largescale systems of provisioning is currently not allowed by water regulations safeguarding sanitary and public health values (Interviews 9-11) (Reinstra, 2018). In similar vein, wastewater-to-protein experiments for nutrients recovery is operationally feasible but it is restricted by sanitary regulations. Buiksloterham also hosts experiments employing food grinders to recover nutrients content in black wastewater flows (DELVA Landscape Architects, 2016). Nevertheless, recovery of nutrients from black wastewater flows is prohibited by national and European regulations.

The previous case shows how bylaws and competences (scope), and regulations (network power), exclude the water network from distributing and commercially producing energy (and vice-versa). In contrast, in the current case the water network is neither a commercial producer nor distributor of energy but rather a consumer of the energy network. Structures and functions of these networks do not compete when it comes to connectivity of the energy surplus of AEB and the 
Chapter 3. Network governance and the urban nexus of water, energy and food energy consumption of the wastewater plant for the nutrient's recovery. What is remarkable from this case then is not the compatibility or incompatibility of scopes between WEF but the incompatibility of values between water and food networks. In this sense, networks thus block the connectivity of particular flows or nodes, switches. In this example this block occurs, between recovered nutrients from wastewater flows and possible food applications, as a response to presumable trade-offs (sanitary risks) and incompatibility of values (water safety).

\section{Conclusions}

Amsterdam shows a certain level of Urban Nexus progress among its WEF networks. This has been evidenced and discussed through some of the projects that cross-connect WEF flows and networks. We argue that structure, function, and power enacted through networks shape the nexus of WEF into different configurations and connections. It shows how the studied projects start to reconfigure and reconnect networks with new values, goals, actors, and processes. Despite of the barriers encountered in the studied projects, switchers and programmers make a step forward towards the nexus of WEF networks, and the city ambitions, via innovative and collaborative sustainability projects.

Giving attention to strategic points of connection, for example experimental projects, is key for steering the WEF urban nexus towards more desirable configurations. This paper provided empirical examples to understand and identify how different types of power relations, structures, and functions shape WEF networks. From the projects exemplified, some switches represented barriers, whilst others functioned as triggers for connecting WEF within the 
Chapter 3. Network governance and the urban nexus of water, energy and food nexus of networks. Barriers mainly related to compatibility of values, competences, and organisational structures (e.g. safety and health concerns, standards, and policies). Those barriers have limited the growth of projects towards denser and more connected WEF flows and network, however, they have also partly kept those projects in a start-up and experimenting level of development.

Pursuing cross-sectorial values and goals proved of crucial importance. These goals have the potential to disrupt fragmented practices from provisioning systems into more nexus-oriented outcomes. When values are compatible, it allows actors, nodes, flows, and networks to be brought together into a stronger, denser and better-connected nexus network (e.g. overlapping sustainability values and goals between networks). However, both competing values and power dynamics in part hampered the cross-sectorial interaction that the nexus aims for.

Power showed to be a critical relational dynamic in the convergence of WEF systems. Network power, networked power, and network-making power have in this paper been evidenced as critical dimensions to address for further strengthening the nexus of WEF networks. On the one side, WEF networks still have to cope with current and prevailing provisioning systems that somehow impose a lock-in effect on the infrastructures, and organisational and economic factors around the way WEF systems are provided. On the other hand, the analysis of switchers and programmers provides lessons on what actors, and how, are shaping the ongoing provisioning systems (and its barriers) towards innovative reconfigurations of networks of provisioning. 
Chapter 3. Network governance and the urban nexus of water, energy and food It might be that many cities, as in this case Amsterdam, still depend on outdated modes of provisioning; outdated modes that do not achieve sustainable urban development of WEF. Reliance and dependency on current provisioning systems are challenges that cities need to tackle to effectively govern the WEF urban nexus. Further efforts are needed by switchers and programmers in their role of reconfiguring and reconnecting networks into more nexus-oriented systems of WEF provisioning. 
Chapter 3. Network governance and the urban nexus of water, energy and food 


\title{
Chapter 4: The making of a Sustainable Food
}

\section{City in Barcelona: Insights from the Water,}

\author{
Energy and Food Urban Nexus
}

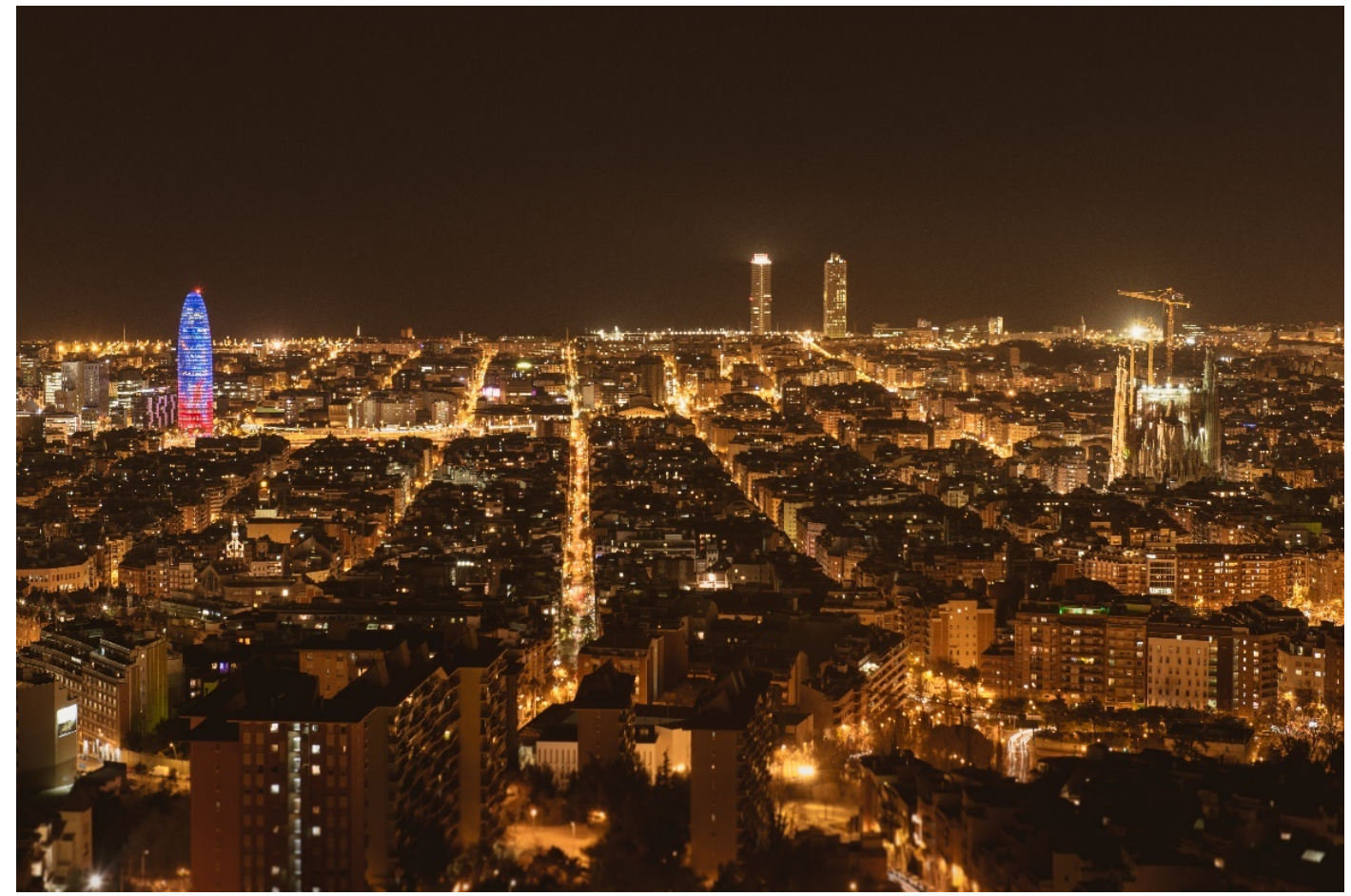

Image Source: https://www.pikrepo.com/nesir/brown-and-white-concrete-building-duringnight-time

This chapter has been published as: Moises Covarrubias \& Ingrid Boas (2019) The making of a sustainable food city in Barcelona: insights from the water, energy, and food urban nexus, Journal of Integrative Environmental Sciences, DOI: 10.1080/1943815X.2019.1675715 
Chapter 4. The making of a sustainable food city in Barcelona

\section{Abstract}

This paper examines the making of urban sustainable food provisioning through the case of Barcelona. Barcelona is seeking to develop a more sustainable food system. It aims to green its municipal food markets by reducing the distances from which the food is sourced from. This has been labelled by the city of Barcelona as "proximity food". We shed light on how, and to what extent, proximity food contributes to making the city more sustainable. To frame our analysis, we employ concepts from networks and flows as developed in sociology by Manuel Castells. We examine the provisioning processes that proximity food goes through before they enter retail markets. This includes an analysis of connections with urban energy and water flows. This so-called water, energy and food Urban Nexus, which we argue to be a key factor in the greening of urban food systems. This means that sustainability of food is not just determined by physical distances between its provisioning processes per se but by the specific ways in which food flows relate to connections (both physical and social) with energy and water. 
Chapter 4. The making of a sustainable food city in Barcelona

\section{Introduction}

The Sustainable Development Goals (SDGs) are pushing cities forward to develop sustainability agendas and action plans to address climate change and greenhouse gases emissions. Some of the core domains requiring action relate to water, energy, and food (UNDP, 2016; United Nations, 1992). Cities are critical places where stresses occur (e.g. traffic congestions, air pollution, land use change, etc.), but cities also represent the places for innovation and action to address unsustainable practices (Giezen, 2016). There have been numerous efforts of cities around the world toward the greening of their policies, activities, and infrastructures, toward sustainability (Hopwood \& Mellor, 2007). Most of the European cities, in their commitment to become sustainable habitats, have focused on energy efficiency, followed by guaranteeing the resilience of cities, the internet of things, and the circularity of resources (Giezen, 2016). In that context, cities commonly adopt labels to brand and promote their endeavours, e.g. green cities, ecological cities, smart cities, or resilient cities (see overviews in Serbanica and Constantin 2017; Khan and Zaman 2018).

Food in the city is an aspect of sustainability that has often been overlooked in these endeavours, at least in Europe (Morgan, 2009). But it is gradually taking off. European cities such as Barcelona, Ghent, Marseille, Milan, Thessaloniki, and Utrecht have started to give some attention to food in their policy and decisionmaking (see e.g. Milan Urban Food Policy Pact 2015). In approaching cities into sustainable habitats, food has been placed into the urban equation in different manners. For instance, food has been addressed in terms of public food procurement (e.g. local and organic food served at school canteens); urban 
Chapter 4. The making of a sustainable food city in Barcelona

farming initiatives; bridging the rural-urban divide (Sonnino 2009; see e.g. in Dubbeling 2013); but also in terms of an urban governance response which looks to include food as an asset of cities (Sonnino 2009; see e.g. Milan Urban Food Policy Pact 2015). In any such approach, gains toward sustainable food cities require a rearrangement of their food system as a configuration or network that organises flows of urban food.

This paper will examine the case of Barcelona in its ambition to becoming a sustainable food city. Barcelona is one amongst the pioneering European cities that is working on its urban food policy and a sustainable food system. In particular, Barcelona, as an emerging sustainable food city, aims to gain on sustainability by strengthening, promoting, greening, and using its municipal food markets and the flows of "proximity food" commercialised through these markets (Ajuntament de Barcelona, 2014). Proximity food means that the (fresh) food flows are easily accessible and organised with only a few intermediaries (see Spaargaren et al., 2012). It is a concept that is actively used in Barcelona's policy and practice on sustainable food (Ajuntament de Barcelona, 2014). Food markets are a key puzzle in the food system of Barcelona as these are connected through short circuits of commercialisation with local food producers in the proximity of Barcelona City. These short circuits employ two or fewer intermediaries in connecting food production with its commercialisation through markets. What this equation assumes is to reduce food miles, and the related energy consumption and $\mathrm{CO}_{2}$ emissions, along with food provisioning processes. In parallel, this equation also implies reconnecting and reconfiguring actors and flows, more locally, in the food system of Barcelona. 
Chapter 4. The making of a sustainable food city in Barcelona

We shed light on how, and to what extent, food markets and flows contribute to making the city more sustainable. In doing so, we examine the main actors, their organisation, and the policies and practices involved in the governing of urban food flows. To better understand Barcelona's development toward a more sustainable food city, we look into the provisioning processes for proximity food flows e.g. the distribution, wholesaling, and local production of this kind of (fresh) food. In our analysis, we consider how the city addresses the urban nexus of water, energy and food (WEF). How key actors for WEF flows interact, or fail to interact, and how they use urban nexus thinking and planning to improve sustainability in the city.

This chapter is structured as follows. Section 3 presents a background of the positioning of food in cities and the approaches cities have taken to address food and its connections with water and energy. Section 4 addresses the methods used in this research. Section 5 provides the case of proximity food flows retailed through municipal food markets in Barcelona and the role of these markets in building a more sustainable food system in the city. First it introduces the background of food markets and flows in Barcelona. Then it positions the aims of Barcelona toward reconnecting and reconfiguring the proximity of food. As a further step, it analyses food proximity distribution through markets and their relationship with other upstream processes within the proximity food network. Then, it discusses the main findings and reflects on the added value of using a broader WEF urban nexus perspective when addressing the puzzle of sustainability. Section 6 concludes. 
Chapter 4. The making of a sustainable food city in Barcelona

\section{Background: a WEF urban nexus perspective in cities}

Cities, in their quest to become more sustainable habitats for their citizens, have gone through a transition from being places of economic growth toward places that represent an integrated and overall sustainable urban environment (Hodson \& Marvin, 2017). Sustainable cities research and practice have opened debates about what sustainability in an urban context means, and about the best possible strategies to develop toward a sustainable city (Williams 2010). Cities take different approaches to become more sustainable urban environments. In the last decades, adopting branding profiles by cities has become a popular practice (e.g. Smart City, Sustainable City or Food City). Those profiles anchor visionaries and values that cities seek to attain (e.g. the smartness or circularity of a city) (Khan and Zaman, 2018). Cities use branding profiles as a way to push forward particular working agendas, urban planning principles, and policy and decision-making processes (Khan and Zaman, 2018). For instance, extensive literature reviews examining different city profiling labels identified over a dozen of different city labels (see Hodson \& Marvin 2017; Khan \& Zaman 2018)1. Those mainly reflect different values, visionaries, and priorities portraying pathways toward sustainability. 'Smart Cities', 'Sustainable Cities', and 'Low-Carbon Cities' are examples of the most recurrent labels adopted by cities (Hodson \& Marvin, 2017).

Food is a question that is often overlooked in the sustainability profiling, labelling, framing, and policy and decision-making of cities. When food interventions happen, they primarily focus on either ensuring food security, nutrition, poverty

\footnotetext{
${ }^{1}$ Other examples of labels include garden city, creative city, liveable city, zero carbon city, regenerative city, compact ${ }^{1}$ city, eco-city, resilient city, zero waste city, sharing city, etc.
} 
Chapter 4. The making of a sustainable food city in Barcelona

alleviation, or as a tool to reinforce community engagement (FAO, 2018; Haysom, 2015). Studying sustainable food provisioning in the city requires understanding and analysis of food from a more systemic perspective which also considers the different provisioning processes involved in the organisation of access to more sustainable food (Dubbeling, 2013). Learning about the key actors, networks, and flows is important since the strengthening of urban food systems so far has been constrained by weak governance structures, low capacity of human resources, and conflicting policies and practices between actors and jurisdictions (FAO, 2018).

Effective and sustainable governance of urban food also requires attention to how it relates with energy and water in order to ensure a more integrated and informed food provisioning in cities (Covarrubias, 2018). These urban-level cross-sectoral interactions have been defined by previous research as the Water, Energy and Food (WEF) urban nexus (Covarrubias, 2018). The WEF urban nexus perspective is defined as a cross-sectorial policy-making approach which aims to overcome trade-offs between different flows and to stimulate synergies across and between networks that are important for sustainable urban development (Dubbeling, 2013; Vogt et al., 2014).

Water and energy resource flows are domains that have already received special attention in nexus literature (Endo et al., 2015; Kenway, Lant, \& Priestley, 2011; Kenway, Lant, Priestley, et al., 2011; Nair et al., 2014). Nexus literature has already put some efforts forward on quantifying WEF resource flows and the implications of providing one resource in relation to the others at the regional, national and global levels (see e.g. Bazilian et al., 2011; Howells et al., 2013; Nair et al., 2014; Endo et al., 2015; Daher and Mohtar, 2015; Chen and Chen, 2016; 
Chapter 4. The making of a sustainable food city in Barcelona

Smajgl et al., 2016; Tevar et al., 2016). Nevertheless, the urban level of the nexus has received less attention in the literature when compared to the regional and national levels (for recent calls see Artioli et al., 2017; Covarrubias, 2018; Covarrubias et al., 2019), just as food in the city has received less attention as compared to water and energy domains (Morgan, 2009; Sonnino, 2009). Understanding the WEF urban nexus of flows in the city, therefore, deserves further exploration.

Barcelona is one of the European pioneers emerging as a sustainable food city. The promotion of urban food markets and their proximity food flows are important elements of the sustainability strategy of the city. To make this proximity food strategy work, the city authorities engage with different societal actors from the food system in the context of a more horizontal process of policy and decision-making. Horizontal relations and frequent interaction between actors and organisations operating in the different networks that constitute the WEF urban nexus are considered key in the shaping of Barcelona as a sustainable food city.

To better understand this making of a more sustainable urban food system, we employ the concepts of networks and flows as developed in sociology by the Spanish sociologist Manuel Castells (2009). His theory on networks and flows is used to analyse and understand the policies, actors, processes, and relations at work. From this perspective, we examine in what manner the governance of food in the city is emerging as a more horizontal way of policy and decision-making (FAO, 2018; Milan Urban Food Policy Pact, 2015). Networks, as in this case the urban food network, are social organisation structures that emerge around 
Chapter 4. The making of a sustainable food city in Barcelona

visionaries, values, and goals shared by two or more actors (Castells, 2009), for instance, markets, wholesalers, or producers. Social actors in the food network, for example, envision a more sustainable city by means of greening its food markets and flows. Networks, as organisational structures, configure and process flows (Castells, 2009, 2010). For instance, the different actors through the food provisioning processes shape the way proximity food flows are provided in Barcelona. The different nodes within the network (food markets, producers, retailers, regulators, etcetera) organise the flows of urban food in particular ways. Flows are the continuous streams of materials, natural resources, information, or any other form that moves along between two or more nodes in the network (Covarrubias, 2018). To deserve the title or brand of 'proximity food' the network and its flows have to follow a particular program or code, referring to the values and goals promoted by the network (see Section IV for details). To establish a continuous stream of proximity food moving from places of local production to places of access, the network has to be programmed in order to function in a particular way. The proximity food system includes certain values, strategies, products while not considering others (Castells, 2009). Both the values and goals of the network refer to the ambition of Barcelona to become a sustainable food city which enhances its markets and flows for proximity food. The key actors in this process of building (new) networks are referred to by Castells as 'programmers' and 'switchers'. They are the experts that stand out for their capacities and skills in (re)connecting and (re)configuring networks. They bring together the flows, actors, and programs that envisage the sustainable urban food system of the future. 
Chapter 4. The making of a sustainable food city in Barcelona

\section{Methods}

Working from a WEF urban nexus perspective means investigating the work of urban programmers and connectors who seek to integrate formerly separate networks into one, more encompassing and sustainable urban network. In that quest, questions of how, and to what extent, proximity food and its markets address issues of sustainability in Barcelona, on site and beyond, receive further attention in the following sections. ${ }^{2}$

In this context, we trace and follow proximity food flows in Barcelona City, and the way those interrelate with water and energy. For conducting this research, we borrow inspiration and insights from mobilities methodologies. Mobilities methodologies are useful tools to capture the complex dynamic movement of objects and actors as they happen in social life (Sheller, 2011). Mobilities, similar to flows, is a commonly used terminology to refer as to 'something that moves or is capable of movement' (Urry, 2007, p. 7). Mobilities insights add value to the theory of networks and flows by understanding beyond movement of flows, or flowing, between two points toward actually understanding what 'the content of the line between them (the two points)' is about (Cresswell, 2006, p. 2). As such, mobilities methodologies offer us the possibility to actually trace and follow the proximity food flows and network under study in detail, enabling a thorough understanding of the phenomenon of food markets and their proximity food flows in Barcelona. In particular, by understanding the dynamics of mobility of flows in creating movement or lack of movement (Sheller \& Urry, 2006), these methodologies help to provide answers to why and how flows and actors actually

\footnotetext{
${ }^{2}$ This is done without claiming to conduct an ethnographic study.
} 
Chapter 4. The making of a sustainable food city in Barcelona

move, connect, and get configured with particular codes. In the making of such connections and pattering, these settings of connections form networks (Urry, 2012), which in turn shape systems of governance (Boas et al., 2018).

In more detail, in this case, we trace the different places and processes proximity food flows go through in order to assess their contribution to the making of the sustainable food city of Barcelona. We start our analysis at the Municipal Food Markets of Barcelona by shedding light on the main actors and practices governing food flows. We analyse beyond markets (as access points of consumption) by analysing their relationship with other actors and processes within the proximity food network such as distribution, wholesaling, and production in the proximity (see Figure 6). As a second step, we shed light on what the actors, networks, and flows are in these processes; and how these networks interact or fail to interact, from the perspective of the WEF urban nexus (see Figure 7).

\subsection{Mobile Observations}

We employed simple and unstructured observations as a tool to trace the proximity food flows (traceable object in movement) through different networks and processes of provisioning, and to identify the WEF networks. In more detail, we visited the places that the proximity food flows go through (see Boas, 2019 for such a methodology). We examined seven food markets, the main foodwholesaling centre 'Mercabarna', and an important production area with the name of Agricultural Park of the Low Llobregat located in the peri-urban area of the City of Barcelona. This included interviews and guided walks together with local directors and other practitioners of the food markets and other relevant locations in the provisioning networks. This was supported by observations of daily 
Chapter 4. The making of a sustainable food city in Barcelona

activities and the tracing of how food was sourced and distributed. We traced panels and meetings of the Food Council network as well in which actors from public, private and community sectors gather to discuss issues such as strategies to improve sustainable urban food through its provisioning processes. We also visited the main water treatment facilities around the city which have a connection with the urban food provisioning of Barcelona. Following these connections and networks around proximity food provided insights to better understand the actors around the positioning of Barcelona as an emergent sustainable food city.

\section{Distribution Wholesaling Production}

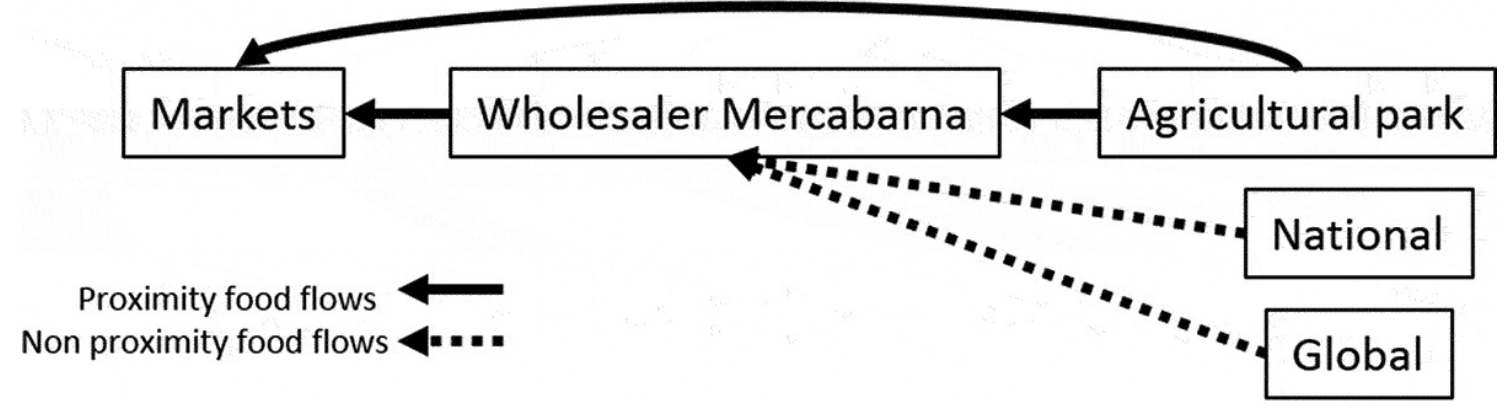

Figure 6: Proximity food flows and processes in Barcelona

Distribution

Wholesaling

Production

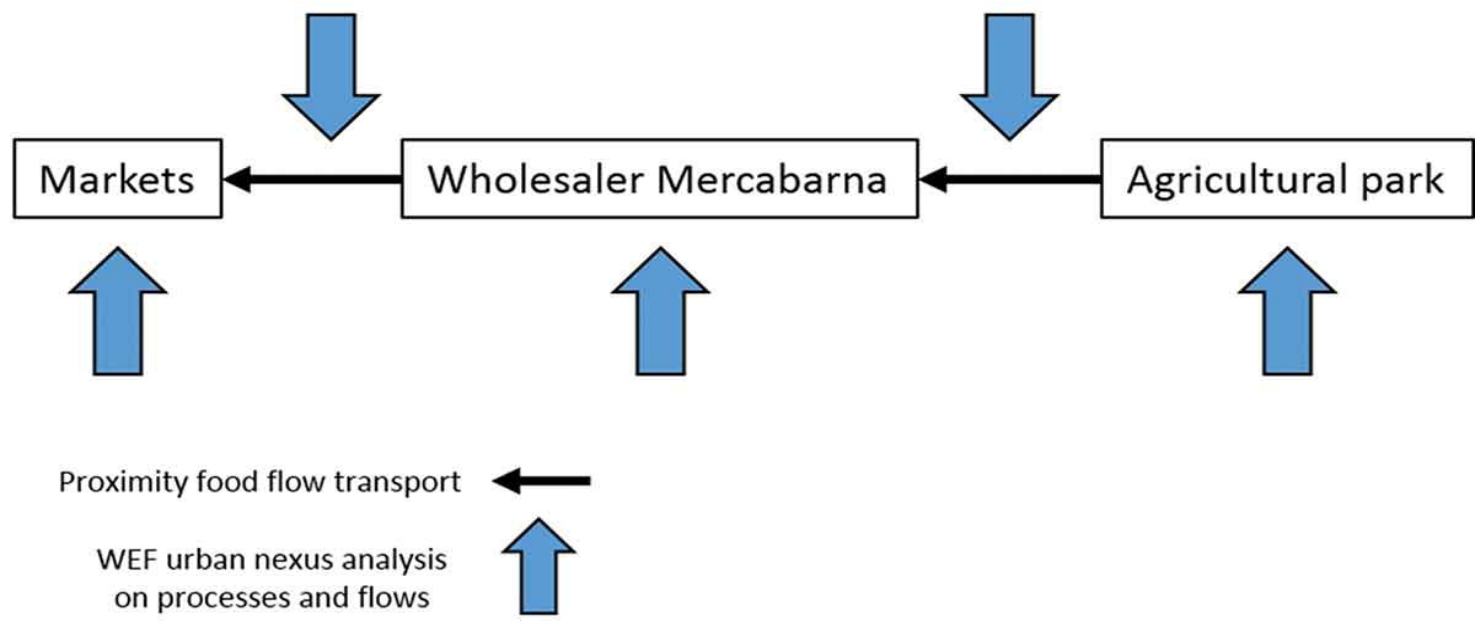

Figure 7: WEF urban nexus analysis. 
Chapter 4. The making of a sustainable food city in Barcelona

\subsection{Interviews}

To gather data for this research we conducted one round of Semi-Structured Experts' Interviews ( $\mathrm{n}=27)$. After identifying WEF networks around the city and identified the social actors contributing to making Barcelona a sustainable food city, we contacted knowledgeable and accessible participants to conduct our interviews. As a second step, we snowballed the contacts in order to explore WEF networks and to explore further respondents until we established a data saturation point. The aim of the interviews was to gather insights about the points of integration and connection between the actors involved in contributing to Barcelona with sustainable food, including from the actors involved in the governing of water and energy in Barcelona ${ }^{3}$. Table 2 shows the list of interviewed organisations, including the societal sector they belong to, the provisioning sectors they work on or address, and the number of respondents interviewed from each organisation.

\footnotetext{
${ }^{3}$ In searching for respondents, it was not possible to establish contact with energy companies and operators. When contact was established with possible respondents for interviews, energy companies and operators argued they do not have time or permission to establish communication with third parties.
} 
Chapter 4. The making of a sustainable food city in Barcelona

Table 2: List of interviews: chapter 4

\begin{tabular}{|c|c|c|c|c|}
\hline $\begin{array}{l}\text { Interview } \\
\text { reference }\end{array}$ & Organisation & Societal Sector & Sectors & $\begin{array}{c}\mathbf{N} \\
\text { respondents }\end{array}$ \\
\hline 1 & $\begin{array}{c}\text { Agricultural Park of the Low } \\
\text { Llobregat }\end{array}$ & Private & Food & 2 \\
\hline 2 & Farmers Union & Community & Food & 1 \\
\hline 3 & Farmers & Community & Food & 5 \\
\hline 4 & Deputation of Barcelona & Public & WEF & 1 \\
\hline 5 & Deputation of Barcelona & Public & WEF & 1 \\
\hline 6 & Municipality of Barcelona & Public & WEF & 1 \\
\hline 7 & Barcelona Strategic Plan & Public & Food & 2 \\
\hline 8 & $\begin{array}{l}\text { Socio Economical Development of } \\
\text { the Metropolitan Area of Barcelona }\end{array}$ & Public & WEF & 1 \\
\hline 9 & Food Wholesaling Centre & Public/Private & Food & 3 \\
\hline 10 & $\begin{array}{l}\text { Institute of Municipal Markets of } \\
\text { Barcelona (IMMB) }\end{array}$ & Public & Food & 1 \\
\hline 11 & $\begin{array}{c}\text { Municipal Food Markets } \\
\text { La Llibertad } \\
\text { La Concepció } \\
\text { Les Corts } \\
\text { Sant Martí } \\
\text { Fort Pienc } \\
\text { Galvany } \\
\text { Sant Gervasio }\end{array}$ & Markets & Food & 7 \\
\hline 12 & Water Company & Public & Water & 1 \\
\hline \multirow[t]{2}{*}{13} & $\begin{array}{c}\text { Water Company-Waste Water } \\
\text { Treatment Plant }\end{array}$ & Public & Water & 1 \\
\hline & & & $\begin{array}{l}\text { Total } \\
\text { respondents }\end{array}$ & 27 \\
\hline
\end{tabular}


Chapter 4. The making of a sustainable food city in Barcelona

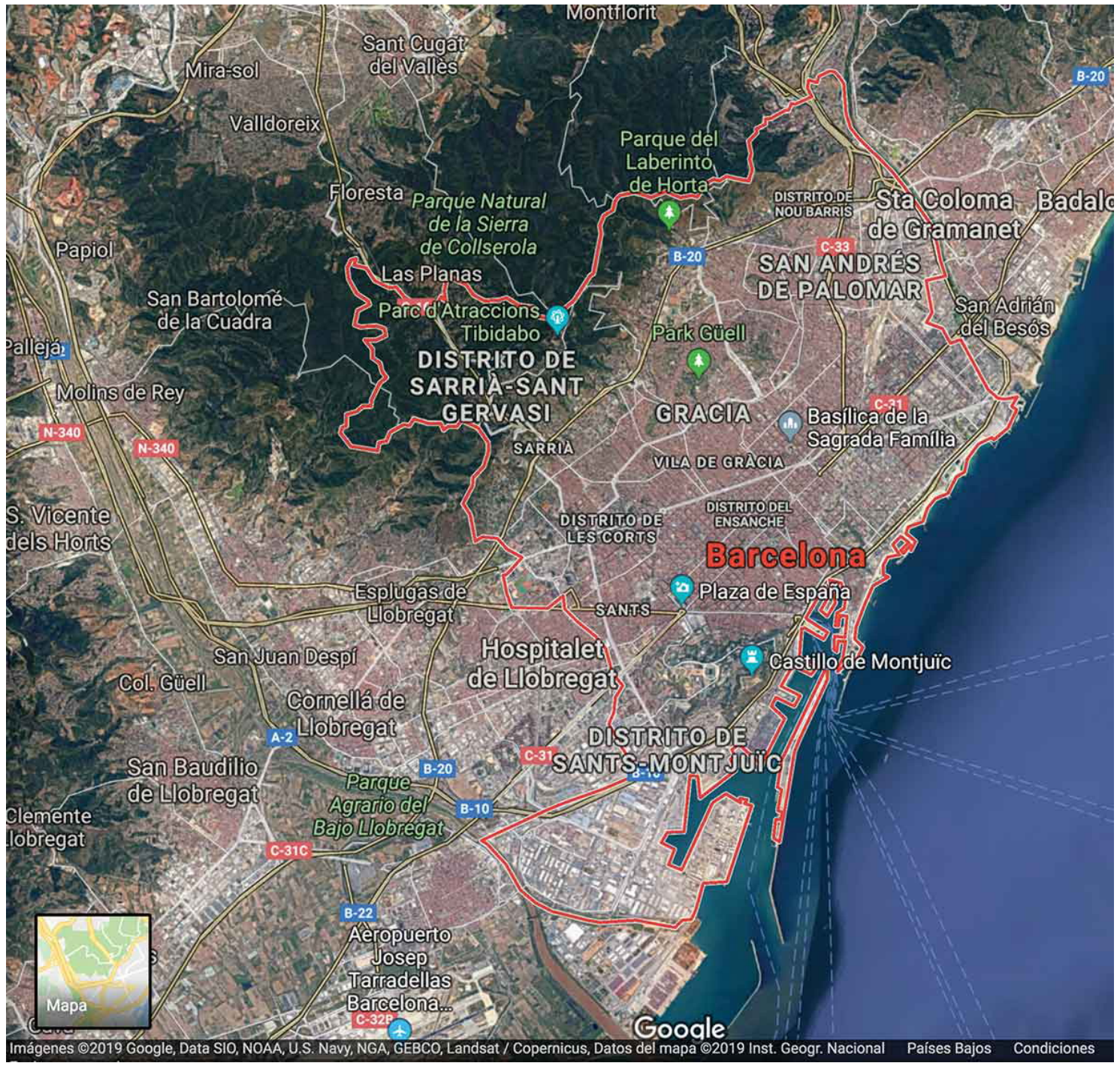

Figure 8: Map of Barcelona city (from Google maps 2019)

\section{The Making of a Sustainable Food City in Barcelona}

\subsection{Background: food markets and flows in Barcelona}

The City of Barcelona is located between the rivers Llobregat (South and Southwest limits) and Besós (Northeast). The Collserola Sierra delineates the Northwest of the city while the Mediterranean Sea shapes the South and Southeast borders of Barcelona (see Figure 8). Historically, the city of Barcelona has been fed with food produced, both, within its city borders and from the 
Chapter 4. The making of a sustainable food city in Barcelona

immediate fertile lands along the low Llobregat River. This river has been key as a freshwater input for food production in the region of Barcelona.

Since the Roman Age, commerce and exchange of goods have characteristically identified the city of Barcelona (Ajuntament de Barcelona, 2018, January 22). The first market established in Barcelona 'dates back to the 10th century' (Ajuntament de Barcelona, 2017). From the Middle Age, the city of Barcelona has exerted authority over food provisioning. Food security, food safety, and taxation were the major values and objectives for taking over the control of food provisioning in cities such as in Barcelona. In part, those concerns led to the physical development of municipal markets in which food could be provisioned in a safe and secure way (Ajuntament de Barcelona, 2017) (Interview 10, see Table 2).

Later in the '70s and '80s, advances in food technologies related to production, storage, and transport, contributed to reducing the number of small-size food retailers in the city (Ajuntament de Barcelona, 2013). Such advances also gave room in Barcelona to the breakthrough and boom of supermarkets (being Carrefour the first supermarket established in the region in 1973) (Ajuntament de Barcelona, 2013). During the ' 90 s in Western Europe, already only a small number of large retailing companies, some of them operating globally, accounted for the vast majority of groceries sales (Spaargaren et al., 2012). These events, among others, have stamped a landmark in the ongoing dynamics of modern food provisioning in cities like in Barcelona (Interviews 10,11).

The turn from a localised and controlled food provisioning system back in the Roman Age into a liberalised and global food system has brought a 
reconfiguration of the food provisioning dynamics. Nowadays, different societal actors interplay in the scene of shaping food systems. In Barcelona, these actors interact with each other through social dynamics that reflect more as networked configurations in which the state is just one of the players, among private and community sectors, shaping its food system.

The turn, then, from sourcing the city, in the past, with food from the proximity toward sourcing the city with food coming from all over the world has come along with logistical, distributional, commercial, organisational, environmental, and water and energy trade-offs and synergies. One of those trade-offs relates to the growing distances that food needs to travel, mainly by fossil-fuels modes of transport, in order to reach consumers in cities. Another one relates to the actual manner of food retailing and access in the city. However, the emergent sustainable food system of Barcelona aims to position back proximity food in the city; it aims to do so by synergistically reconfiguring and reconnecting foodrelated actors, nodes, and networks and flows.

\subsection{Toward Reconnecting and Reconfiguring the Proximity of Food}

Nowadays, Barcelona aims to strengthen its position as a sustainable food city. In such commitment, the city envisions to invigorate the use of its food markets as a way to reduce its food miles and as a way to transition back to source its food intake from the 'Proximity'. Food from proximity is characterised as the food in which 'the physical and social distance between the primary producer and the ultimate consumer is reduced compared with conventional contemporary systems that may involve many social and economic actors and cover large distances' (Spaargaren et al., 2012, p. 136). 
Chapter 4. The making of a sustainable food city in Barcelona

The physical distance that the current Proximity Accreditation Decree ${ }^{4}$ aims for is one that does not exceed a radius of 150 kilometres $(\mathrm{km})$ between places of production and access for consumers. Nevertheless, Barcelona targets to source its proximity food from places located at even shorter distances around the outskirts of the city. Between food proximity production and its retail, Barcelona aims to reduce social distances by employing two or fewer intermediaries. Proximity assumes a source of food that has used less energy during its transportation between its places of production and its access. In making the city more sustainable, proximity is targeted as a key element to pursue. Proximity Food in Barcelona finds its commercialisation route through the series of municipal food markets. These represent an accessible option for city inhabitants to food. Proximity food and its distribution through food markets might make a contribution to greening the overall food system in the city and thereby contributing to making the city overall more sustainable. In the next lines we explain how, and to what extent, this contribution occurs.

In its commitment to go through an organisational, commercial, and infrastructural modernisation of its food provisioning system, Barcelona puts a high emphasis on its food markets, as channels to food access, and on the proximity food those distribute (Interviews 6 and 10). These efforts come along with an organisational restructuration of the food actors and flows of the foodprovisioning network in Barcelona. Such restructuration has given space to the emergence of the Food Council of Barcelona, in which different societal actors (re)organise and (re)configure food in the city. The Metropolitan Area of Barcelona,

\footnotetext{
${ }^{4}$ Decree of accreditation of sale of proximity approved by the Department of Agriculture, Livestock, Fisheries, Food and the Natural Environment.
} 
the city of Barcelona, food markets, the wholesaler Mercabana, the Municipal Institute of Markets of Barcelona, and the Agricultural Park El Baix de Llobregat are the main actors constituting the council, giving shape to the sustainable food system of Barcelona. Such modernisations include, as well, upgrading and updating food markets into a highly competitive actor within the food system (both local and global) in which more actors (e.g. supermarkets, international chains, and e-commerce) interact and compete one to each other (Interview 7) (Ajuntament de Barcelona, 2017).

In short, these modernisations imply to re-connect and to re-configure food networks and flows in Barcelona for providing a more sustainable food system. The city and its food council shape the re-setting of the origin of the input of food flows, the intermediary actors related to such flows, and the channels of distribution providing food access to consumers in Barcelona.

\subsection{Food Proximity Flows Provisioning and its WEF Urban Nexus Interactions}

\section{Markets and their on-site water, energy and food dynamics}

Municipal Food Markets have been appointed as key places, and actors, for connecting the access to proximity food flows with local production. The 39 markets play a key role in feeding Barcelona City. These are the most visited places where consumers buy $45.2 \%$ of their meat and fish, and $27.9 \%$ of their fruits and vegetables ${ }^{5}$ (Ajuntament de Barcelona, 2014). When zooming in into Proximity Food, the Institute of Municipal Markets of Barcelona (IMMB)

\footnotetext{
${ }^{5}$ Food markets are the second most visited place by costumers for buying Vegetables and Fruits
} 
Chapter 4. The making of a sustainable food city in Barcelona

estimates that $70 \%$ of meat ${ }^{6}, 22-28 \%$ of fresh fish and seafood, and between 22 $28 \%$ of fruits and vegetables that municipal markets commercialise come from proximity (Interview 10). 8.3\% of sellers in markets source food directly from the producer or they have their own food sources of production (Ajuntament de Barcelona, 2014).

Markets are key food retailers that relate to water, energy, and food (WEF) dimensions in their daily operations. These dimensions relate to on-site dynamics and to processes in the food network. For example, next to the organisational and commercial modernisations that markets have gone through, their facilities have gone through an infrastructural modernisation process. This modernisation includes the upgrading of installations and saving appliances for water and energy use, among others. These modernisations are in part triggered by 2 reasons. 1) Water and energy intake by municipal markets came at the cost of their merchants, and 2) an increasing environmental awareness that merchants have acquired toward a conscious use of these resources (Interview 11). In terms of water installations, these have gained the most upgrades in the majority of markets. Those gains mainly relate to repairing water leakages (directors of the markets stated this was a big and general problem) and to the actual paying of the water bills by merchants in the markets ${ }^{7}$ (Interview 11).

Up to date, out of the 39 food markets, 5 have had their last remodelling (building upgrading) after 2010, 20 markets had it between the 2000 and 2010, 12 markets before 2000, and the remaining 2 markets do not record any related data

\footnotetext{
${ }^{6}$ Municipal Markets explain that they source their meat from different places than Mercabarna ${ }^{7}$ Directors of markets explained that the lack public enforcement for collecting the payment of water bills led to unconscious water consumption by the markets.
} 
Chapter 4. The making of a sustainable food city in Barcelona

(Departament d'Estadísitca de la ciutat de Barcelona, 2018). Infrastructural modernisations of markets represent a step forward on the making of a sustainable food city from a nexus point of view. However, this is not the case in every market. Some markets have not been physically upgraded for a considerable period of time. For instance, there are markets that were built in the '20s and '30s and had their latest upgrade in the '90s. This translates into outdated energy and water installations and appliances (Interview 11).

There are markets that have gained more progress with regard to energy and water savings and efficiency. Some of them already include appliances such as automatic lighting, LED lighting, solar photovoltaic (PV) panels, solar water heaters, common freezing chambers with low energy consumption, and water saving taps. One of the most important factors with regard to energy consumption and savings relates to whether each market building has natural ventilation or not. Some of them have natural ventilation (with part of the upper walls open) whilst others are completely closed and rely on artificial ventilation systems. This factor represents an issue when it comes to air-conditioning the markets during summertime. For the ones that do not have natural ventilation, keeping an indoor temperature of 25 degrees in summertime represents a very energy intensive practice (Interview 11). Adoption of renewable energy technologies such as solar water heaters and solar PV panels, in particular, is not the case at every municipal market in Barcelona. In many cases, these technologies compete with heritage protection schemes, which safeguard the artistic and historical value of the 'Catalan Modernisme' architectonical style portrayed on the facades and roofs of market's buildings (see e.g. Mercat de Galvany in Figure 9) (Interview 11). 
Chapter 4. The making of a sustainable food city in Barcelona

Distances between WEF in the provisioning of proximity food through markets reflect different physical and social dimensions. Water and energy intake at markets reflect mostly inputs-and-outputs dynamics of consumption. In the cases of markets with renewable energy technologies or saving appliances installed, physical distances from food to water and energy are reduced. The lack of interactions between WEF actors on sustainable food retailing practices reflects a social distance between these resource domains. The urban nexus of food and energy relates to further distances between markets and their related upstream processes of food provisioning, as we further elaborate on below.

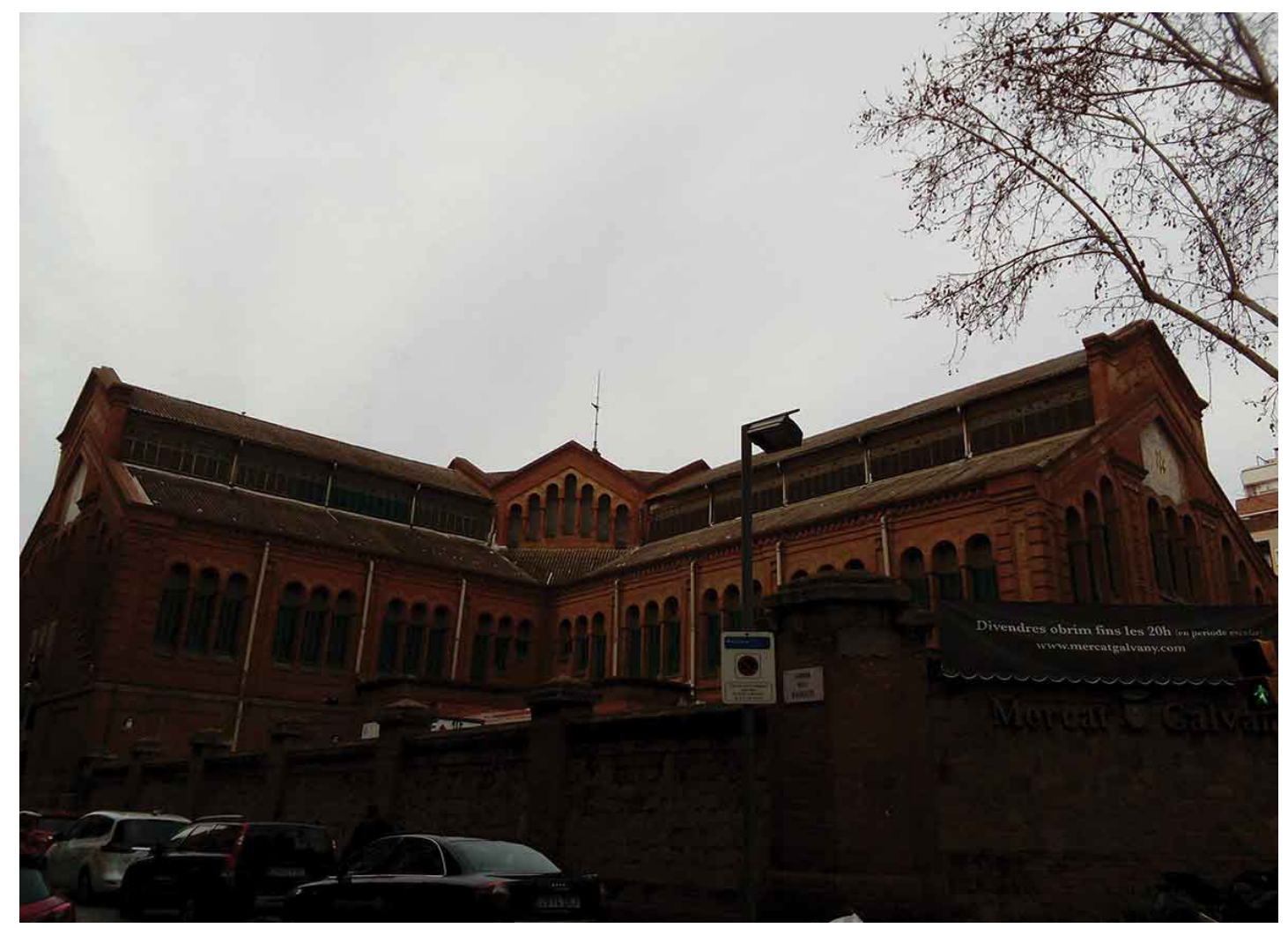

Figure 9: Mercat galvany (self-taken picture 2018) 
Chapter 4. The making of a sustainable food city in Barcelona

\section{Markets, wholesaling and their WEF dynamics}

The network of 39 markets, distributed all over the city and across its 10 districts (see Figures 10 and 11), needs to be sourced by food coming from either Mercabarna or from direct sales from farmers (to markets and by farmers at markets) (Ajuntament de Barcelona, 2014). Mercabarna is the largest wholesaling market in Barcelona.

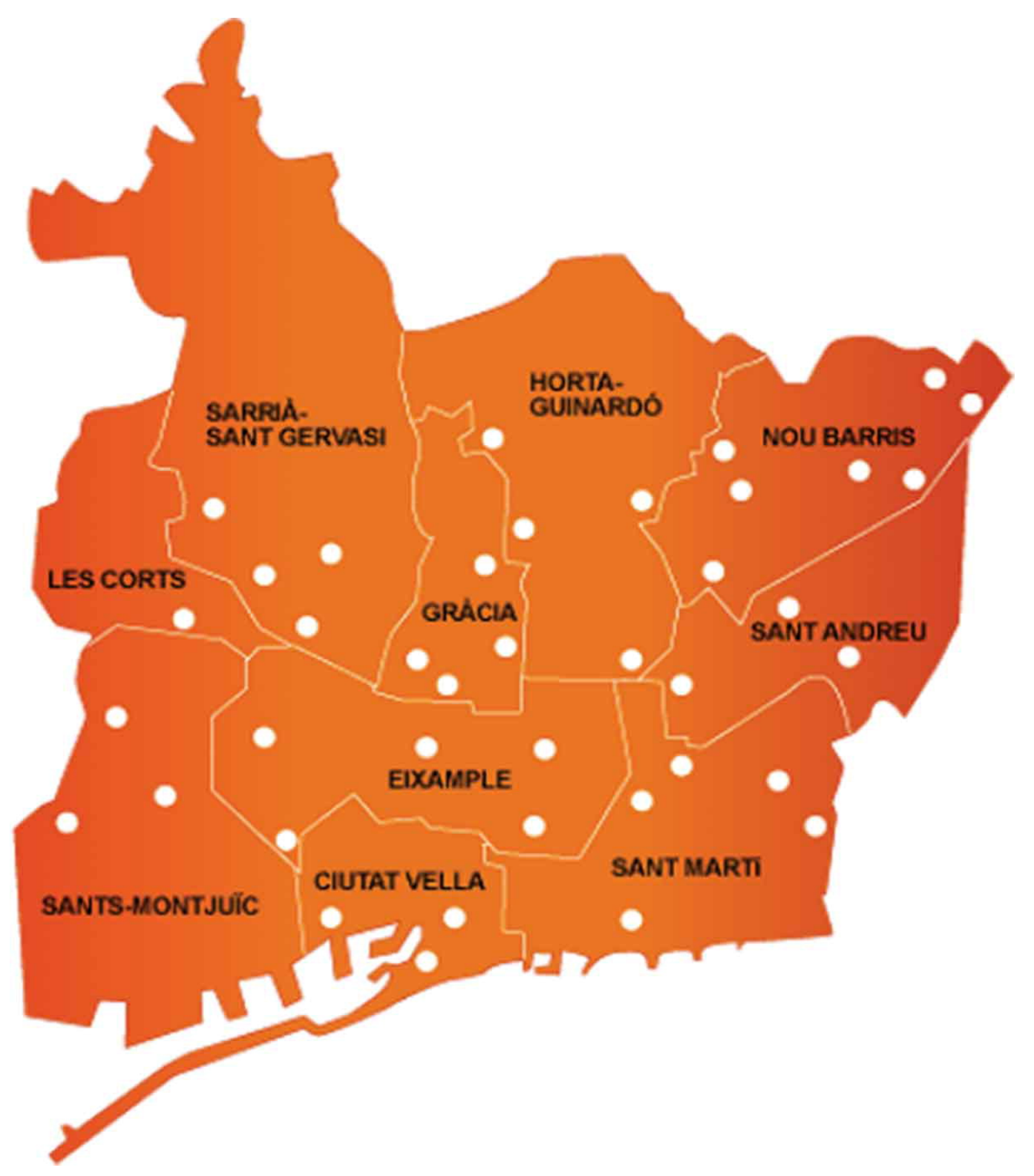

Figure 10: Distribution of food municipal markets through the Barcelona's districts (from Ajuntament de Barcelona 2014) 
Chapter 4. The making of a sustainable food city in Barcelona

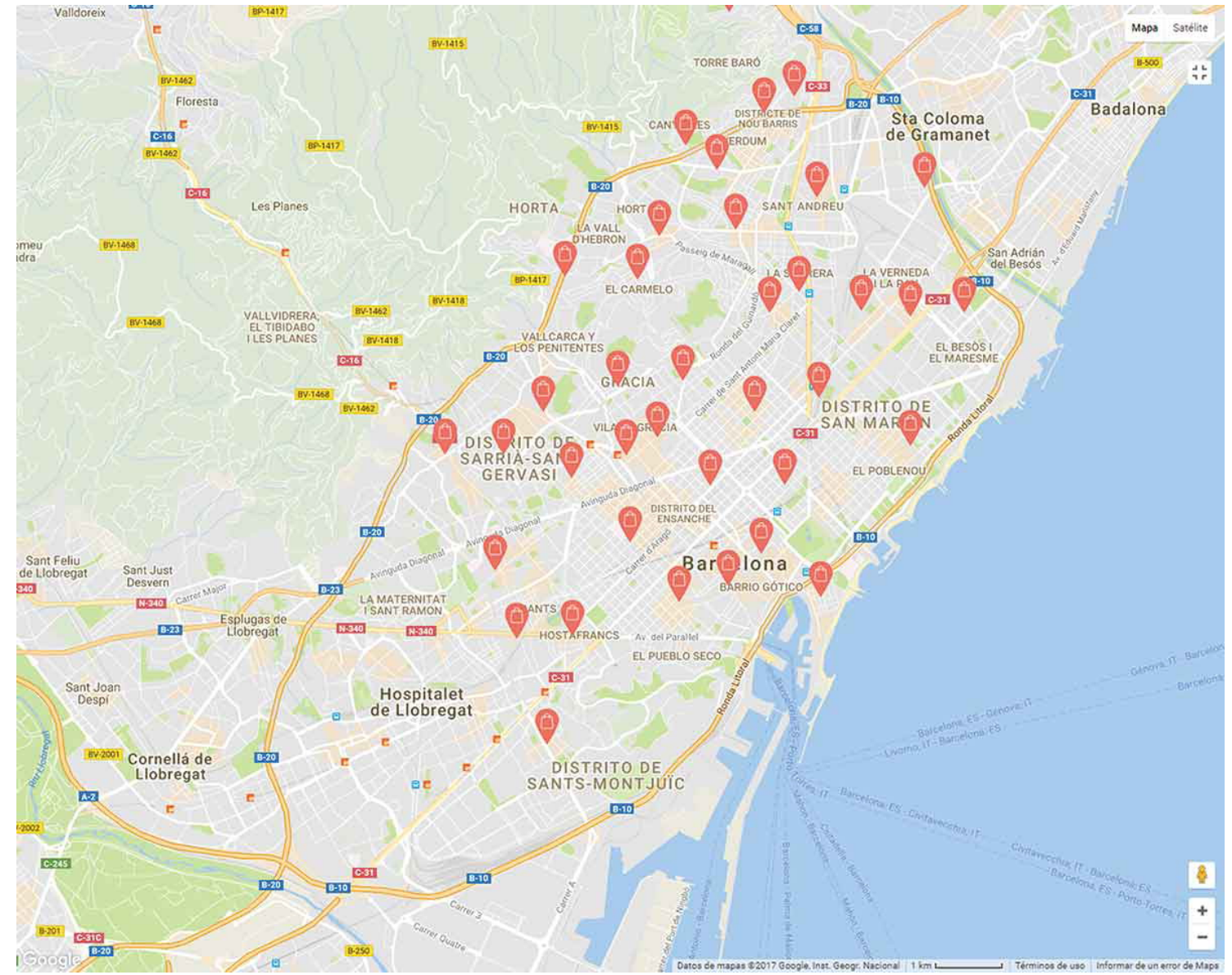

Figure 11: Map of food municipal markets throughout the city of Barcelona (from Google maps 2018)

The functioning of markets depends on both the available offer of food products and the way these products are sourced. The origin of food sourcing relates to an energy and food urban nexus. The physical distance of $10 \mathrm{~km}$ between Mercabarna and the city centre brings an energy-related advantage in terms of the length that food needs to travel in its last mile, referring to the physical distance that food transport takes in the last stretch of its supply chain (Morganti \& Gonzalez-Feliu 2015). Mercabarna is a key intermediary between producers (proximity, national, and global), distributors, and markets. It is organised in different wholesaler markets that commercialise different food types. Particularly, within the fruits and vegetables wholesaling market, the 'Silo G' stands out for 
Chapter 4. The making of a sustainable food city in Barcelona

being dedicated to commercialising food from proximity. Mercabarna trades yearly an approximate to 225,000 tons of fruits and vegetables of proximity ${ }^{8}$. This represents around $19 \%$ of the total vegetable and food traded in Mercabarna (Interview 9).

Proximity Food suggests that shorter radius between food wholesaling and retailing might be more energy and environmentally friendly. Nevertheless, food flowing in and out from Mercabarna accounts for approximately 14,000 vehicles a day visiting its facilities. Most of these vehicles are powered by fossil fuels (Interview 9). Every sales-point owner from each market in Barcelona is responsible for its own food sourcing and logistics (Interview 11). These are 1667 independent sales-point owners from the 39 markets (Interview 10). It is a common practice that almost everyday merchants from markets go to Mercabarna to get food sources. They often do it with their own means of transport (Interviews 9, 10,11). This results in a myriad of vehicles (mainly LightDuty Vehicles or cars powered by diesel) commuting to Mercabarna almost every day, instead of just a few larger vehicles distributing food to each market. The main reason they do so is that if sellers skip going to Mercabarna they miss the opportunity to negotiate or bargain the prices and to benefit from discounts or last-minute offers' (personal communication). Indeed, the choice for commercialising proximity food represents a step forward in shortening food miles. However, if this would result in a myriad of additional vehicles frequently commuting to Mercabarna, the benefits of proximity food will be reduced.

\footnotetext{
${ }^{8}$ This data is based on a radius of $150 \mathrm{~km}$ and includes the Agricultural Park El Baix Llobregat
} 
When zooming into the site's operations of Mercabarna, these do not reflect a standardised account of its energy and water consumption nor a close collaboration with such sectors (Interview 9, 12). The energy system of Mercabarna depends ${ }^{9}$ on the inflow of electricity from the public energy grid (Interview 9). Water sourcing comes from two flows: the water network (exogenous flow) and a water well (endogenous flow). Water extracted from the well is high in its salinity content and it mainly serves for rinsing Mercabarna's infrastructures (e.g. roads, buildings, fish markets, etc.). Water from the public network is used in the markets for the wholesaling operations (e.g. rinsing and washing food). Wastewater from the slaughterhouse and fish \& seafood markets goes to an on-site wastewater treatment plant (because of the content of organic solids). After this wastewater flow is treated on-site, it goes out of Mercabarna into a public wastewater treatment plant. The rest of the wastewater generated goes directly to the public wastewater network system (Interview 9).

The extent Barcelona addresses the puzzle of food sustainability lacks active connections, both physical and social, with water and energy networks. Instead, most of the physical connections, through wholesaling process and between retailing and wholesaling, relate to inputs-and-outputs relations in which water and energy flows engage with food as mere inputs of production. On top of that, there is a lack of social connections between the WEF networks. There have been, for instance, no formal or informal meetings or discussions held between the relevant actors from WEF networks to discuss on the policy and decision-making of these food processes and their implications in terms of water and energy.

\footnotetext{
${ }^{9}$ The slaughterhouses have an inflow of natural gas for their operations
} 
Chapter 4. The making of a sustainable food city in Barcelona

\section{Wholesaling and local production and their WEF dynamics}

In connecting markets of Barcelona with proximity food flows, via Mercabarna, there is a key source of local food production: The Agricultural Park of the Low Llobregat (In Catalan: El Parc Agrari del Baix Llobregat). It is located in the alluvial plains of the delta area of the lower basin of the Llobregat River (Diputació Barcelona, n.d.). Its main objective is to safeguard and promote the agricultural activity within this Agricultural Park. This is the most proximate agricultural park and food producer for the city of Barcelona (Interview 1) and it is located 11.5 $\mathrm{km}$ from the city centre and $5.5 \mathrm{~km}$ from Mercabarna. This Park commercialises, approximately, $20-30 \%$ of its total production through direct sales via municipal food market, farmers markets, or shops (or it is sent to other cities), and the remaining $70-80 \%$ is commercialised through the wholesaler Mercabarna, as an intermediary (Interview 1).

Such proximity represents an energy-related advantage with regard to the distance food needs to travel from production to wholesaling (and then to retailing at markets). The way to arrange food transport from farms to Mercabarna depends on each food producer (Interviews 2, 3; personal communication with farmers). It is a common practice that farmers employ trucks or tractors (fuelled with diesel) to pick up or tow their food production. In terms of renewable energy power usage for food transport, farmers experience difficulties to transport their products by these means (e.g. e-bikes or e-vehicles) due to the lack of biking infrastructure, the heavy loads of freights, and the lack of suitable e-vehicles offer (in terms of power and price) (Interviews 2, 3). 
Chapter 4. The making of a sustainable food city in Barcelona

With regard to water and food interrelations in the agricultural park, its water intake provides an example of circularity of wastewater flows. A wastewater treatment plant, located in the proximity, partly sources the agricultural lands with treated water, which is high in nutrients for agricultural applications (Interviews $12,13)$. The water network and seasonal rains provide the rest of the water needs of the park. Whilst for the energy intake of the agricultural park, this mostly relates to fuelling agricultural machinery by diesel or to powering refrigerating chambers for food storage with electricity (Interviews 1, 2).

Whether or not food produced in the Agricultural Park ends up flowing through Barcelona food markets, does not just depend on infrastructural circumstances. It is shaped by social dynamics. There is a lack of interactions between energy and food actors in Barcelona, preventing the urban nexus from taking shape in an effective manner. For instance, there is no evidence supporting formal or informal meetings held by actors from the energy and food sectors to discuss or to address possible synergies or trade-offs. In addition, dynamics around global markets and economies of scale play a role in connecting proximity food with food wholesaling process and retailing through food markets (Interviews 2, 11). Provisioning proximity food via Mercabarna competes with similar food products coming from different origins (national or global), and often offered at more competitive prices (Interviews 2,11). This has resulted in part of food produced in the proximity of Barcelona being commercialised through other channels of distribution (e.g. another city, self-consumption or composting) (Interview 2). This puts pressure on further efforts by farmers in the proximity for increasing food production shares without having a guaranteed commercialisation channel for it (Interviews 2, 3). Although the framing of this study does not aim to 
consider the global dimensions of food supply, it is important to notice how in particular economies of scale, and global and liberalised markets exert consequences on the wholesaling and retailing of food from both, the proximity and abroad.

\section{Moving into a more sustainable food city}

In short, the way the sustainable food network is coded often excludes dimensions of water and energy from the framing of what a sustainable food city is about. What this coding misses is an urban nexus perspective when envisioning food in the city through its provisioning processes and flows. Establishing such an urban nexus does not just refer to physical connections along the food processes. Proximity also refers to distances between WEF networks, flows, and resources, and the distances between social actors in the practice and policy and decision-making of such resources governance.

To move forward in an urban nexus fashion, Barcelona could further anchor values on food as an asset of the city (Interview 7); and as an asset intertwined with water and energy dimensions. This implies a need to address urban systems as systems of food production, wholesaling, distribution, and consumption; and not exclusively as systems of resources consumption (Interviews 4, 5). Although water and energy are resource systems that already have a stake on the urban agenda, food per se is still an emerging dimension in the city politics and policy (Interview 7). Further efforts to address food policy in the city, from a more urban nexus-oriented point of view, still challenge the often-separated WEF networks in articulating cross-sectorial actors, values, and goals into one common direction (Interview 2, 5, 6, 8, 10, 12, 13). 
Chapter 4. The making of a sustainable food city in Barcelona

\section{Conclusion}

It is often taken for granted that proximity food is a more sustainable alternative in the greening of food systems (Spaargaren et al., 2012). However, proximity flows and the circuits of provisioning in which those go through show different dimensions to observe and reflect on, as we have discussed in this paper. Shortening physical distances between food processes does not per se mean more proximity. Approaching social distances, such as organisational practices and level of interactions between relevant actors, play a crucial role not only in understanding the proximity of food but also on understanding it nexus with water and energy.

This case study has shown the emergence and attempts of a Food Council to accommodate the different food puzzles into a proximity food system. Switchers and programmers from the food system, through the Food Council, configure steps forward towards an urban food policy framing and practice for Barcelona. In doing so, it aims to push the city endeavours to become a sustainable habitat. However, there are weak points that deserve further interventions and attention. The extent the city addresses the puzzle of food sustainability lacks active connections, both physical and social, with water and energy networks. Instead, most of the physical connections, through food processes and flows, relate to inputs-and-outputs relations in which water and energy flows engage with food as mere inputs of production. On top of that, there is a lack of social connections between the WEF networks. There have been no formal or informal meetings or discussions held between the relevant actors from WEF networks at the Food Council nor are there shared practices around food provisioning processes. 
Chapter 4. The making of a sustainable food city in Barcelona

Proximity is developed as a concept by the Food Council to improve and gain on food sustainability in Barcelona and it has been employed as a crucial element in the (re)coding by switchers and programmers of the urban food network and flows. However, such code and coding still deserve further development on closing physical and social distances, not only within the food network (through its processes) but between the WEF dimensions through every process of food provisioning in Barcelona.

It might be that other European cities than just Barcelona do not yet actively engage with WEF domains in their food policy and decision-making. Yet, effective and sustainable governance of urban food provisioning in these cities, as in this case Barcelona, would profit from integrating more cross-sectorial thinking and practices among practitioners, and policy and decision-makers from WEF domains (Artioli et al., 2017; Covarrubias et al., 2019). An effective level for action and innovation to address (un)sustainable practices of WEF connections would for instance be through a coordinating body similar to the Food Council as in the case of Barcelona. Specifically, by considering the council's members and their capabilities to connect with and to configure the relevant actors, policies, networks, and flows to further address the WEF urban as part of the coding of what a sustainable food city is about. 
Chapter 4. The making of a sustainable food city in Barcelona 
Chapter 5. Emerging food distribution networks in the last mile, Amsterdam

\title{
Chapter 5. Emerging Food Distribution
}

\author{
Networks in the Last Mile, Amsterdam: Water,
}

\section{Energy and Food Urban Nexus Governance.}

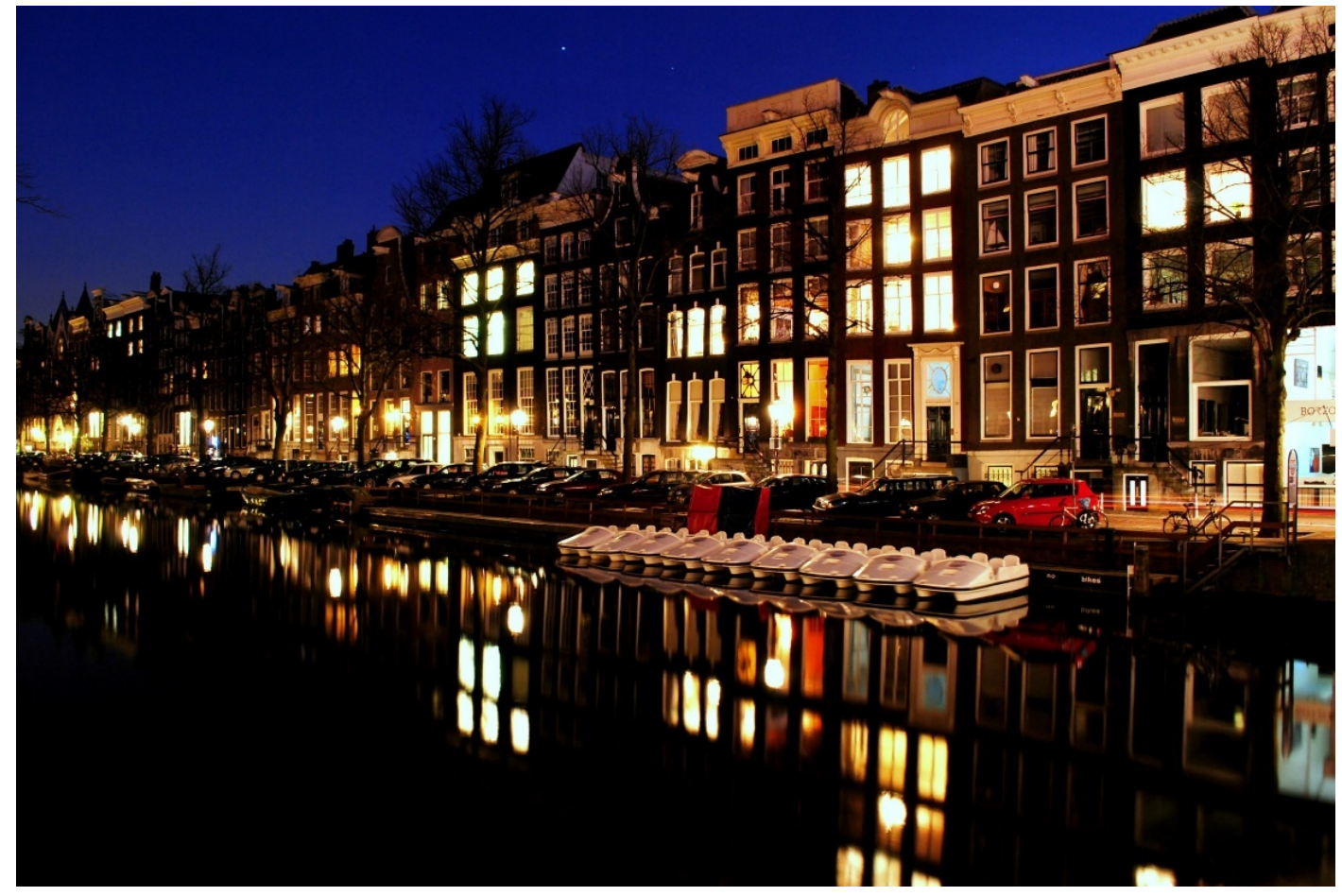

Image Source: https://www.pikrepo.com/nesir/brown-and-white-concrete-building-duringnight-time

This chapter is submitted to Cities, The International Journal of Urban Policy and Planning by Elsevier. 
Chapter 5. Emerging food distribution networks in the last mile, Amsterdam

\section{Abstract}

Transporting food in and through the city is one of the main contributors of $\mathrm{CO}_{2}$ emissions in urban areas (van Bossum, 2017). Amsterdam is one of the cities that strives to contribute to an urban sustainability agenda by investing in more sustainable food transport and a less car-oriented city (including food). It does so by limiting traffic, encouraging cycling, and promoting electric means of transport. This article examines the greening of the last mile of food in Amsterdam by using concepts and methods from mobilities studies (Urry, 2007). Specifically, we aim to open-up the black box of the last mile to better understand how it is becoming reconfigured in a more sustainable manner. This research uses the case of Amsterdam and examines its last mile of food distribution between wholesaling and Hotels, Restaurants, and Cafes (Horeca sector). We traced and mapped three alternative transport networks distributing food in the last mile: electric boats, electric vehicles, and electric and conventional bikes. We focus on mapping the social actors involved in the actual movement of food between $\mathrm{A}$ to $\mathrm{B}$ and aim to understand how and why food moves and relate to water energy and organic waste through the food distribution network in Amsterdam. Via this analysis, we conclude that a more sustainable last mile in Amsterdam requires a mobility agenda that looks beyond a car free city. It is also about the wider supporting urban infrastructure, including fuel shifts, alternative and crosssectorial infrastructure provisioning, and socio-political infrastructure.

Keywords: Urban Nexus, food last mile, Sustainability Governance, Networks, Water-Energy-Food. 
Chapter 5. Emerging food distribution networks in the last mile, Amsterdam

\section{Introduction}

By 2050 cities will face the challenge of doubling food production to feed an urban population growth of 2.5 billion whilst societies also need to reduce the related negative impacts of producing and distributing food (Bloemhof et al., 2015; WWR, 2015). Feeding an expanding urban population does not exclusively put pressures on increasing food production. Transporting food in and through the city is one of the main contributors of $\mathrm{CO}_{2}$ emissions in urban areas. In Amsterdam, this contributes to roughly $30 \%$ of the total $\mathrm{CO}_{2}$ emissions in the city (van Bossum, 2017). As such, feeding the city brings forward questions around increasing the size, capacity, and sustainability of food distribution systems (Fredriksson \& Liljestrand, 2015).

This paper examines to what extent and in what manner food systems (can) address food distribution in a more sustainable and integrative manner, taking into account their connections with energy and water. In researching this, we centre on the last mile of food. The last mile refers to both the physical transport of food taking place in the last stretch of its supply chain (Morganti \& GonzalezFeliu, 2015) and the movement it needs from wholesaling to retailing in cities (the former as an access point for consumption). Connecting food from wholesaling to retailing, in the last mile, is often powered by the fossil fuels-based means of transport. As such, the last mile of food has been critiqued for exerting pressures on traffic congestions, enhancing $\mathrm{CO}_{2}$ emissions, and worsening air quality in urban areas (Born \& Purcell, 2006). In the context of smart city developments, focused on embed technological and data advances solutions on urban infrastructures (Maye, 2019), attempts have been made to "green" food 
Chapter 5. Emerging food distribution networks in the last mile, Amsterdam

distribution in the last mile. There are for instance efforts on shortening the distances between food processes, on re-localising food within the city, and on the use of greener means of transport (Sonnino \& Moragues Faus, 2018).

We examine the greening of the last mile of food by opening up the black box of the last mile to better understand how it is becoming reconfigured in a more sustainable manner. As opposed to just examining the producing (A) and receiving (B) end, we want to study their connection and what is within: dynamic actor networks with some more powerful and others marginalised, and how this relates to sustainable or unsustainable connections with other environmental flows such as energy and water. We do so empirically by unpacking the last mile of food in the city of Amsterdam by using insights from mobility studies (Urry, 2007). In doing so we guide our research by employing concepts and methods from mobilities studies (Büscher \& Urry, 2009). We have traced and mapped three alternative transport networks distributing food in the last mile: electric boats (e-boats), electric vehicles, and electric and conventional bikes. These are emerging practices by food distributors using renewable energy options and alternative distribution infrastructures such as water cannels, bike lanes and roads. They operate in the context of the city's sustainability agenda to strive for a more walkable city by regulating car access, with extra emphasis on the more congested areas of the city centre (Agenda Amsterdam Autoluw 2019). These policy changes aim to have impacts on emissions reductions, air quality improvements, carbon neutralisation, and less congested and more liveable city space for its citizenry (Gemeente Amsterdam, 2019a). In addition, these policies are expected to have consequences on a general mobility level in Amsterdam, including specific consequences for food mobility practice. Concretely, we focus on mapping the 
Chapter 5. Emerging food distribution networks in the last mile, Amsterdam

social actors involved in the movement of food between $A$ to $B$, and aim to understand bow and why food moves and relate to water, energy and organic waste through the food distribution network (between wholesaling and Hotels, Restaurants \& Cafes, also known in Amsterdam as the Horeca) in Amsterdam. The involved actors include electric-transport providers, wholesalers, retailers, the Horeca, and water-energy-food (including organic waste) policy and decisionmakers.

Via this analysis, we argue that a more sustainable last mile of food requires more than a shift toward greener modes of transport. It is about the wider supporting urban infrastructure, including fuel shifts, alternative infrastructure provisioning (e.g. the use of canals as opposed to roads), and socio-political infrastructure (e.g. who supports or obstructs the transition).

The chapter is structured as follows: Section 3 introduces for the study of the last mile of food distribution from a mobilities point of view. Section 4 explains the methodology. Section 5 then explores the three cases of emergent distribution alternatives of food in the last mile in the city of Amsterdam. Section 6 concludes on the emergence of the urban sustainability agendas in the context of a wider infrastructural and socio-political perspective.

\section{Movement of Food in the Last Mile}

Distributing food in the city is often regarded as a matter of moving food from A to B (e.g. from wholesaling to access points of consumption) (Cresswell, 2006). For example, it has been discussed as such in research about distances (food 
Chapter 5. Emerging food distribution networks in the last mile, Amsterdam

miles), inputs, emissions, efficiency, revenue, etcetera, in sustainability of food logistics research (see overview in (Bloemhof et al., 2015). This A to B view has in Mobilities literature been discussed as a reductionist way to understand the movement of objects between two points (see discussions in (Cresswell, 2006; Faulconbridge \& Hui, 2016), as in this case of food distribution in the last mile. The "mobilities paradigm" (Sheller \& Urry, 2006) is an approach that has challenged the predominant focus of social sciences and humanities on fixed places and territories. Instead, it argues to study and understand social life and social organisation from the perspective of movement, as our world is increasingly characterised by things, people, ideas and images that move and interconnect along the way (Sheller \& Urry, 2006; Urry, 2007). In the study of transport and food, a mobilities lens highlights the importance to examine the socio-cultural dimensions of movement of flows by understanding why and how these move between or through A to B, and the actors and resources shaping such movements (see discussions in (Cidell, 2012; Sheller \& Urry, 2016).

In studying transport, mobilities literature has given particular attention to the domains of automobility (Urry, 2007) and aeromobility (Adey, 2006), overseas shipping (see (Cidell, 2012), cruise tourism (see (van Bets et al., 2017), freight of shipping containers amid a myriad of different study fields (Gregson, 2017). The mobilities paradigm has also inspired applied research on the domains of sustainable urban transport and planning (for example cities in Denmark) (see discussions in (Sheller \& Urry, 2016). However, further efforts are yet to study urban food distribution in the last mile. 
Chapter 5. Emerging food distribution networks in the last mile, Amsterdam

Employing insights from Mobilities studies can contribute to further analysis of flows of resources and the socio-material networks that enable them, such as in the case of the last mile of food. We will study flows of food in Amsterdam in relation to water and energy networks of provisions in the city, this has in earlier research been termed "the urban nexus" (Covarrubias, 2018; Covarrubias et al., 2019). Mobilities provide helpful insights that shed light on why and how flows of water, energy or food (WEF) move or make connections in urban settings, and how this is shaped by networks of social actors (e.g. practitioners, entrepreneurs or decision-makers), policies and practices. Networks are the social organisational structures that configure the provisioning of WEF flows (Castells, 2009; Covarrubias et al., 2019). Mobilities insights can help then to shed light on understanding how these flows move within and through networks creating and re-creating patterns of movement or circulation (Urry, 2007), including the encountered tensions, struggles and conflicts (Urry, 2007).

\section{Methodology}

\subsection{Moving with the Patterns of Food Through the Last Mile}

Mobilities offers a mobile lens to explore how the urban nexus of the last mile of food in relation to energy and water networks of provisioning takes shape empirically (Sheller \& Urry, 2006). Sheller \& Urry (2006) suggest mobile methodologies to research things or people on the move, to focus on capturing movements, its connections and its performative effects. One of the methodologies to approach the nexus of WEF resources is 'moving with flows' (see Sheller, 2011). This methodology has allowed us to trace and follow the movement of flows (WEF) in order to capture how these are shaped by or 
Chapter 5. Emerging food distribution networks in the last mile, Amsterdam

generate political relations. It sheds light on understanding and complementing the bigger picture of food flows by analysing why and how these connects with water and energy infrastructures and networks, and who it involves in such connections (Czarniawska, 2014).

Specifically, this research aims to understand how and why food moves and relate to WEF through the food distribution network (between wholesaling and the Horeca) of Amsterdam and how these are shaped by, or generate, political relations. In doing so, we focus on the interface between the social (e.g. dynamics, policies, standards, or economic factors) and the material (e.g. urban infrastructures: roads or water canals) dimensions of WEF networks pattering. We base this analysis on three cases of food distribution in Amsterdam, each portraying a different means of distributing food in the last mile. These are: electric modes of boats, vehicles, and bikes (including conventional bikes), and represent emerging mobility practices by food distributors who employ renewable energy options and use different distribution infrastructures such as water cannels, bike lanes and roads. Simultaneously, the City Government is pushing forward its sustainability agenda to strive for a car-regulated city, with the goal of achieving air quality improvements, carbon neutralisation, and less congested and more liveable city space for its citizenry. In doing so, it imposes infrastructural and policy changes upon the distributors of food. We will examine this interplay between these top-down changes and the bottom-up emerging green distributing practices.

\subsection{Methods}

To conduct this research, we use observations and semi-structured interviews whilst being on the move (see mobile techniques in Laurier, 2002, cited in Sheller 
Chapter 5. Emerging food distribution networks in the last mile, Amsterdam

\& Urry 2006), complemented with a literature review. We employed mobile and unstructured observations as a tool to trace food flows through the three different means of distribution in the last mile of food in Amsterdam. This means that we participated in the transport of food via e-boats, e-bikes and e-cars. While doing so, we interviewed the people involved, observed and traced the transportation routes, infrastructural connections and struggles faced along the way. This was supplemented with one round of semi-structured expert interviews $(n=13)$ (Bogner et al., 2009) to gather answers about the points of integration and connections between the WEF actors and networks in provisioning food distribution. The literature analysed involves governmental publications, policy documents, and corporate publications related to food distribution and from WEF sectors (Gemeente Amsterdam, 2016a, 2019a; Klimaatbureau Amsterdam, 2010; Levelt et al., 2017).

Table 3 shows the list of organisations approached for the expert's interviews, the societal sector they belong to (public, private, research, consultancy or community), the provisioning sectors they work on or address (water, energy and food). 
Chapter 5. Emerging food distribution networks in the last mile, Amsterdam

\section{List of Interviews}

\begin{tabular}{|c|c|c|c|}
\hline $\begin{array}{l}\text { Numeric } \\
\text { code }\end{array}$ & Organisation & Societal Sector & $\begin{array}{c}\text { WEF } \\
\text { Resource(s) } \\
\text { addressed }\end{array}$ \\
\hline 1 & $\begin{array}{l}\text { University of Amsterdam - Smart } \\
\text { Mobility \& Logistics }\end{array}$ & Research & Food \\
\hline 2 & $\begin{array}{l}\text { Wageningen University \& } \\
\text { Research Centre - Urban-rural } \\
\text { relations in Agriculture }\end{array}$ & Research & Food \\
\hline 3 & $\begin{array}{c}\text { University of Amsterdam - Food } \\
\text { Logistics }\end{array}$ & Research & Food \\
\hline 4 & $\begin{array}{c}\text { University of Amsterdam - } \\
\text { ReOrganize Project }\end{array}$ & Research & Food \\
\hline 5 & $\begin{array}{c}\text { Amsterdam Institute for } \\
\text { Advanced Metropolitan Solutions }\end{array}$ & Research & $\begin{array}{c}\text { Water, Energy } \\
\text { and Food }\end{array}$ \\
\hline 6 & $\begin{array}{l}\text { Urban Planning Department of } \\
\text { the City of Amsterdam }\end{array}$ & Public & $\begin{array}{l}\text { Water, Energy } \\
\text { and Food }\end{array}$ \\
\hline 7 & $\begin{array}{c}\text { Horeca business } 1 \text { supplied by e- } \\
\text { boat }\end{array}$ & Private & $\begin{array}{l}\text { Water and } \\
\text { Food }\end{array}$ \\
\hline 8 & $\begin{array}{l}\text { Horeca business supplied by e- } \\
\text { vehicle }\end{array}$ & Private & $\begin{array}{l}\text { Energy and } \\
\text { Food }\end{array}$ \\
\hline 9 & $\begin{array}{c}\text { Horeca business supplied by e- } \\
\text { bikes }\end{array}$ & Private & $\begin{array}{l}\text { Energy and } \\
\text { Food }\end{array}$ \\
\hline
\end{tabular}


Chapter 5. Emerging food distribution networks in the last mile, Amsterdam

List of mobile interviews

\begin{tabular}{|c|c|c|c|}
\hline $\begin{array}{l}\text { Numeric } \\
\text { code }\end{array}$ & Organisation & Societal Sector & $\begin{array}{l}\text { WEF } \\
\text { Resource(s) } \\
\text { addressed }\end{array}$ \\
\hline 10 & $\begin{array}{l}\text { Organic Waste collector after the } \\
\text { 'last mile' via e-boats: Mariteam }\end{array}$ & Private & $\begin{array}{c}\text { Water, Energy } \\
\text { and Food }\end{array}$ \\
\hline 11 & $\begin{array}{c}\text { Food distributor in the 'last mile' } \\
\text { via e-vehicles: BidFood }\end{array}$ & & $\begin{array}{l}\text { Energy and } \\
\text { Food }\end{array}$ \\
\hline 12 & $\begin{array}{c}\text { Food distributor in the 'last mile' } \\
\text { via e-boats: Rederij Kees }\end{array}$ & & $\begin{array}{l}\text { Water, Energy } \\
\text { and Food }\end{array}$ \\
\hline 13 & $\begin{array}{c}\text { Food Distributor in the 'last mile' } \\
\text { via e-bikes: Food Logica and E- } \\
\text { bakkie }\end{array}$ & Private & $\begin{array}{l}\text { Energy and } \\
\text { Food }\end{array}$ \\
\hline
\end{tabular}

\section{The Last Mile of Food in Amsterdam: unpacking dynamics of movement}

Amsterdam has 844947 inhabitants (I amsterdam, 2020). The city's landscape is dominated by water canals and bike lane infrastructures (see Figures 12 and 13). It has 165 canals that sum up of a total length of 50 kilometres (I amsterdam, 2020) and a bike's infrastructure of $767 \mathrm{~km}$ length and 881,000 bikes (Gemeente Amsterdam, 2019b). In the heart of Amsterdam's city centre, the Food Centre Amsterdam plays a nodal and strategic role as the main food wholesaler. It is located approximately $2.5 \mathrm{~km}$ from the city centre. The heart of Amsterdam is also shared by a myriad of Horeca establishments (and it is communicated with water and terrestrial transport infrastructures) (see Figure 14). The Horeca clusters around 5000 establishments from which only restaurants oscillate around 2470 (Levelt et al., 2017). Distribution of food to the Horeca is primarily done via vehicles powered by fossil fuels (Amsterdam Smart City, 2016, October 19), 
Chapter 5. Emerging food distribution networks in the last mile, Amsterdam

which contributes with approximately $15 \%$ to $25 \%$ of the total transport in the city (Levelt et al., 2017). Distributing food from wholesaling to the Horeca includes on average 6.5 weekly deliveries per address and in total this whole industry carries out approximately 31,785 deliveries per week (Amsterdam Smart City, 2016).

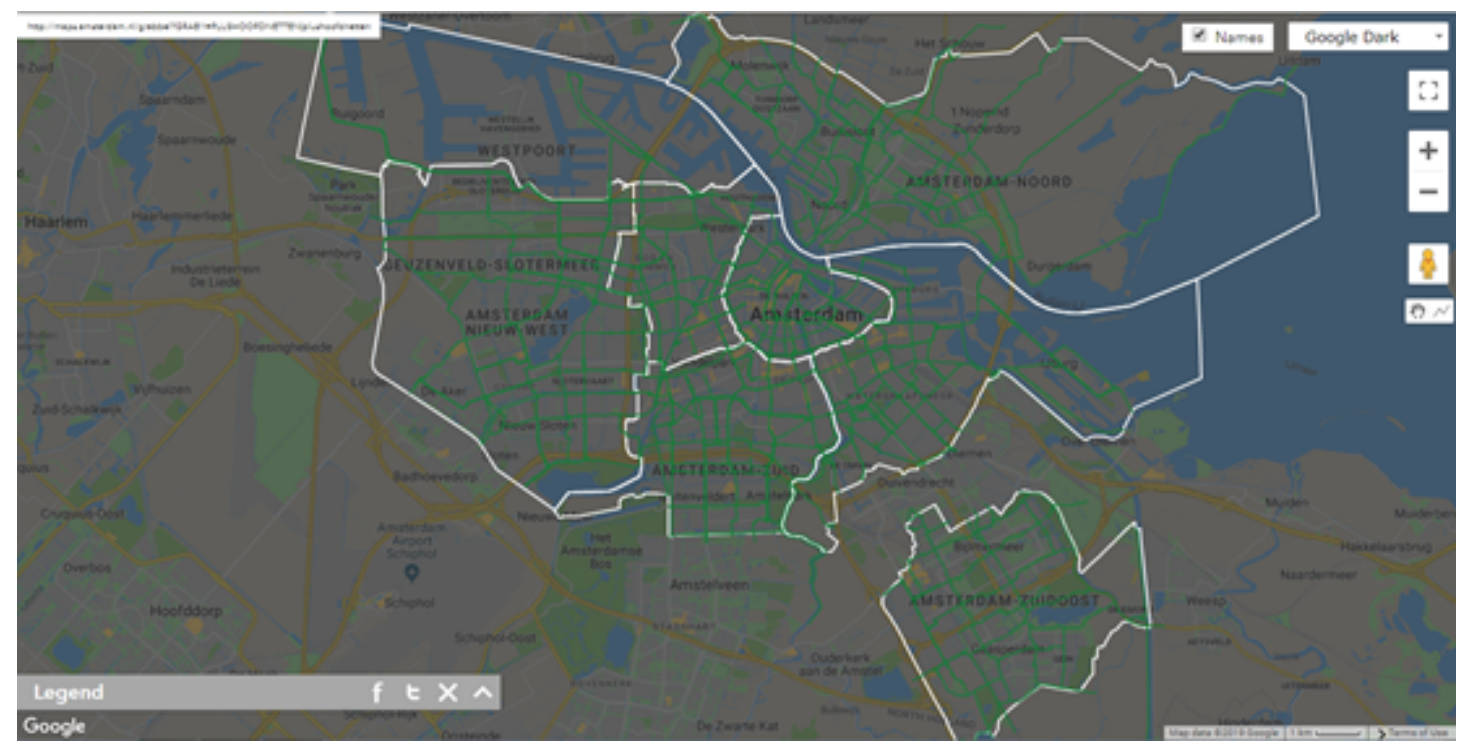

Figure 12: Mapping of bike lanes in Amsterdam (bike lanes are marked in green colour)

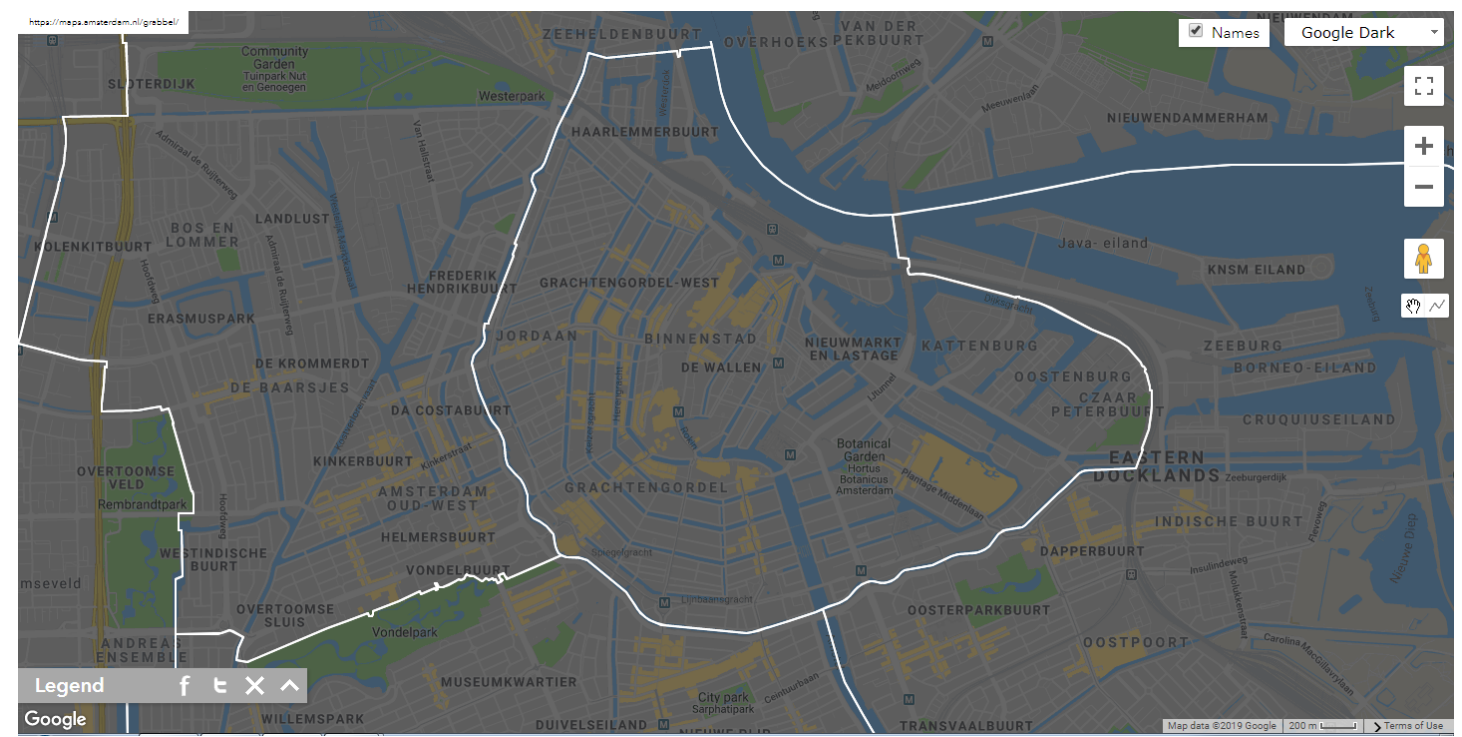

Figure 13: Mapping of water canals in Amsterdam 
Chapter 5. Emerging food distribution networks in the last mile, Amsterdam

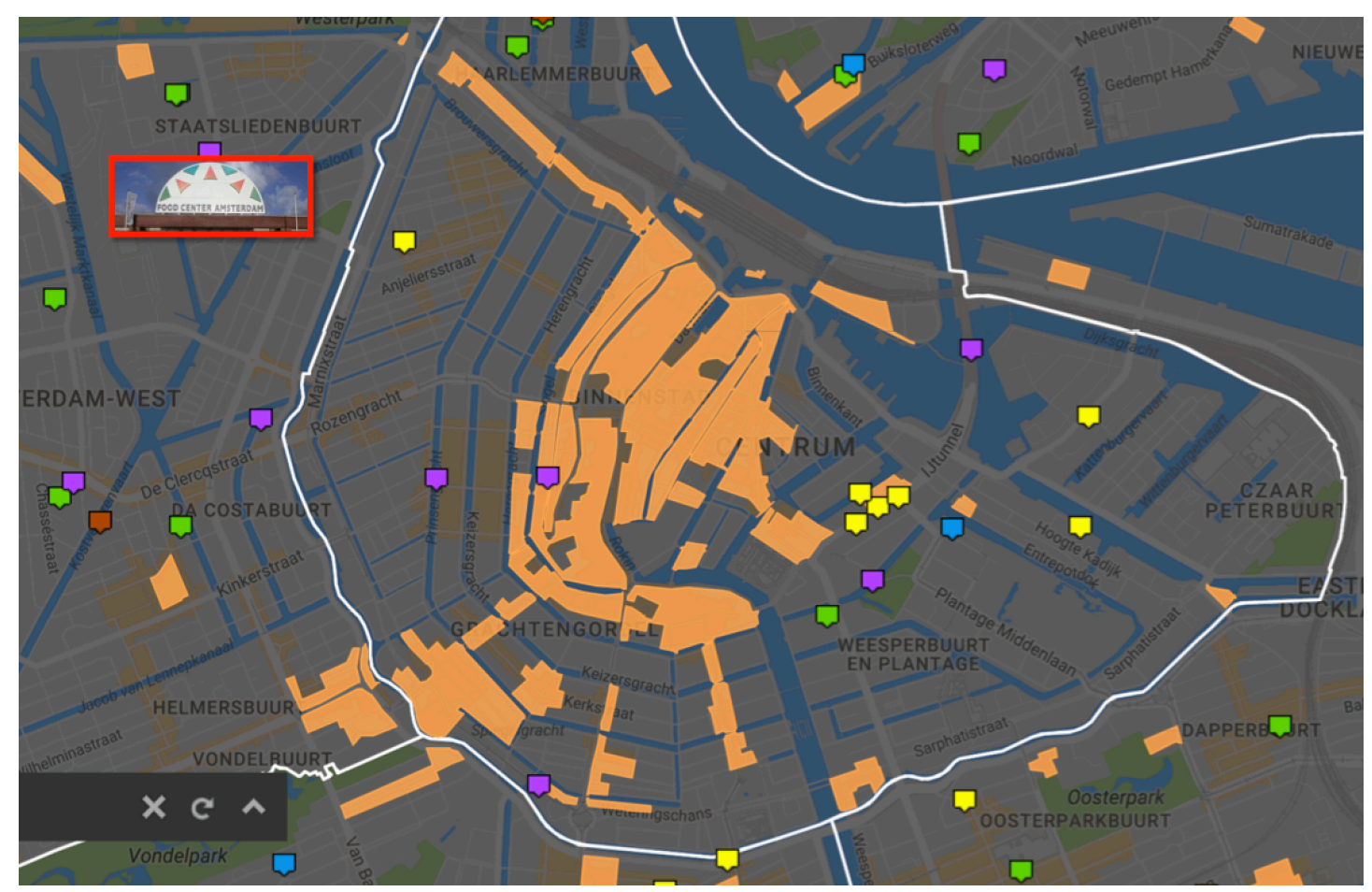

Figure 14: Mapping of the Food Centre Amsterdam and the Horeca sector

The city government of Amsterdam aims to re-pattern its urban food system by taking actions from different visions and goals arising from different policy fields. Our focus is on how Amsterdam's food ambitions relate to its Sustainable Urban Mobility agenda (EIP-SCC, 2013; Gemeente Amsterdam, 2016c; Van Wilden et al., 2016), and to policy and decision-making on energy transport and food logistics (Levelt et al., 2017). One of Amsterdam's priorities is the transition to a car-restricted city, in which cars have limited access to the city centre. It is currently trying to achieve this through drastic infrastructural changes, such as blocking the main road in the City Centre for cars (Prins Hendrik Kade), and restricting access to canals and small streets, based on its policy 'Agenda Amsterdam Autoluw' AAA policy 2019, translated as Agenda Amsterdam Car Restricted). The ultimate goal of the AAA policy is to enable a more walkable 
Chapter 5. Emerging food distribution networks in the last mile, Amsterdam

city. The city is using a set of tools to achieve its goals. They aim to strengthen public transport services, intelligent access and control of traffic for all type of transport, and work on logistical improvements. Specifically, for the Horeca and logistical services in general the city aims to experiment with solutions based on smart traffic, and modal shifts hubs.

To restructure the city, the city government is working from an experimental and learning by doing perspective (Interview 6). Though experimentation is can be understood as starting from below via small-scale pilots and trial and error practices (Bulkeley \& Castán Broto, 2013a; Castán Broto \& Bulkeley, 2013), in this case experimentation takes place through the top-down placing of interventions for social organisation change. For example, in making the city more walkable, the city government is the closing of streets or limiting their use. In this way they aim to test the city's infrastructure and its mobile systems while the city is being renovated. In general terms, the main premises of the policy interventions are to promote at city that is more friendly for pedestrians and bikers while at the same time regulating and discouraging the use of cars in the city.

In addition, the city council aims to promote electric transport. The aim is to have at least $60 \%$ of the kilometres travelled by vehicles within Amsterdam to be powered by green electricity by 2040 (Klimaatbureau Amsterdam, 2010). This involves large-scale recharging networks for e-vehicles and for terrestrial emobility (Department of Physical Planning of Amsterdam, 2013). 
Chapter 5. Emerging food distribution networks in the last mile, Amsterdam

Water as a medium of transport of goods and food by electric boats is furthermore part of this strategy towards green mobility to repattern its urban food and energy system (Gemeente Amsterdam, 2016b). What this policy aims to accomplish is to diversify food related traffic by shifting traffic from roads to water infrastructures. Further policy and infrastructural interventions are however still needed to create more efficient and less crowded navigation through water.

Overall, ambitions for greening mobility in the city and its last mile of food are expected to have positive consequences on $\mathrm{CO}_{2}$ reductions and air pollution levels as transport is considered to be one of the main contributors of $\mathrm{CO}_{2}$ emissions and air pollution in and around Amsterdam accounting for the 30\% of the total emissions (Klimaatbureau Amsterdam, 2010), as well as up to 50\% of air pollution in Amsterdam (Circle Economy et al., 2016).

Yet, despite these efforts, such policy and decision-making does not necessary translate into practices straightforwardly. Whilst policy ambitions of Amsterdam are being developed, simultaneously the last mile is being patterned from the bottom-up. Emerging types of e-transport initiatives try to translate such city ambitions into more sustainable practices of food distribution in the last mile of Amsterdam. The three types of electric transport (for food distribution) emerging in Amsterdam are e-boats, e-vehicles, and e-karts/bikes. In the next section, we analyse how practitioners translate the city ambitions into new practices of transporting food, to what extent and in what manner food systems address food distribution in a more sustainable and integrative manner, and to what extent these are supported or actually hampered by the city government. In analysing 
Chapter 5. Emerging food distribution networks in the last mile, Amsterdam

this, we will be taking into account the connections food systems have with energy and water.

\subsection{E-boats for Food and Organic Waste}

Distributing food and collecting organic waste through water canals is an emerging practice in Amsterdam to decarbonise transport in the city and reduce $\mathrm{CO}_{2}$ emissions (interviews $10 \& 12$ ). These use the inland waterways (canals) to navigate electric boats (in short, e-boats) (see Figure 15). E-boats are emerging as an option to address the last mile of food by connecting the main wholesaler in Amsterdam (FCA) with the Horeca sector. In doing such service, these initiatives still depend on terrestrial assistance in order to deliver a door-to-door service (e.g. draggers, LDV, or trucks, often powered by green gas and electricity) (interviews 1, 3, $410 \& 12)$. Further efforts are still required to deliver a more effective service (seamless) in which water and terrestrial infrastructure match more synergistically with e-boats and the service these deliver, as we further discuss.

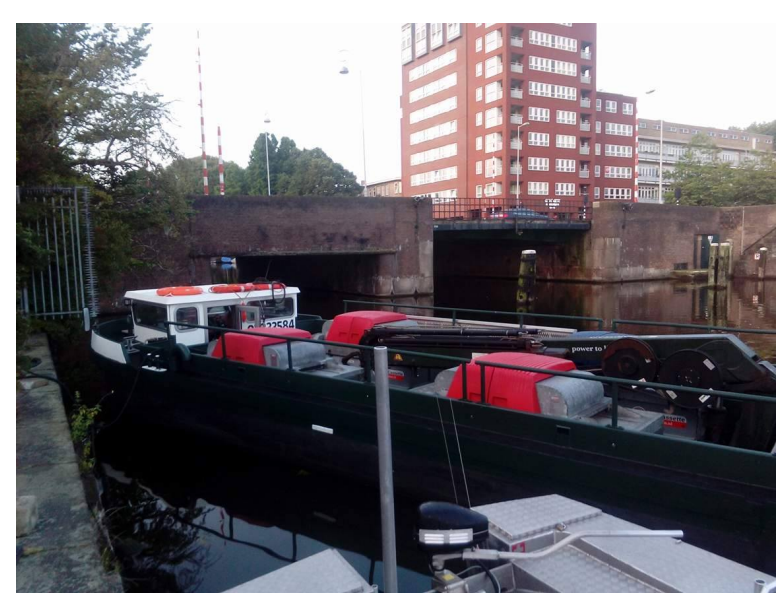

Figure 15: E-boat anchored at the FCA

The e-boat modality emerged as an urban logistical solution for bringing goods, waste, and food in and out of the city by using the water canals as a medium of 
Chapter 5. Emerging food distribution networks in the last mile, Amsterdam

transport (interview 10). The logistics involved in collecting and delivering entail different suppliers, the transporting of small quantities of different ingredients and a wide range of customers to make a profitable business case out of waterbased food distribution. Frequency, quantity, and quality of food are then standards that play a role in shaping how transport of food unfolds in the city.

E-boats in part emerged because the Horeca is becoming more specialised. For instances, a very specific restaurant (Thai) might need a myriad of very specific ingredients that do not necessarily come from the same supplier (Interview 10). Frequency, quantity, and quality of delivery play a role on food distribution on water. For instance, 'One ingredient might be delivered, for a particular restaurant, fresh and twice a day; whilst another ingredient might be needed once per day, frozen, and in light quantities' (Interview 10).

Navigating the canals of Amsterdam for distributing food is not necessarily a straightforward and seamless process. Such distribution comes along with complementary transport and infrastructural challenges. Water based distribution still depends on complementing modal shifts of transport in the making of a door-to-door delivery. The way infrastructures, suppliers and receptors are organised does not seamlessly match the logistical flows of food or organic waste. For example, points of collection and delivery of food are often not connected, or placed, nearby the water canals fieldwork observations, 07-2018). When such points are located in the proximity to water cannels, there is no connectivity or access points to actually load and unload food or waste on the boat and to ship it to or from addresses in Amsterdam. Such challenges put further constraints on the dependency of water-based food distribution on complementary road transport 
Chapter 5. Emerging food distribution networks in the last mile, Amsterdam

in the making of door-to-door deliveries (fieldwork observations, 07-2018). In logistics, 'adding an extra mode of transport within the last mile of food and organic waste (the post mile of food) represents an extra cost for logistical providers' (Interview 10). This is one the reasons why food distributors find challenging to do food logistics via water (Interviews 1, 3 \& 10).

Some companies have found it difficult to continue with food distribution through water. In order to supply to a single costumer, for example one restaurant, a boat might have to collect the ingredients from different sources scattered around the city. Consequently, as e-boats navigate at a slower and less frequent pace compared to e-bikes and e-vehicles, they often fail to meet the Horeca's demanding standards. The Amsterdam Horeca industry in general is characterised for having limited storage space for perishable goods and therefore depends on timely and frequent resupply. Some water-based distribution companies such as Mokum Mariteam (MM) switched to providing less pressing services, such as organic waste collection ${ }^{10,11}$ from the Horeca. These clients depend on waste collection either once per day, twice weekly or even just once a week. It brings empty waste containers to its clients and collects the full waste containers from them. Some of these clients are also restaurants, hotels, and cafes ${ }^{11}$. MM explains that this configuration brings a profitable business case. Some of the factors that make it successful are the type of cargo, the standardisation of cargo, the collecting frequency required by the costumer, and the type of clients they service to.

\footnotetext{
${ }^{10}$ It also handles other types of waste besides organic waste

${ }^{11}$ Another company in Amsterdam doing e-boat logistics is focusing mostly on importing empty bottles from beer ingredients for beer brewery.
} 
Chapter 5. Emerging food distribution networks in the last mile, Amsterdam

In doing such waste logistics, e-boats also experience complementary transport and infrastructural challenges (see Figure 16). For instance, when collecting the full containers, additional terrestrial support is required. These are electric cargo vehicles that drag the containers the closest possible to the shore of the dock next to the canals, and the closest possible to the crane of the e-boats. This, however, contradicts with the philosophy of water transport, which is to get rid of terrestrial logistics. Moreover, the original location of the client being serviced (e.g. the restaurant) and the actual location from where the container is loaded on the boat, are not necessarily the same place (fieldwork observations, 07-2018). Those places are often not proximate one to each other. It is also often the case that the terrestrial dragger needs to move the containers, through bikes lines and shared roads, to another location where the boat can anchor and where there is enough space along the quay for the boat to manoeuvre its crane. Then, when the boats are full, a waste management company unloads these containers from the e-boat and brings those out of the city by employing diesel trucks (fieldwork observations, 07-2018). This adds once again on the dependency of land-based complementary mobile systems and infrastructures.

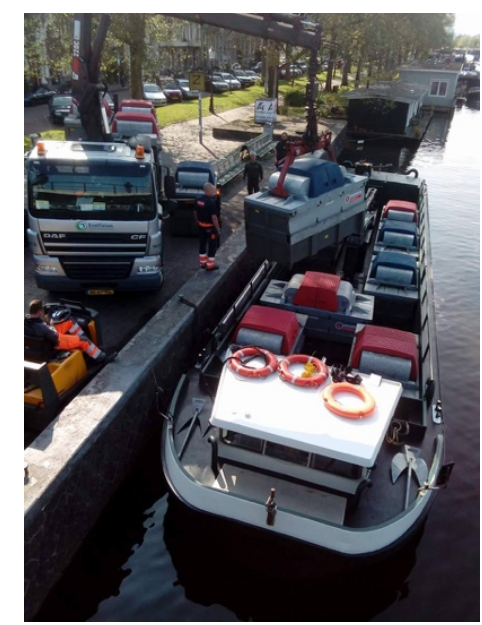

Figure 16: Multi-modal transfer between vebicles 
Chapter 5. Emerging food distribution networks in the last mile, Amsterdam

The challenges of either food, or waste collection by water also relate to water, and roads infrastructures. Canals infrastructure does not particularly address the needs for logistics throughout water. Loading and unloading areas are not sufficient, adequate, and strategically distributed around the city. There are few 'loading and unloading' designated areas, and the existing ones present some challenges. These designated spaces are not exclusive for water logistics as they compete with terrestrial vehicles. The size of these reserved areas is as large as one or two minivans size. If one of these spots is occupied by a minivan then boats need to wait until it gets free and vice-versa. In other cases, taxis or regular vehicles temporally occupy these spots. Next to these challenges, there is a problem of inadequate loading and unloading areas. Most of the addresses that MM services to are not nearby a reserved space for manoeuvres. Most of the times the company has to struggle with limited space for manoeuvre within the compact city of Amsterdam. Parking spaces for cars, restaurants and cafes, fences, publicity kiosks, among others, are infrastructures that are often located on the quays (see Figures 17 and 18). These often interfere between the e-boats and the access to the waste containers on the proximity of the dock (fieldwork observations, 07-2018). Therefore, food distribution via water competes with the terrestrial infrastructures. By trying to avoid road traffic congestions through the increase of distribution via water, boat users run the risk of water traffic also becoming congested. Amsterdam's canals are full of touristic boats, resident's boats, floating houses, etc. These boats or floating houses are normally anchored or tied to the shore of the canals occupying most of the available loading and unloading space along them. 
Chapter 5. Emerging food distribution networks in the last mile, Amsterdam

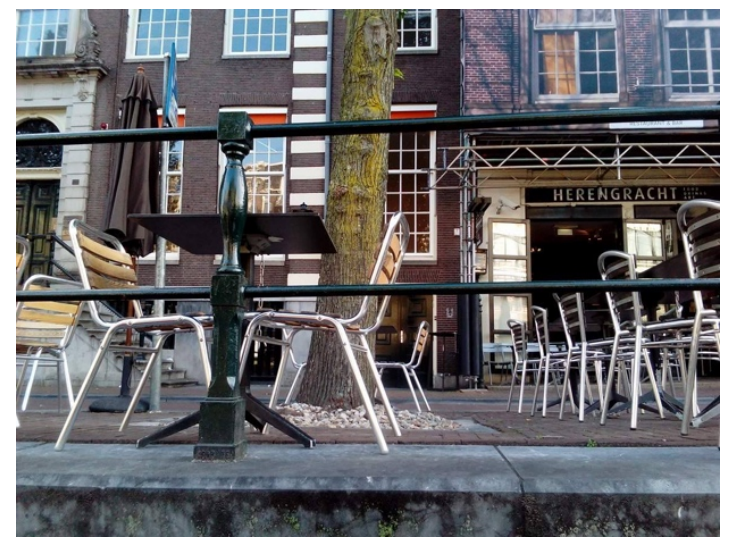

Figure 17: Restaurants as obstacles to logistics via water

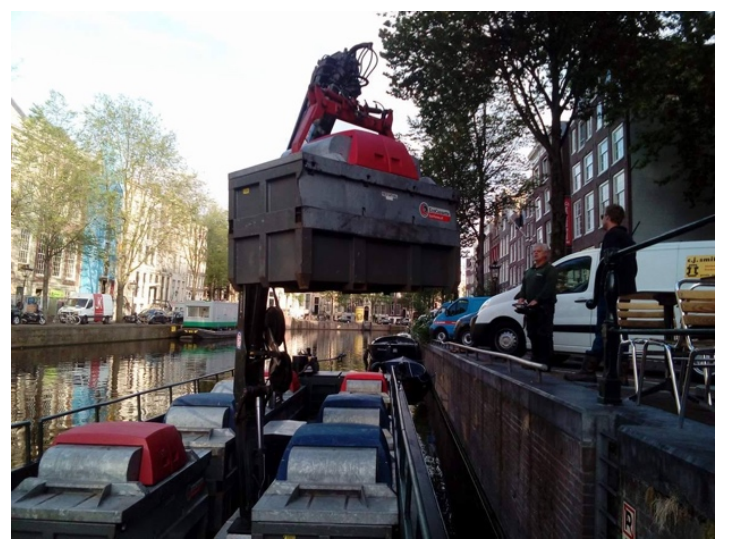

Figure 18: E-boat collecting waste containers from a restaurant

When MM was asked about any collaboration with the municipality they answered that it is important for the municipality to provide the city with targets and ambitions, but that they perceive this to be insufficient for their type of eboat initiatives. One interviewee (with Mokum Mariteam) noted that 'the municipality is more interested in subsidising e-cars' (Interview 10). In other words, whilst the municipality applauds what MM does there is no record of substantive support from their part to stimulate MM's efforts. Instead, the municipality just sets the new mobility standards without any incentive for the water-based distribution companies, leaving them to figure out how adapt to these changes. 
Chapter 5. Emerging food distribution networks in the last mile, Amsterdam

\subsection{E-bikes and E-carts}

Distributing food in the last mile of Amsterdam using e-bicycles, conventional bikes, and e-carts (see Figures 19 and 20) are also more sustainable alternatives. This type of transport has been practiced by a larger number of entrepreneurs (compared to e-boats) (Interview $9 \& 13$ ). These alternatives use the network of cycling lines in Amsterdam. E-bikes and e-carts also emerge as an option to address the last mile of food between the FCA and the Horeca sector. In providing such service, these initiatives are capable to deliver a more seamless door-to-door service (Interview 1, $3 \& 13$ ). Standards of frequency and timing demanded by the Horeca are better met by bicycles as compared to e-boats. However, further efforts are needed to address the capacity of cargo these means of transport can deliver, which is sometimes a limitation in servicing clients. Additionally, the number of cycling lines users is growing either by people commuting to their daily life activities or by cyclers performing different delivery services.

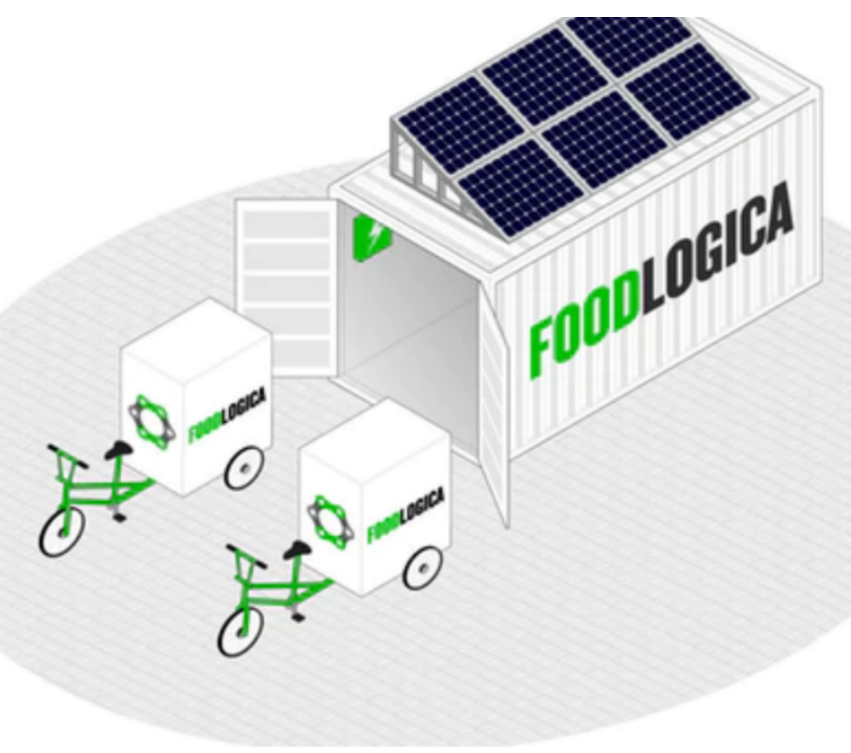

Figure 19: Food distribution by e-bikes (source retrieved in January 6, 2020 from: https:// amsterdamsmartcity.com/products/foodlogica) 
Chapter 5. Emerging food distribution networks in the last mile, Amsterdam

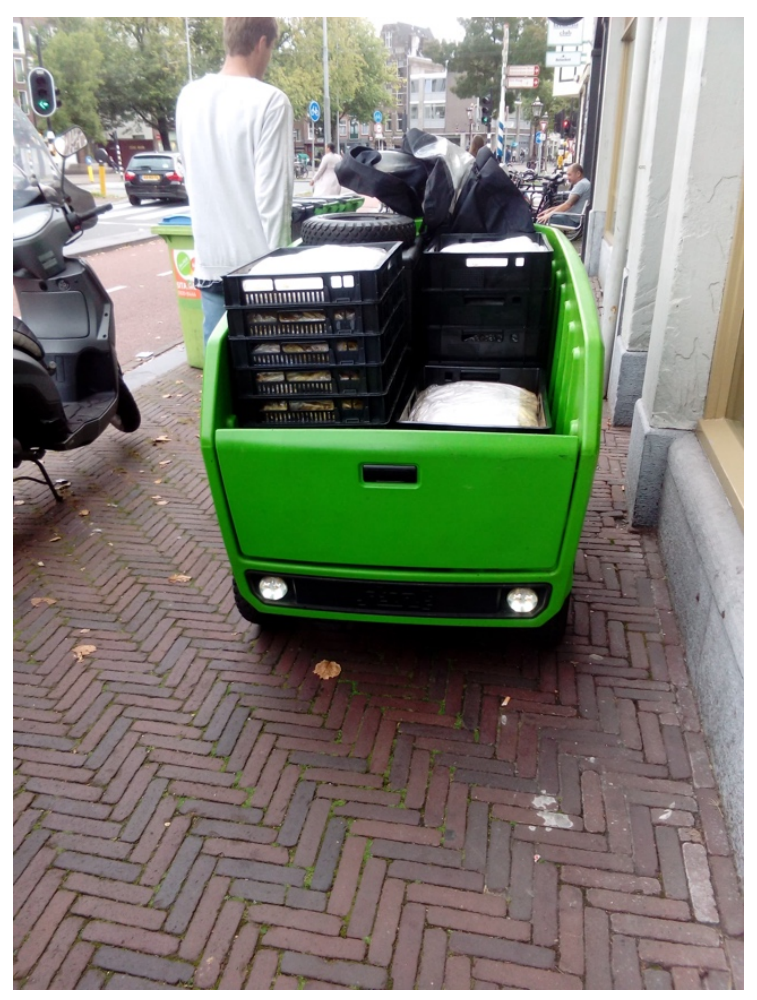

Figure 20: E-bakkie distributing food to restaurants

E-carts and e-bikes can have a maximum carrying capacity of up to up to $500 \mathrm{~kg}$, while making use of the bicycle lanes and mixed roads to transport food through distances to up to $100 \mathrm{~km}$. The value these services provide are to deliver food in a more sustainable option that employs less invasive transport in urban food logistics, while at the same time contributing to less road traffic congestions (compared to fossil fuels vehicles).

These e-logistical providers relate to energy in different fashions. E-carts services normally power their fleets with a mix of sources of electric energy (both, renewable energy and non-renewable energy). Oftentimes, the batteries of this transport are not dismountable; making it challenging to actually switch empty rechargeable batteries for already charged ones. For e-bikes, specifically, it is 
Chapter 5. Emerging food distribution networks in the last mile, Amsterdam

relatively more common to have exchangeable and rechargeable batteries. Some initiatives, for instance Food Logica, have electricity-charging infrastructures distributed around the city. These charging points consist of old shipping containers with solar PV panels from which bicycles and their batteries can recharge.

These types of transport bring a competitive advantage when compared to eboats. These can actually benefit from an extended biking infrastructure that connects more door-to-door with most of the Horeca addresses, making loading and unloading easier and seamlessly without requiring any complementary transport (fieldwork observations, 04-2018). One of its main advantages is that this modality is allowed to use bike lanes and to park on the sidewalks (as if it was a regular bike). E-bikes can also board other transport vehicles, e.g. ferries, which makes for easier connectivity (Interview 13).

Drivers of these vehicles experience the biking infrastructures as being optimal for food distribution, generally speaking. However, those have also encountered some infrastructural challenges to be addressed, namely the width of the biking lanes (approximately $1.5 \mathrm{~m}$ ), and the traffic during peak hours (by civilian cyclists in general). At times, the mix of e-bikes and e-carts, and the inhabitants of Amsterdam using bikes, compete for the packed space through the bike lanes in the city. This translates into packed bicycle traffic. On the field, practitioners use day-to-day experience to avoid more heavily trafficked or congested lanes (Interview 13, and fieldwork observations on 04-2018). 
Chapter 5. Emerging food distribution networks in the last mile, Amsterdam

Although at peak hours bike lanes are more congested, these vehicles are still an effective way to distribute food in the city centre area of Amsterdam as compared to other means of transport. On average, moving food from A to B by bike or cart, within the last mile of food, can take half of the time when compared to motorised trucks or vans (Interview 13).

With regard to standards of timing, size, and frequency, these vehicles do not experience major struggles as compared to the other vehicles studied. These services are better able to match current needs of the Horeca. The different types of Horeca clients may demand different sizes of cargo to be delivered by these vehicles. For instance, restaurants often require small quantities of a myriad of ingredients in a higher frequency of supply at a fast pace. E-bikes and carts are more equipped to match with these standards. However, cafes, bars or breweries often demand a service that must deliver larger volumes (larger than $1000 \mathrm{~kg}$ ). For instance, breweries need big volumes of beer ingredients, and empty or full bottles of beer and drinks, which are often heavier than other food products (Interview 7, 9 10, $12 \& 13$ ).

For the city, these alternatives are an effective way to profile and showcase the city endeavours towards the future of sustainable food distribution (Interview 13). The relation this service has with public sector is one that primarily translates into meetings and platforms for knowledge exchange and discussions. Any other type of connection or collaboration is not evidenced. For instance, there are no subsidies that incentivise the uptake of this e-mode of transport in Amsterdam as compared to the case of private e-LDV or e-trucks. Between related e-logistical services providers, there is an informal exchange of practices and experiences 
Chapter 5. Emerging food distribution networks in the last mile, Amsterdam

platform. This basically consists of practitioners of this specific modality gathering and discussing common challenges and ways to solve them. When asking about whether or not these providers lobby or get together to discuss with local authorities about further efforts on decarbonising the last mile of food, the answer is "no, we do not do that" (Interview 13). One of the reasons is that practitioners have not found the right medium to establish a collaborative dialogue with local authorities. Instead, practitioners pushed their own initiatives by their themselves.

In general terms, the infrastructural settings of bike lanes and their connectivity with the Horeca provide a logistical advantage for this type of means of transport to actually deliver a seamless service. However, standards related to size of cargo require further development in order to service a higher share of clients from the Horeca.

\subsection{E-trucks and Trucks Modality}

Although e-trucks have been the electric transport vehicle that has enjoyed a caroriented city design in the past, they suffer most from the innovations of the carregulated policies, compared to e-bikes and e-boats. This type of transport has been practiced by a larger number of food distribution companies and entrepreneurs (compared to e-boats and bikes). These alternatives use the roads infrastructure in Amsterdam, and this transport modality directly competes with conventional (diesel) trucks distributing food (see e-truck in Figure 21). Both etrucks and conventional ones operate in the last mile of food between the FCA and the Horeca sector. In providing such service, these initiatives are also capable to deliver an effective door-to-door service, as is the case with e-bikes. Standards of size, frequency, and timing demanded by the Horeca are in general satisfactory. 
Chapter 5. Emerging food distribution networks in the last mile, Amsterdam

In particular, size of cargo is the main advantage of this transport. The current challenge of this transport type is to further match distributing food in a city that is progressively regulating the access of cars to the city. Other challenges are that they need to share the limited space, not only with food distributors, but also with other logistical service providers.

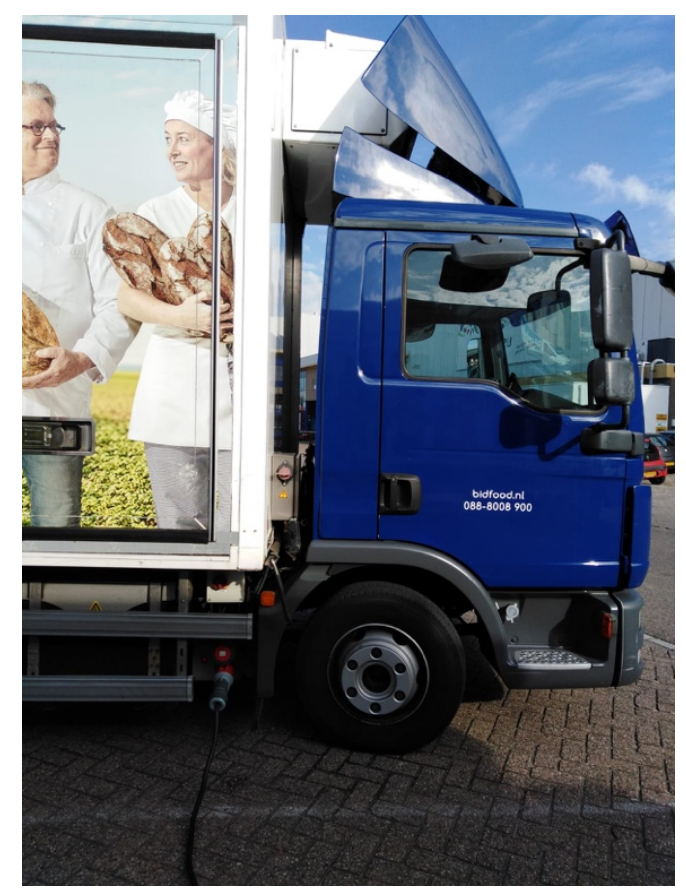

Figure 21: E-truck at the Food Centre Amsterdam

While moving with the food on e-trucks it becomes very clear how moving food from wholesale to the Horeca is not simply a matter of driving the vehicle from A to $B$. There are other factors that influence the time and ease of an efficient delivery. For example, effectively moving from A to B, depends on the distance of distribution from point $\mathrm{A}$ to $\mathrm{B}$, the amount of food to be delivered, the time of the day, the difficulty to access the addresses with the food trolleys, the receptor (availability and capacity), and the occupancy of the city infrastructure (by pedestrians, vehicles, loading \& unloading spots, etcetera). 
Chapter 5. Emerging food distribution networks in the last mile, Amsterdam

Starting the journey on October 16, 2018 at 6 AM, the first impression was that traffic in the city centre is already busy. Most of the vehicles on the streets, pedestrian paths, and public spaces observed, relate to logistical services in general, for instance, food distributors, post, public transport, cleaning services of the municipality, and waste collectors. The combination of these vehicles competes for the loading and losing infrastructures, as well as parking spaces and streets in general, around Amsterdam (Interview 11, and observations conducted on the road, 10-2018).

Moving food from A to B relates closely to energy and traffic congestions. First, 'finding the exact address of the costumer is a challenge (even though some drivers use GPS navigators)' (Interview 11, and personal communications with truck drivers), like finding the exact door for goods reception. Also, streets are closed off due to car-restrictions set by the city council making such delivery complex. Second, 'to find ideally a place to load and lose on the streets is a challenge' (Interview 11). Sometimes drivers just try to find a parking space to do these manoeuvres. Load \& unloading infrastructure is highly competed by different types of delivery companies. Other infrastructures, for instance public spaces or sidewalks, are also used by pedestrians, bikes, chairs and tables from restaurants, tourists, other cars and trucks, and so on (observations conducted on the road, 10-2018) (see illustrations in Figures 22, 23 and 24). Third, costumers (receptors) are not often ready to dispatch the reception of the food. It often happens that costumers are not punctual at the shop when deliveries are ready, or they are busy dispatching other deliveries, or simply the way to load food from trucks to the kitchens of the Horeca shops is full of obstacles that make the 
Chapter 5. Emerging food distribution networks in the last mile, Amsterdam

delivery to last longer (e.g. step stairs, small elevators for logistics, etc). The sum of these situations, already at $6 \mathrm{am}$, makes the distribution of food a not seamless and straightforward process. These factors translate into time of, not only food related vehicles, a myriad of logistical vehicles moving or being parked through the city, wherever is possible, contributing to traffic congestions and more emissions. As time progresses during the day, the city and its citizenry start to wake up and start to make use of the city infrastructures. Distributing food then becomes more challenging for food distributors, but also for drivers in general, cyclists, pedestrians, and for the city infrastructure itself. Food distributors drive, park, load, and lose through and around higher concentrations of vehicles, pedestrians and cyclists. This translates into more time consumed on visiting addresses to distribute food to.
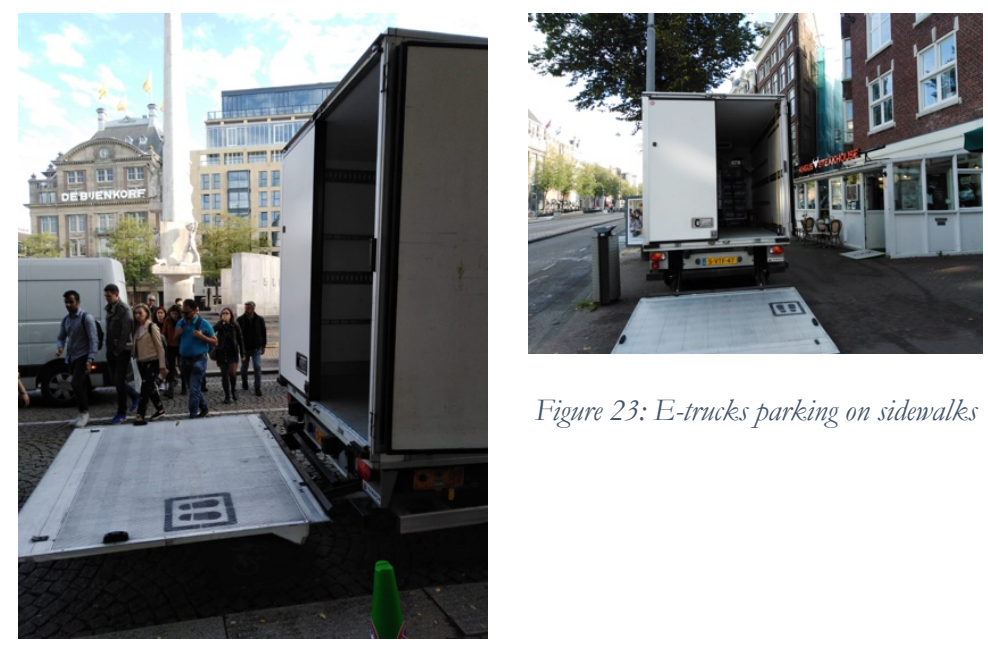

Figure 23: E-trucks parking on sidewalks

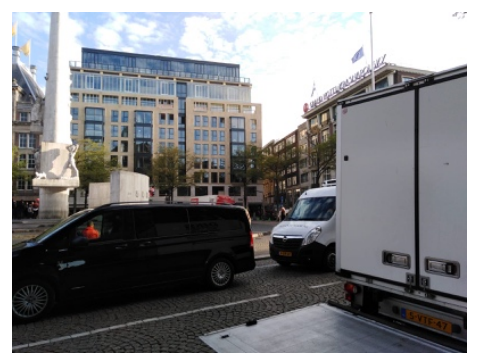

Figure 24: E-trucks competing for parking spots

Figure 22: E-trucks encountering pedestrians and sidewalks

Next to timing standards, frequency and size of food distribution by e-trucks are also standards to consider. E-trucks can often deliver cargo over 1000kg. And those can drive from 30 to $40 \mathrm{~km}$ a day per e-truck on (renewable) electricity. Such 
Chapter 5. Emerging food distribution networks in the last mile, Amsterdam

volume is considerably different from what e-bikes and e-carts can carry. Nevertheless, considering the timing and congestions implications of distributing food by this means of transport, frequency is also affected. For example, these evehicles must often make detours around the centre to find a point of entry to the costumers as many streets have been closed off to car-traffic due to new city regulations (Interview 11).

E-trucks are eligible to receive public financial incentives (e.g. via tax deductions for companies). Companies with familiarity/good experience with diesel trucks may experience reluctance to switch to e-trucks (personal communication with drivers). This puts a lock-in effect for further acquisitions. Companies with recently purchased diesel fleets may not be incentivised by the deductions that come with e-vehicle acquisitions. Companies with a modern fleet need to use the trucks for the rest of its lifespan to achieve profitable return-on-investment (Interview 11). This is due to the long lifespan of the diesel trucks. In this respect, the municipality of Amsterdam expects that $10-15 \%$ of the current diesel fleet of logistical companies can be replaced by e-options by 2022 (Gemeente Amsterdam, 2019a)

Although the main advantage of this transport is that cities are more-car oriented in general, the current restructuring of the city is affecting the playground for terrestrial food distribution. The vision of the Agenda Amsterdam Autoluw (Policy AAA 2019) is preparing the city centre towards a more walkable city. Interventions on intelligent mobility and intelligent timing and zoning (as suggested by AAA) are yet to be tested on whether they can provide a seamless transport network in a car-regulated city. 
Chapter 5. Emerging food distribution networks in the last mile, Amsterdam

\section{Conclusion}

This article has examined the current greening of the last mile mobility system in Amsterdam in the context of food and waste distribution between wholesaling and the Horeca, also in relation to energy and water usage. In doing so, we traced three alternative transport networks distributing food in the last mile: electric boats, electric and conventional bikes and electric vehicles, in relation to the actors, infrastructures and policies involved.

In particular, this article shows how these novel mobility options seek to anticipate the ongoing major infrastructural changes in Amsterdam and its new zoning plans. We identified key challenges encountered by the involved etransport entrepreneurs that are in need further attention and experimentation, of which in particular: the lack of connectivity between mobility infrastructure and modes of e-transport; the lack of appropriate policy planning; and mismatches between e-transport capacities and the Horeca sector's expectations.

In terms of the lack of connectivity between mobility infrastructure and modes of e-transport, there is still much to be gained in matching transport needs with water and terrestrial infrastructure. E-boats still struggle with inadequate docks and loading and unloading areas, making efficient delivery complex and expensive. Further efforts on reframing the urban mobility agenda need to consider the actual capacity of water as medium of transport and not only targeting the canals as an alternative medium of transport. Conversely, bike lanes infrastructures are generally better connected and can serve as an example to learn from to improve e-boat distribution networks. For example, bike infrastructure 
Chapter 5. Emerging food distribution networks in the last mile, Amsterdam

is better integrated with other mobile systems, such as being able to board ferries, or use car roads, to cross areas in Amsterdam.

In terms of lacking appropriate policy planning, there is exists a mismatch between what the Amsterdam city government is planning for and problems experienced by the e-transport practitioners on the ground. For example, in the domain of bike transport, Amsterdam is experiencing a dual expansion. On one hand, the city is expanding its bike lanes infrastructure. However, at the same time, the number of bikes is rapidly increasing as a result of more companies carrying out deliveries via this modality (e.g. post service, Deliveroo, UberFoods), which results in a continued crowded space that requires attention. Such capacity problems also relate to the transport mode of e-boats. Whilst on the one hand the city government is promoting canal usage for transport in its policies, this is not matched by infrastructural changes, whilst the number of boats using the canals continues to rise, also given its usage for tourist and leisure purposes. As such, e-transport infrastructures (being bikes, boats or cars) would benefit from further planning, timing and zoning to look after sustainability of logistics. To allow for such transformation to emerge, Amsterdam needs to provide further incentives to facilitate emergent alternatives of transport develop. So far, policy interventions are mostly perceived by alternative food distributors as top-down measures of infrastructural changes to which they are just expected to adapt. Alternative food distributors have not yet obtained an active role in the policy and decision-making of the current transformation of the city, and in doing so, helping to make these more effective. As mentioned in the cases cited, their efforts for cleaning up the last mile are positively welcome by the city government. Nevertheless, what is missing is an active channel of communication 
Chapter 5. Emerging food distribution networks in the last mile, Amsterdam

and further policy and decision-making process in which the city and food practitioners can engage in closer relations.

In terms of challenges and mismatches between available infrastructure and the Horeca sector's expectations, there is still much to be gained in better matching these expectations and in adjusting the Horeca's stocking system so that it could match with the smaller quantities of food being delivered through e-transport. For instance, e-bikes have shown to be a very effective way of transport of food to restaurants, as this sector requires a frequent and quick form of delivery. Yet, one of the many struggles of this transport relates to its cargo capacity not matching the needs of pubs and bars which need require heavier and larger deliveries. E-vehicles, however, are able to match these expectations and demands, and is as such the most up taken modality to distribute food in the last mile of Amsterdam. The used infrastructure is basically the same as used for conventional vehicles, which is already well developed in the city. However, as discussed, this form of distribution is also facing increasing hurdles, given the AAA policy scheme is currently rapidly changing the accessibility of cars into the city. Although electric vehicles might have a time window to still get into the city centre to distribute services such as food, this policy might imply a green light for alternative transport as boats and bikes to gain a higher share in the last mile. In this context, Amsterdam is yet to discover to what extent the ambitions for smart traffic and smart modal shifts might contribute and incentivise e-transport to provide seamless food services.

To end with some final policy recommendations, our study suggests that further efforts need to actively consider feedback from e-transport practitioners who experiment with the last mile in Amsterdam. This should not only involve voices 
Chapter 5. Emerging food distribution networks in the last mile, Amsterdam

and expectations from food practitioners, but also from members of the Horeca, and connect these to the ideas and plans developed by the city planners. This will help to exchange and align expectation around how the city should look like (as expected by the AAA policy) and how the city is needed to be for distributing food (or any other good) in a more sustainable fashion (as expected by the Horeca member and transport practitioners). Closing the feedback loop represents an opportunity for actually exploiting the potential of the three transports discussed in this paper. All in all, we conclude that a more sustainable last mile in Amsterdam requires a mobility agenda that looks beyond a car free city. It is about the wider supporting of urban infrastructure, including fuel shifts, alternative and cross-sectorial infrastructure provisioning, and improved socio-political exchange. 


\title{
Chapter 6. Conclusions: Conceptual Approaches
}

\author{
for the Making of the Nexus City
}

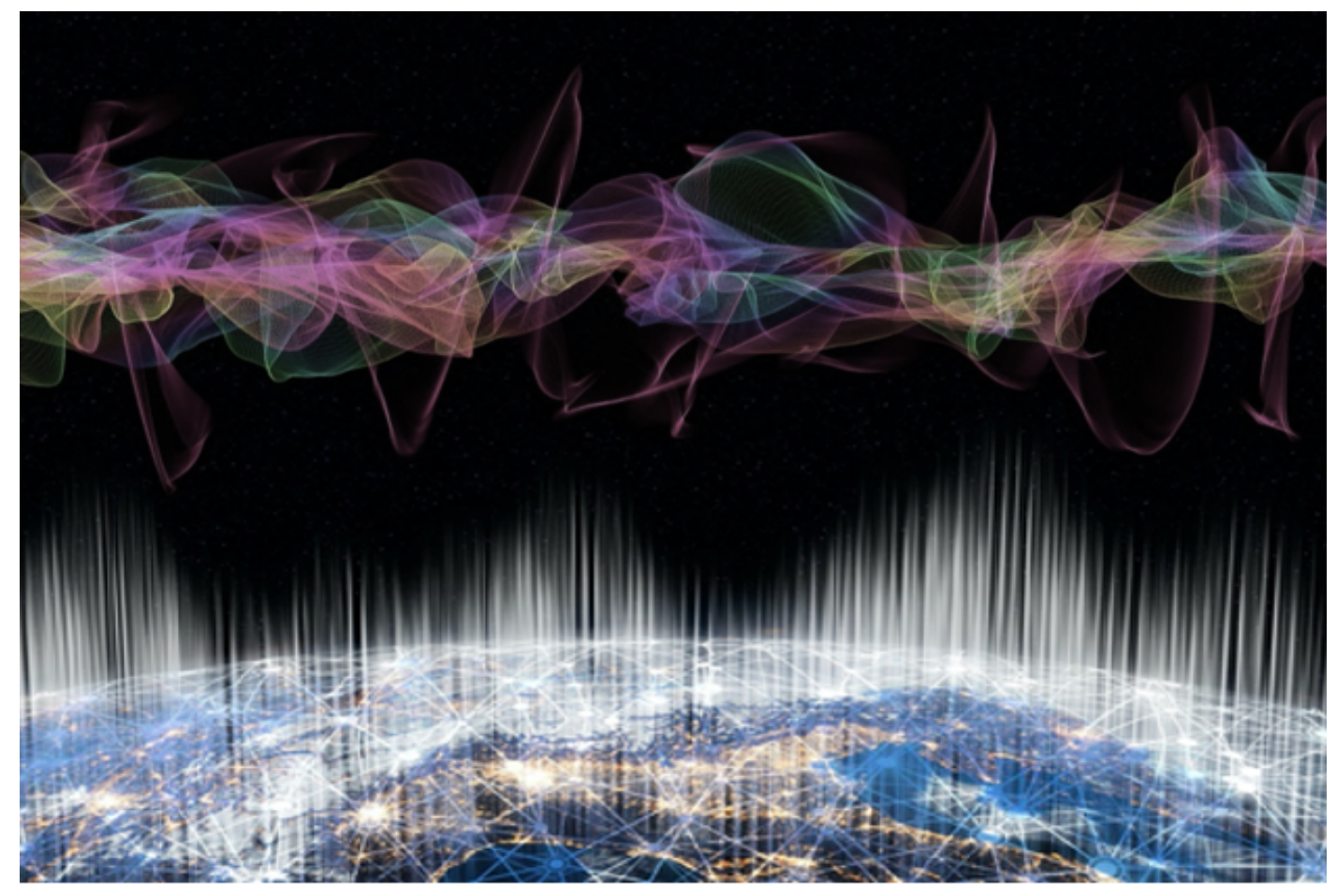

Image Source: https-pixabay.comillustrationsnetwork-earth-block-chain-globe-4894813 


\section{Introduction}

\subsection{Recapitulation}

In the quest to understand and analyse the urban nexus, this thesis drew on the networks and flows theory from Manuel Castells (Castells, 2009) to develop a conceptual lens to define, understand, and empirically study the urban nexus between water, energy and food (WEF). In particular, this conceptual lens was helpful to understand both resource systems as networks organising and delivering flows of WEF, and the role of key actors in reconnecting and re-coding the current resource flows into more sustainable outcomes. In this regard, this research primarily questioned:

1) what concepts can be used to unpack and trace the (un)sustainable connections between water, energy, and food networks and flows, 2) how do WEF networks organise and connect flows in cities, and 3) what are the identifiable steering points for sustainable urban governance to further address the connectivity, challenges and opportunities, of networks and flows of water, energy, and food.

In answering this, the objective of this research was to 1) formulate a conceptual framework which aims to unpack the connectivity of water, energy, and food networks and flows, than can 2) help to shed light on how empirical networks connect flows with a specific set of WEF connections, and 3) to provide specific concepts which help to unravel steering points for furthering sustainable urban governance. The preceding four chapters in this thesis provided insights into what WEF connectivity is from both a conceptual and empirical level, showing how WEF connectivity emerges in different contexts. This conclusion first provides a recapitulation of the main findings and contributions of this thesis. Thereafter, it 
introduces the main conclusion directions of this Ph.D. thesis. It concludes on the role of two groups of actors in the building up of the nexus interface (switchers \& programmers, and incumbents). It concludes further on the need of an interface in which all relevant actors can interact and work toward more nexus approaches. In examining the identifiable steering points for sustainable urban governance through the urban nexus, this research finds and concludes on two approaches as used by these actors to build upon a re-coding of food systems and for steering the governance of the urban nexus. These strategies are the search for 1) proximity food and the vision of 2) creating new social relations by experimenting in the city. A last set of conclusions remarks on the importance of cities as leverage points for global sustainability of resource flows. Cities, as leverage points for sustainability, need to allocate further efforts toward a more nexus city by refining (nexus) interfaces in a way that positions urban sustainability into a wider global context in more explicit ways.

\subsection{Summary: a conceptual vocabulary for resource connectivity governance}

This research contributes to the conceptualisation of the urban nexus by outlining a conceptual framework that helps to identify interconnections between different systems of provisioning of WEF. In doing so, it sheds light, along with the different chapters of this thesis, on what concepts can be used to unpack and trace the (un)sustainable connections between water, energy, and food networks and flows? It did so in Chapter 2, by analysing, in the first place, the interactions between the social and material flows shaping these connections. This research found that material-focused methodologies have already provided an essential building-block to understand resource interactions (Bazilian et al., 2011; Fischer-Kowalski, 1998; Wallsten, 2015). One of the initial and core contributions of this thesis was to build up a 
social flows analysis that pays attention to the socio-cultural meaning shaping WEF provisioning at the urban level. For example, this involves the social actors (switchers and programmers), governance networks, policies, and practices at play.

This research found two ways in which material and social flows of WEF can drive the 'nexus'. Chapter 2 elaborates, conceptually, on both drivers and illustrates them using examples of cross-sectorial WEF approaches in different European cities (Reykjavik, Bologna, Amsterdam, and Braunschweig). The first is where the material flows are the main driver in creating a WEF nexus, which was shown in the portfolio case of Reykjavik. In this example, material flows of hot water sourced from geothermal reservoirs were easily and naturally connect to electricity and heating flows feeding Reykjavik. In this specific nexus, connecting water with energy was primarily a matter of effective planning and provisioning to achieve cross-sectorial management of natural resources and natural conditions. The second way in which a nexus can emerge is a result of social interventions of actors in networks that have the capability to link, configure and steer the material flows of WEF in an integrated manner through collaboration, policy and decision-making, or other social flows. For example, in the portfolio cases of Bologna and Amsterdam. The case of Bologna portrays an example of a showcase project, designed from scratch, that integrates all the processes taken in a food supply system and its related water and energy inputs into one site. The Amsterdam case shows a more bottom-up project that involves entrepreneurs seeking opportunities and experimenting with innovative methods of food distribution to make urban management more efficient and sustainable. Both projects showed that interventions by social actors played the most important role in the making of such nexus projects. In doing so, an emergent 
constellation of actors from the WEF sectors worked on aligning and mobilising resources, visions, policies, and actors from different sectors.

In governing resource systems of provisioning, Chapter 3 of this Ph.D. thesis argued that structure, function, and power enacted through governance networks, shape the nexus of WEF into specific configurations and connections. By analysing a set of projects being developed in Amsterdam (nutrients and energy recovery from wastewater flows), this thesis showed how these start to reconfigure and reconnect WEF networks into more innovative and cross-sectorial formats. Switching and programming WEF into more desirable configurations can be enhanced by focusing on strategic points of connection between networks and flows. Such strategic points of connectivity are identified as switches. Switching WEF needs to align the different (either common or competing) structures, functions, and power dynamics between different networks.

This research found that switches often came in the shape of barriers, whilst others functioned as triggers for connecting WEF networks involved in the nexus. When switches were found in the form of barriers, these mainly related to compatibility of values and goals, competences, and organisational structures. For example, in the experimental project to recover nutrients and energy from wastewater flows in the city of Amsterdam, water and energy sectors shared values and goals related to the circularity of urban resources. However, the circularity of wastewater does not only represent a key source of energy and nutrients, but it also represents a source of harmful pathogens and residual hormones that can trigger diseases in humans. In this sense, the core value and goal for the water sector and the municipality is to provide safe water. This concern is reflected in the competing 
values safeguarding different priorities. Those values also pursue more resource circularity and sustainable development versus water safety for water users. In a similar vein, water safety regulation showed to exercise networked power by restricting connectivity between these two sectors before the experimental status was granted. Similarly, structures (bylaws and exclusive competences) of the energy and water companies compete with each other (e.g. excluding the water company from commercially distributing and producing energy). These are some of the core reasons why, in a non-experimental status, these two resource systems are separated in Amsterdam.

Switches in the form of trigger points came in the form of common values, goals, structures, power, and processes enhancing connectivity. Building on the example above, removing exclusivity of competences (structures) between water and energy networks allowed for experimenting with such a connection. A specific set of common values and goals were critical to steer these two networks to connect. For example, sustainable development of urban water and energy is a value that overlaps values and goals between the municipality, AEB, and Waternet. What these have in common is that these key actors envision an energyneutral city in which the water sector decarbonises its processes, and the energy sector shifts toward circular and renewable energy provision. Specifically, network-making power showed to be a leverage point to further strengthen the connectivity of WEF networks by breaking through silo-approaches. For example, AEB and Waternet (acting as switchers and programmers) worked together, through common values and goals, framing projects that look for more resource circularity approaches. Such common goals and the power those actors exercise, 
function as trigger points to switch two independent and exclusive sectors to work on a common nexus project.

In the quest to find out how water, energy, and food networks organise and connect flows from a sustainable provisioning point of view in cities, and to identify steering points for sustainable urban governance to further address the connectivity, challenges and opportunities, of networks and flows of water, energy, and food, this research contributed with two case studies. First in Chapter 4, this research analysed the case and concept of proximity food in Barcelona and how it is distributed through municipal food markets from the approach of their water and energy dimensions. This thesis argued that proximity food is a concept that can improve food sustainability. However, this thesis also found that the proximity concept is often taken for granted as a more sustainable alternative in the greening of food systems. What is needed is to observe, account for, and reflect upon what are to be considered the social and material dimensions of proximity when aiming for more sustainable food systems, as shown in this thesis. With this case study, the thesis argues that shortening physical distances between food processes does not necessarily mean more proximity. It is also about shortening social distances such as organisational practices and levels and intensity of interactions between relevant actors. Understanding the proximity of food is also about understanding its nexus with water and energy, and how proximate food itself is to relevant sources of water and energy.

Chapter 5 of this thesis contributed to understanding how the urban nexus emerges from a WEF experimental point of view and the new social relations such experimentation is bringing on board, taking the case of Amsterdam. It 
studied the experimental practices of food transport in the last mile within the context of Amsterdam's car-regulated policy. This research contributed to identifying three key challenges encountered by e-transport entrepreneurs in making food transport more sustainable. 1) The lack of connectivity between mobility infrastructure and modes of e-transport; 2) the lack of appropriate policy planning; and 3) mismatches between e-transport capacities and the Horeca sector's expectations. In conclusion, it argued for the need to actively consider feedback from e-transport practitioners who experiment with the last mile in Amsterdam in further policy and decision-making, and that a more sustainable last mile in Amsterdam requires a mobility agenda that looks beyond a car-free city. To further improve the last mile of food within the car-regulated context of Amsterdam, it is essential to allow for a wider transformation of urban infrastructure, including fuel shifts, alternative and cross-sectorial infrastructure provisioning, and improved socio-political exchange.

In general, this Ph.D. thesis has examined how the social organisation of WEF resource systems is changing from silo approaches of governance toward a more integrated set of systems of provisioning. In the making of such a change; switchers, programmers, and incumbent actors developed and used two approaches: 1) making a proximity food city and 2) the experimental city (as this conclusion will further elaborate). This Ph.D. thesis argues that WEF networks cross-connectivity from a more nexus manner comes along with a reorganisation of the governance actors of such resource systems. This study aimed at identifying and understanding examples of such cross-sectorial governance reorganisation as one way to inform and inspire further nexus research. 
The rest of this concluding chapter is structured as follows. Section 2 presents the concluding theoretical reflections. Thereafter, Section 3 provides concluding reflections on the methodology pursued in this research. Lastly, Section 4 provides insights for further research.

\section{Theoretical Reflections}

The theoretical reflections in this chapter make a step forward in unravelling some of the relevant building blocks for making the Urban Nexus. This concluding chapter proposes that in the quest of working towards an integrated form of sustainability governance of the Urban Nexus, societal actors reorganise and identify the relevant resource networks and flows and start developing a common and translatable interface to design and conduct nexus interventions across silos. What this means is the development of a group of nexus-makers across the three resource systems. The group of switchers and programmers work on the interface by bringing onboard different actors (including incumbent actors), values and interests, and by addressing both the social and material dimensions of the WEF nexus in the context of developing a more integrated form of policy and decisionmaking. This chapter concludes on two interfaces at work as used by these actors to build upon a re-coding of food systems and for steering the governance of the urban nexus. These are 1) Food proximity: learning from food short supply chains and practice, and 2) New social relations organising water, energy, and food: the open-code experimental city. This thesis concludes that urban sustainable development and the nexus of WEF either from a proximity or experimental city approach, needs to consider further efforts toward a more nexus city by refining 
(nexus) interfaces in a way that positions urban sustainability into a wider global context in more explicit ways.

\subsection{Unravelling the Making of the Urban Nexus}

Social organisation of resource systems has developed into more horizontal fashions in terms of their social organisation (see discussions in Mol \& Spaargaren, 2006). The introduction of this thesis highlighted that such development has facilitated the inclusion of different societal actors to participate in the provisioning of WEF systems (e.g. differentiation of resource provisioning as in the case of decentralised energy systems). Nexus thinking also brings forward new insights for horizontal ways of organising resource systems governance. In particular, governing the nexus brings on board 1) actors from the public, private, and community sectors in the domains of water, energy and food for switching and programming resources provisioning (as switchers and programmers); and 2) actors that translate and adopt changes in the organisation of resources systems (as incumbent actors). In translating nexus approaches, what is needed is a common interface of interaction which serves as a platform that connects different actors (and their interests) in converting common values and goals, from the conceptual level, down to the level of resource practices in the making of urban nexus projects. One example of an interface is the policy ambitions for greening food distribution in Barcelona. These ambitions need to be adopted by farmers producing food within the proximity of the city, but also farmers and sellers at the markets need to find the way to use less intermediaries when connecting food production to its access to consumers. In doing so, they need to reorganise their daily operations to connect local production with local access to food via municipal markets. 
This thesis introduced and summarised the main historical advancements of WEF resources in terms of their developments in security, safety, standardisation, and universal provisioning. One of the initial findings was that such advancements (including their different attempts to obtain a level of integration) have already benefited from a long history of technical and material development. Nevertheless, neither material nor technical advancements by themselves can improve the sustainability of resource systems without a fundamental reorganisation of the social dimension of urban resources provisioning (Isenhour et al., 2015; Mol \& Spaargaren, 2006a, 2006b). Understanding what this social dimension of flows entails, was one of the core contributions of this thesis. This is useful in further understanding the WEF urban nexus and in breaking down its silos, the social silo included. In breaking silos, this research gave answers to what the actors (e.g. who gets involved and how), resources, and flows are in connecting or disconnecting WEF systems into more integrated and sustainable configurations. Such a discussion on the social dimension contributed to the analyses of power dynamics exercised through and between WEF networks, by switchers and programmers, that either challenged the business-as-usual way of organising provisioning systems or prevented WEF systems from substantial change.

This thesis elaborated on the idea of breaking silos between urban resource systems as a way to embark into more integrated provisioning practices. In pushing this forward, urban actors (e.g. municipal authorities, water and energy companies, and food producers, distributor and merchants) are key when it comes to influencing how urban-environment relationships evolve and how urban flows are managed more sustainably and in a more integrated way (World 
Bank 2007). Policy and decision-makers, at the urban level, are actors that have the capabilities to influence environmental practices for developing a more integrated management system for local sustainability (B. Evans, 2005). Nevertheless, silo-thinking still places barriers when it comes to further developing the integration of urban policy and planning (World Bank, 2007). To break down the silos (see discussions in Chapter 1), urban nexus approaches require 'building up staff capacity to create an awareness of the need for policy integration and of how this can best be achieved.' (World Bank, 2007, p. 20). Nevertheless, procuring such staff to look after more systems integration is not a simple task. Often, the way things have always been done in providing WEF creates 'a "silo mentality" among the staff in the WEF sectors. The literature suggests that how things are always done might place barriers on further (WEF) policy integration (B. Evans, 2005). To break such silo-mentality, actors, in general, need to understand that the myriad of departments, branches, practitioners, and consumers from WEF sectors require to work hand in hand for making nexus solutions (B. Evans, 2005). In other words, further developing nexus practices requires even a more 'horizontal' approach, meaning that local officers and politicians (practitioners and consumers) look at issues from different perspectives rather than delegating them to specific sectors, where there are adequate structures that facilitate everyday exchange and cooperate between various departments' (B. Evans, 2005, p. 118).

In sum, this research proposes that in the quest of breaking silos, and in working towards an integrated form of sustainability governance of the Urban Nexus, societal actors reorganise and identify the relevant resource networks and flows and start developing a common and translatable interface to design and conduct 
nexus interventions across silos. What it means is the development of a group of nexus-makers across the three resource systems. This group of switchers and programmers work on the interface by bringing onboard different actors, values and interests, and by addressing both the social and material dimensions of the WEF nexus in the context of developing a more integrated form of policy and decision-making.

\subsection{The Role of Two Groups of Actors in the Building Up of the Nexus Interface: switchers \& programmers, and incumbents}

To understand how the urban nexus emerges in empirical practices and processes, this thesis has demonstrated the need to examine more than what happens on the surface of policy and decision-making. This subsection focuses on two specific groups of actors, both theoretical and empirical in nature, that play a central role in unpacking the (un)sustainable connections between water, energy, and food networks and flow. These are groups of network makers actors (switchers and programmers) on the one hand and incumbent actors on the other. This subsection will elaborate on the role of switchers and programmers, using their power of network-making, in building up such a nexus interface and how they engage incumbents in the interface. The interface here is understood in terms of platforms of communication, interaction, collaboration, and co-creation between WEF sectors. An effective interface making, requires to be sufficiently integrated by the two groups of actors: switchers and programmers as network makers (using the power of network-making) on the one hand, and incumbent actors.

Incumbents showed to be key actors in maintaining WEF systems and in executing nexus visionaries, values, goals, projects, among other approaches. For example, in this research incumbents were mainly food merchants at the markets, 
wholesalers, farmers, food distributors using innovative means of transport, the technical departments of water and energy companies, among others. In the context of the nexus, they stand out as actors that have two main advantages. 1) They have the know-how of provisioning the systems in the day to day practice (e.g. selling food in the market), and 2) they have reproduced the, historically developed, standardised and reliable resource systems that we as a society have attained through WEF historical developments. Building on these two advantages, incumbent actors have the background and expertise of local urban management through specific departments providing either WEF resource systems. A good example of the role of incumbents comes from the case of proximity food distribution in the food markets of Barcelona, in which merchants know their costumers, the different types of costumers, their purchasing preferences, and how much of proximity food costumers normally consume. Such knowledge and specific expertise is useful in responding to the manifold and specific challenges in providing cities with resources in the day to day (B. Evans, 2005). These two advantages of incumbents enable them to contribute to the nexus interface by findings the ways to execute nexus-making (by switchers and programmers) into practices. The incumbents also provide a second remarkable contribution to the nexus. They take over the tasks of shaping, translating, and adopting changes (via policies and decisions-made) in the reorganising (e.g. nexus projects) of resources systems (e.g. WEF).

Governing the nexus also requires the specific expertise of switchers and programmers. These actors have specific knowledge about the material, social, and environmental points of connectivity between urban WEF resource flows. This thesis came across three specific contributions by these actors in the making 
of the nexus and its interface. Switchers and programmers ${ }^{12}$ have 1) a higher level of information about the programs and codes of the network they emerge from and their points of connectivity. This means that, compared to incumbents, they do also have general knowledge about the day-to-day operations of WEF, but they also know the systems, the networks, the politics, overarching visionaries, and the policy and decision-making context around these resources. 2) By using such programs and codes, these actors, working hand to hand with incumbents, contribute in the building up of the nexus interface; and 3) in building up such interface they have the burden to create an interface of compatibility in which all type of actors can level up to it. Some good examples of these three contributions stand out from the cases of Barcelona and Amsterdam, as explained in Chapters 2 and 4 , and as further elaborated below.

These two different groups of actors 1) switchers and programmers, and 2) incumbents, are actors that need to work together in such a translation. They work together in the making and settling down of specific nexus interfaces, for example, urban flows experimentation. They do so from the abstract level of values, goals, policies, or any other socio-cultural aspect possible, into more tangible and prevailing practices. A good example of an interface in this regard is the one created by the municipal bodies in Amsterdam and the water and energy companies around the visions and goals for the circularity of urban resources. In this example, the municipality (together with AEB and Waternet) sets the experimentation settings for recovering energy and nutrients from wastewater. The step of translating such visionary views into actions of actually recovering

\footnotetext{
${ }^{12}$ Switchers and programmers in this research often related to municipal authorities, water and energy companies, food councils, and entrepreneurs.
} 
nutrients and energy is done by AEB and Waternet reorganising parts of their operations. To enable such nexus translation requires not only a nexus program (e.g. visionaries and goal-making) as this thesis argued in the preceding chapters. It also requires such a nexus interface. An important remark when making nexus interfaces is to think about how a nexus ambition would look in reality, what steps are needed to convert visions into practices, and what actors need to be involved. What did we learn in this respect from the case-studies in Barcelona and Amsterdam?

First, the case of Barcelona illustrates how food actors follow a specific and delineated program to attain more sustainable food distribution. The municipality of Barcelona (delivering a group of programmers), through its municipal food markets (one of the core incumbent actor to get involved in the process), can be regarded as the epicentre of re-programming food distribution which needs to be local and fresh. As switchers and programmers come and emerge from WEF governance networks, they have a higher level of information about the programs and codes of the network they emerge from and their points of connectivity, as compared to the incumbents. For example, the food council of Barcelona and municipal authorities know the energy flows in the city and the distances involved between food processes in the city and what those distances represent in terms of energy savings. They use that knowledge to frame a program and an interface that allows for more local food sourcing by reconnecting specific actors and flows in particular ways. In doing so, switchers and programmers push forward local farmers, wholesalers, and consumers (as incumbent actors) to switch into the commercialisation and distribution of proximity food. They do this by re-coding how food needs to be distributed in the city and who needs to be involved in the 
process. What is scripted in the proximity code is that food needs to be cleaner in terms of energy (according to food miles and distances) and food usage, but it also needs to be safer in terms of the food quality of its process of access and distribution. In other words, as the literature suggests, it is not just about the knowledge of administration of specific (WEF) domains, but it is also about allowing for expert knowledge (B. Evans, 2005) that can cross-understand and cross-connect the different WEF domains from a particular (visionary) perspective.

Second, from the portfolio of cases in Amsterdam (Chapter 2) we learned about the impact of higher levels of information on programs and codes from the side of switchers and programmers operating at the interfaces between silo's. In these examples, water and energy companies are switching together to better reconnect flows of energy and proteins contained in wastewater flows. In these examples, actors from WEF systems know the specifics of each system. Specifically, they know the restrictions between water and energy domains that prevent them from collaborating. Such knowledge of restrictions relates to the hazards of micropollutants contained in wastewater and the value of public health in preventing human diseases. In interfacing nexuses, switchers and programmers add value to the current ways of resource provisioning by reconnecting networks and flows (that were not connected and restricted from connecting) into (safer and controlled) configurations that look for alternative and more sustainable connections.

Third, also Chapter 5 provides a good example of creating an interface of compatibility in which all types of actors can level up and adopt the structures, 
values, and goals framed to co-shape WEF systems. Amsterdam placed a regulated car-mobility policy in the very heart of its city centre. This policy has a specific set of values and goals that aim to create a more walkable and carbonneutral city by regulating access to cars. In accepting and adopting such ambitions, wholesalers, and food distributors need to adapt their fleets, fuels, routes, and timings of deliveries to the Horeca sector. Working towards more nexus practices does not only end up in re-programming (from the policy and decision-making level) how urban infrastructure should look like. It is also about translating policies and decisions into practices. Creating an interface needs to consider in its design, to enable any type of actors, with a relevant stake, to be included in nexus projects. For example, greening the last mile requires entrepreneurs to come up with zero-emissions solutions for food transport that use water canals or bike lanes as infrastructure. Then, the actual task of accepting and adopting the remaking of resource systems, made by switchers and programmers, is partly done by the incumbent actors from each system.

To surmise, it is of crucial importance to consider that different groups of actors involved in WEF networks have different information on what the codes of each network are about, how they go together, and who are in the best position to make the connections by 'reprogramming' and switching in the context of organised governance and decision making processes at the urban interfaces. Switchers and programmers add value in the making of the nexus since these actors are experts on the codes of water, energy, and food. They know the content of the programs, making possible the functioning of networks. WEF systems have their own particular and unique code that unifies and gives identity to each of the networks, meaning they remain as WEF autonomous systems working on 
a specific task, the nexus. Nexus-makers add an extra layer of organisation, a common interface to actually allow for systems to exchange information and to cooperate with incumbents towards furthering nexuses practices. A nexus interface is then a bridge that allows actors to connect in a particular settings which in our case refer to both Barcelona and Amsterdam as experimental urban laboratories.

\subsection{Interfaces at Work: nexus tools and strategies as developed and used by key social actors}

The following two subsections provide examples of how WEF connectivity and programming is created by switchers and programmers and exercised by incumbent actors in the quest of creating nexus interfaces to re-organise resource governance. In examining the identifiable steering points for sustainable urban governance through the urban nexus, this research found two 'tools' or main strategies as used by actors to build upon a re-coding of food systems and for steering the governance of the urban nexus. These strategies are the search for 1) proximity food and the vision of 2) creating new social relations by experimenting in the city. These cases are used to illustrate these two main nexus tools, instruments or strategies as they are being exercised by the key (groups of) actors involved.

\section{Food proximity: learning from food short supply chains and practice}

This research identified the proximity concept as an approach designed by switchers and programmers in the quest for 1) strengthening food sustainability, and 2) building up the nexus interface of food with energy and water systems. When using the nexus as an element to consider in food proximity new dimensions, like optimisation for water and energy production and consumption, emerge when defining proximity. 
Pioneering cities around the world have started to address food as an essential puzzle of urban sustainability by means of, for example, developing urban food strategies (Renting \& Wiskerke, 2010). An essential characteristic of cities and their urban food strategies, is that cities and city-regions become key actors in promoting and developing food policies that facilitate new relations between the public, private, and community sectors (Renting \& Wiskerke, 2010). Proximity in the case of Barcelona was developed and used as a straightforward concept with clear boundaries of its interventions and expectations to develop on an urban food strategy. Proximity food approaches represent one of the building blocks to rearrange food for cities in a more sustainable and localised fashion (Renting \& Wiskerke, 2010). However, proximity also deserves to be taken cautiously. Proximity, as discussed in the scientific literature, is a concept that does not directly define sustainability per se; but is rather a conceptual approach to gain sustainability. The literature on this domain (Boström et al., 2015; Doernberg et al., 2016; Renting \& Wiskerke, 2010) provides a set of warnings and benefits when re-thinking food systems from a more proximity fashion, as explored further below.

Aligned to the literature on Shorth Food Supply Chains (SFSCs) cities, as in the case of Barcelona, can benefit by utilising proximity, as a guiding concept, to reorganise food between its places of production and its places of consumption (Doernberg et al., 2016; Renting \& Wiskerke, 2010). Moreover, proximity food is also well-known for helping to re-establish shorter interactions between producers and consumers (Renting \& Wiskerke, 2010), as this research also examined. This research witnessed some of the risks and benefits of proximity 
food, as highlighted in the literature. For example, since there is already a large number of food products traded globally, the re-creation of short food supply chains might create difficulties and environmental consequences compared to work with the global food chains that currently feed cities (Boström et al., 2015; Doernberg et al., 2016; Renting \& Wiskerke, 2010). Governing the local without properly looking at the global context (Givoni \& Banister, 2013) is perhaps one of the main downsides in the case of Barcelona from which other cities can learn. Givoni \& Banister (2013) would argue in this regard that, local policies often fail to consider the global fluid domain of, as in this case, proximity food in the context of global food markets dynamics. For example, in the case of food proximity in Barcelona, the main aim is to improve sustainability of food by enlarging the share of proximity food distributed within the city contours. Nevertheless, there is no clear target to greening the still important share of nonproximity food consumed in Barcelona. In this regard, governing the local without properly looking at the global might run the risk of green-washing food in the city by actually increasing the food carbon print of cities from a cross-scale perspective that also considers the global dimension of cities (see discussions in (Isenhour et al., 2015). On the other hand, literature also argues that reorganising local food production and consumption might benefit from reducing the environmental impacts of globalised food systems of production and consumption (Renting \& Wiskerke, 2010). In this context, the case of Barcelona shows to have a food system that already benefits from short supply chains connected with an extended network of municipal food markets and an important share of farmers producing local food. For example, food markets in Barcelona are the second most visited place by costumers for buying vegetables and fruits. The main fruit and vegetable producer is the Agricultural Park of the Low 
Llobregat which commercialises around $20-30 \%$ of its total production through direct sales via municipal food market, farmers markets, or shops; and the remaining $70-80 \%$ is commercialised through the wholesaler Mercabarna, as an intermediary.

Oosterveer (2005) discusses global food governance and argues that state-based solutions are not able to respond to the complex interactions placed between food practices organised in the space of flows at the global level and the practices organised in places of production at both global and local levels. Oosterveer's discussions relate to one of the main challenges affecting the proximity food supply in Barcelona. It happens very often that "proximity" food is traded in global food markets, due to the fact that local producers can find more attractive profits in global markets. But this also happens the other way around. Consumers in Barcelona can find more attractive prices when buying food that comes from all over the world, and also by any type of food distribution channel in the city. Renting \& Wiskerke (2010) suggest that a vast number of food systems in the world relate more to a hybrid food geography which combines elements from 1) the dominant and global agro-industrial paradigm of food supply, and 2) the integrated territorial paradigm of food (from which proximity derives) (Renting \& Wiskerke, 2010). In other words, food systems often organise and rely on a mix of both global and local food supply. However, what is missing is to provide further incentives to reconnect local food production and consumption by means of more affordable local food positioning and access to it. In this sense, proximity can be used as a leading concept to sensitise producers, consumers, distributors, and policy and decision-makers (in general, incumbents, switchers, and 
programmers) about the origin of food and its related distances to be provided from its places of production and distributed to its places of consumption.

In further framing SFSCs, this research suggests there is a need for considering not only the social and material dimensions of resource flows, but it is also needed to develop on a sustainability dimension per se. For example, reproducing proximity supply chains might run the risk that some consumers are already used to consume a certain type of non-local food. This can then run the risk of, for instance, food producers in the local starting to produce foods in high-demand in water-scarce regions or to produce high water consumption foods (or energyintensive foods). It may be the case that this particular example of foods can benefit more by importing these foods from regions in which water is more abundant. This relates to (Doernberg et al., 2016) discussions around ecologies of scales. They discuss that in some cases, small-scale farms need more energy or water per unit of food production compared to more industrialised or larger producers (Doernberg et al., 2016). In this vein, innovations around proximity and the nexus can benefit by considering not only the material and social characteristics of short supply chains, but also considering a more critical reflection on how sustainable proximity food really is (including its limitations).

The former sets of critiques discussed in this clause, among others, are context dependent. These might take place in some cities while in other cities they might not. With these pros and cons being said, proximity can then be considered as a guiding principle for further interventions in the quest for nexus building, not only for food but also extending its concept towards water and energy. Addressing the downsides of proximity might help to roll out the benefits of short 
supply chains through other upstream processes and systems. For example, an important lesson to harvest from the proximity concept and its practices is its general principle of 'thinking shorter supply chains'. This means shorter distances, but also shorter connections between the different actors involved in the operation of those chains (Doernberg et al., 2016; Renting \& Wiskerke, 2010). The proximity concept and its practices can be also extended to the energy and water systems. Proximity, along with the discussions in Renting \& Wiskerke (2010), could be defined as a common denominator for improving resource systems in general. Such a common denominator is one that has the intention to connect and create synergies between different public domains that are in one way or the other related to food...' (Renting \& Wiskerke, 2010, p. 1909). In this sense, food and water and energy systems can benefit by bringing consumption and production closer to each other both in the physical and social dimensions. Bringing WEF actors closer, socially and materially speaking, requires an intentionally well-designed interface of communication and collaboration between the different sectors. An interface that envisions proximity food as a concept that can help to bring together the different actors from the WEF system. At the interface, actors are looking for a common proximity coding of food, both in its production, consumption and distribution dimension, considering the nexus for all phases of the value chain. In the quest of such a proximity interface, actors need to look for a common ground in which the city's vision and the actual actors distributing food through markets can find their way in the day-to-day practice to actually commercialise food through short-circuits while consuming less energy and water. 


\section{New social relations organising water, energy, and food: the open-code experimental city}

Experimentation promises a way to challenge the business as usual manner of organising WEF resources in the city. Cities worldwide, as in the case of Amsterdam, increasingly engage into experimental practices. Experimental approaches have been discussed as drivers for emergent modes of sustainability governance at the urban space (J. Evans et al., 2016). In this regard, cities are spaces of experimentation (Karvonen \& Van Heur, 2014). One of the well-known approaches that cities take as spaces of experimentation is urban laboratories. Urban labs challenge the business as usual ways of governance and aim to foster new economic, environmental, socio-cultural, and political configurations in the city. Urban labs provide the space and time to design, implement, and learn from new ways of governing resource provisioning in cities (Karvonen \& Van Heur, 2014), as in the case of Amsterdam. The emergence of experimental practices and their accompanying modes of governance often come along with politics, interests and visions of what urban sustainable development is meant to gain in specific contexts (Karvonen \& Van Heur, 2014). Who is involved and how, and how the different social actors and urban assets get connected to each other are relevant questions in urban experiments. In this regard, for example, an important question to shed light on is: who connects to who in the making of a nexus interface and what are the ambitions to experimenting with WEF resource connectivity or proximity?

Experimenting with urban infrastructures is not a new practice in urban management or sustainable development. Cities have always been places of experimentation (Bulkeley \& Castán Broto, 2013a). Cities often develop 
experimental interventions to further develop the urban setting and the visionaries they want to obtain. In doing so, cities often envision urban experiments that seek to gain on ecology, resilience, climate change governance, and socio-technical transitions (see e.g. study of 100 cities in Bulkeley \& Castán Broto, 2013a; Karvonen et al., 2014). One of the primary objectives of designing and implementing urban experiments is to stimulate change in a particular place and set of circumstances. In this regard, the city has been discussed as the key scale for designing and conducting experimental knowledge. Designing and implementing urban experiments carry along with new modes of socio-material engagement, governance arrangements, and politics that challenge and innovate the conventional way of the urban setting and its management (Karvonen et al., 2014). Chapter 3 examined the nexus experiments in the case of Amsterdam and provided insights on how switchers and programmers, and incumbent actors, design a nexus interface that allows for WEF systems to re-connect in innovative ways.

This research also found the experimental city as an approach used by switchers and programmers to provoke new social relations in re-organising WEF governance networks. Whilst the proximity case showed a tool aimed and designed within more clear boundaries for its intervention, the concept of an experimental city instead is characterised as having less clear boundaries due to its openness (code) for experimentation. Switchers and programmers develop experimental frameworks to try to reconnect governance actors into configurations that can provide more resources integration. The premise of the experimental city is remaking the sustainable city by 'thinking out of the box' in creating and testing new social relations. What was missing, however, is a closer look into its social 
infrastructure. The main conclusion is that experimenting with the city and their visions for more sustainable urban futures are not straightforward and sustainable activities, as this segment discusses. Experimental approaches often relate to politics just like any other urban development strategy. This segment discusses the pros and warnings to consider when designing or implementing urban experiments and their interfaces, with the aim to trigger new social relations that can lead to more integrated and sustainable practices. Moreover, this subsection will argue that making the experimental interface implies creation of a platform that allows social actors to not only interact and collaborate, but also creation of an interface that allows for constant adaptation and learning through experimentation. Moreover, the making of such an experimental interface, relates to politics in the experimental city. Such politics responded to who is in and out in experimenting and designing urban experiments.

\section{Making the experimental interface}

Innovative and experimental policy and decision-making for urban sustainability requires finding and engaging the different actors with a stake in the city (e.g. practitioners, incumbents, and switchers and programmers). Engaging the different relevant actors, in experimenting with urban sustainable development, also needs to consider the different visions and practices of organising specific local urban needs. (Re)organising urban infrastructures goes hand to hand with building new social relations. For example, engaging local authorities, businesses, entrepreneurs, and utility companies in developing local pilot projects or experiments to test urban solutions (B. Evans, 2005). The two cases studied in Amsterdam provide examples of programs that open up the structures and functions (values and goals) of WEF networks to allow for new social relations 
in governing resource systems in ways that were not tried before. For example, AEB and Waternet connected wastewater flows through energy recovery processes to obtain renewable energy flows. This is the case of two systems that 'before their experimental' status, were separated because of issues related to overlapping and exclusivity competences. Nevertheless, they connected in a riskfree and temporal pilot project to experiment with an unusual and restricted connection. Identifying such restriction, or in other words, the switches between networks is one of the very first steps when looking for further interconnectivity between resource systems.

When envisioning and framing the interface of experimenting either for the new mobility agenda or resources circularity in Amsterdam, two dimensions become of crucial importance. These are 1) politics around who is involved in the process or not, and how; and 2) the designing of the experimental city method. These two dimensions are key when aiming to design an interface that allows for compatibility between WEF networks.

\section{Politics in the experimental city: who is in and out?}

Experimenting with urban provisioning systems opens the door for challenging the business as usual way of providing WEF in the city. However, such a process should not be seen as a simplistic and straightforward intervention. Urban experiments are shaped by politics just like any other urban development vision, intervention, or strategy (Bulkeley \& Castán Broto, 2013a; Karvonen et al., 2014). An important warning, in this regard, is to avoid overlooking the role of politics and power dynamics of re-designing urban WEF. The ultimate goal of urban experiments is to provide a framework of collaboration that can actually 1) 
balance politics and power to allow bringing on board actors from the different societal sectors and resource systems, and 2) align and represent their different interests (Karvonen et al., 2014). What the coding of an experimental city might help, is to encourage switchers and programmers, and incumbents to communicate and operate beyond silos, more seamlessly. The compatibility of codes in the nexus is then a complex matter of re-connecting and matching functions, structures, and power dynamics into a common and cross-connecting WEF interface.

The framework of a nexus interface, itself, plays a role in opening or blocking different actors (and their interests) and networks for further integration. A good example of this role is the policy framework of Amsterdam around its mobility system. The aim of the experiment is to have a less congested and carbon-free city centre. In doing so, the city shifts towards a regulated e-mobility system. To do so, the city opens an experimental space and time framework in which (food) transport has to adapt to the changing mobile infrastructure in its last mile. This experimental framework triggers distribution services to come up with innovative logistical solutions that further integrate WEF. Similarly, food distributors need to adapt to the regulated-mobility ambitions of the city for favouring a more walkable city. In this case, the city inserted a new, overarching code for a more walkable city that requires more decarbonised mobility. In other words, the city is experimenting in slow-mobility practices exercised by opening the last mile to new players re-connecting WEF systems.

In framing urban experimental agendas, cities often overlook a critical approach to who is framing urban experiments or who is left out from participating in 
framing experiments (Karvonen et al., 2014). This is one of the main downsides encountered in urban experimental literature, and Amsterdam is not an exception. For example, food distributors and wholesalers were left out when it comes to taking into consideration their interests and needs in re-connecting $\mathrm{A}$ to $\mathrm{B}$ in the last mile of food distribution. In this sense, an important step when framing and analysing urban experiments is to question, critically, who is the experiment designed for and who the experiments are servicing to (Karvonen et al., 2014). The Horeca sector and food distributors in Amsterdam (either e-bikes, evehicles, or e-boats), were not actively involved in the framing of the specific experimental design for the new mobility of the city. Instead, those were left with the only option to adapt to a changing infrastructure which was mostly led by municipal bodies in the quest of making a more walkable city. As discussed in Chapter 5, this situation created a lack of appropriate policy planning that translated into mismatches between what the Amsterdam city government is planning for, the problems experienced by the e-transport practitioners on the ground, and the Horeca's expectations. In this sense, practitioners were left with the only task of reorganising the mobility system by 1) shifting energy sources and fleets for food distribution, 2) re-pattering road and water infrastructures to favour zero-emissions transport, and 3) giving room to a more pedestrian-friendly city.

An experimental city, in the strict sense, is characterised as following a (strict) experimental methodology which aims to involve a set of actors and instruments (e.g. policies), to induce purposeful and controlled change (Bulkeley \& Castán Broto, 2013b; see discusssions in Castán Broto \& Bulkeley, 2013), and to measure change or findings from the experiment (see discussion in (Karvonen et al., 2014). 


\subsection{Cities as Leverage Points for Global Sustainability of Resource Flows}

One of the initial starting points of this thesis is that cities are crucial places to address sustainable development (David Satterthwaite, 1999; World Bank, 2007). In doing so, this thesis argues that urban managers and practitioners (switchers, programmers, and incumbents) are key actors steering key areas of sustainable urban governance to further address the connectivity of WEF networks and flows. In further attaining sustainable development, cities and their actors need to consider and address the existential dilemma of cities as origins and sources of unsustainability (Isenhour et al., 2015). This thesis argues in support of this literature that actors at the level of 'local governments' have an enormous influence on how urban-human-environment relationships evolve, and on how their cities interact with the hinterland and with the wider global community' (World Bank, 2007, p.21). The urban level of the nexus is an important and unique contour (in space and time) to address the interactions between WEF flows both at the urban level and beyond, at more upstream scales. So far, urban governance of WEF at the city level has not extensively been studied from a wider, global perspective. Also, in this research, local WEF governance has been discussed as a crucial building-block for resource organisation. By focusing primarily on proximity policies or experimental spaces at the urban level, we however do not want to deny the value of considering the urban and the global, urban governance as well as global governance. What matters is the continuum of (socio-material) flows on the move across urban and global scales, through resource networks (Givoni \& Banister, 2013). When framing Urban Nexus interventions and their sustainability ambitions, these need to go beyond exclusively considering the sustainability of urban WEF flows toward managing the global context of urban flows. 
Visionaries around greening the last mile, the proximity of urban food, or similar nexus-related interventions, often leave an important question unanswered. Are urban nexus interventions greening the city or greening the global? Learning from the cases studied in this research, the urban nexus (as a sustainable development tool) has not yet been able to expand its settings and scope to help addressing the sustainability of flows from a more global flows perspective. More work needs to be done in this respect, without losing sight on the centrality of the urban level. What could be strengthened is a global perspective that brings awareness to urban actors in the trade-offs and synergies of urban flows at the upstream-level processes and dynamics of provisioning. Failing to consider such awareness in urban strategies can run the risk of city-washing (see discussions in Isenhour et al., 2015). What this means, is to clean up emissions at the urban scale by sending them out of the city contours (or depending on imports out of the city) all the unwanted processes, nuisances, hazards, and the CO2 emissions involved in WEF provisioning to any other time-space level or location of the globe. For example, in the case of Amsterdam, the electricity load process powers zeroemissions food transport in the last mile of cities; most likely electricity generation or its raw materials come from an energy mix at the global scale. From this specific example, a more sustainable perspective of the greening of the food last mile could consider the cross-scale implications of sourcing urban electricity load from an energy mix. Another example is the large imports of high-emission or high-water consumption foods or industries by cities in the Global North (e.g. Barcelona) from countries in the Global South. The notion of scale as in many environmental debates is vital to considerations of how to reduce 1) emissions and 2) all the unwanted trade-offs when providing WEF resources (Givoni \& 
Banister, 2013). In conclusion, further efforts toward a nexus city will be better off by refining interfaces in a way that positions urban sustainability into a wider global context in more explicit ways.

\section{Methodological Reflections}

Providing answers on how the connectivity of WEF is organised in cities is a quest that deserves beyond theoretical or conceptual efforts. This section provides the main methodological reflections of this Ph.D. thesis. Subsection 3.1. provides with insights about the internal validity of this research, and 3.2. elaborates on external validity of this research.

Exploring connectivity was essential to understand the complete picture of the making of the WEF urban nexus. When studying flows on the move, mobilities literature (e.g. Urry, 2007) added value to theories and concepts around networks and flows. In doing so, it shed light on what the content of flows is about when moving between processes of provisioning between WEF networks. More specifically, it helped to unravel what the connectivity points: nodes, policies, discourses, values, or goals between WEF were, while moving through and tracing flows through networks.

Using mobilities methodologies enabled the researcher to conceptually map the social actors and networks of WEF systems, whilst identifying the actors that could play a role in facilitating or blocking connections between WEF networks. As a second step, the researcher followed flows by tracing their movement and by being mobile through the different provisioning processes of WEF networks. When 
moving around networks and flows, this opened the doors to reach the key actors and informants behind the provisioning of resource systems. This step helped to shed light on distinguishing the incumbents, and the switchers and programmers in WEF networks. Incumbents (experts) informed on the current nexus practices and on the current difficulties to attain more nexus practices. Switchers and programmers informed on the current nexus values and goals to strengthen urban sustainable development. For example, these actors were helpful to inform the research about the barriers, bottlenecks, tensions, or any kind of socio-cultural aspect contributing to either weaker or stronger nexus connectivity, both from a practice and policy and decision-making perspective. Such difficulties often fit into structural, functional, or power dynamics categories. Some of the main difficulties encountered through WEF networks related to; regulatory schemes around exclusivity rights, differences in goals while pursuing similar values toward sustainability, or the power of actors or standards making resistance toward social change. Moving with flows and being mobile through flows tools enabled the researcher to identify, trace, and understand what the social dynamics are (function, structure, and power dynamics interactions) between WEF systems, and their processes, in different nexus projects and interventions. Complementing the understanding of the nexus beyond the conceptual world, provided with insights capturing the day-to-day changing dynamics of social actors interacting in provisioning $\mathrm{WEF}$, and their interactions through emergent nexus practices.

Moving with and being mobile through flows allowed the researcher to 1) understand the social dimension of flows facilitating or discouraging WEF connectivity, and 2) zoom in and out, through the different scales and processes of resource provisioning. For example, in the case of Amsterdam, the researcher was mobile 
through the food distribution system by actually taking part during food distribution via three different e-transports. When navigating the canals of Amsterdam by e-boats, for example, the researcher experienced the daily difficulties that boats struggle with when trying to bring food and organic waste from wholesaling to the Horeca (e.g. insufficiency of docks, lack of loading and unloading areas, or congested waterways). By moving through networks, the researcher also benefited from experiencing the infrastructure advantages of, for instance, the existence of an extensive bike lanes system which enables food distribution, more seamlessly, in the last mile. Zooming-out the scope of this research opened up the study to understand resources interconnections on a city scale. For instance, in the case of Barcelona, the scale of analysis zoomed-out into the food system of a city to understand the concept of proximity food through all of its processes of provisioning. On the other hand, zooming into food dynamics within the city context is also an important scale and puzzle to understand food and its WEF nexus. Zooming in allowed the researcher to conduct micro-level analysis down to the last mile of food distribution in Amsterdam. This level of analysis brought the researcher to actually be involved in food distribution by being mobile with different and alternatives ways of bringing food from $\mathrm{A}$ to $\mathrm{B}$ in the last mile and by unravelling the meaning of such.

\subsection{Internal Validity}

Moving with and being mobile with WEF provided a good formula for triangulating data gathered from the methods used in this research. Moving and being mobile through flows, helped to employ a set of different methods in the study design. The methodologies employed enabled the researcher to move with experts from WEF systems across different scales and processes. In doing so, the 
research was not only able to be 'on the move' of flows, but being on the move was the enabler for the researcher to actually unravel the network of actors in governing networks and to interview them while moving through flows and networks, observing how WEF connectivity occurs. The combination and triangulation of such methods gave richness to this study by bringing more aligned stories of how connectivity WEF develops in different cities.

\subsection{External Validity.}

Analytically and theoretically speaking, the results of this thesis could be generalised to other cities in a similar context. This thesis provided two in-depth cases, but it also provided a portfolio of cases with analytical concepts and methodologies that were tested through different cities in Europe. The results from these cities, mainly refer to cities that share similar WEF social, political, and economic regimes. To name one example, free and global markets. These results also respond to the European reality of pioneering cities actively pursuing more sustainable development. The resultant patterns are more likely to be repeated in Northern and Mediterranean (medium-sized) cities that are working towards developing their own urban sustainable development agendas.

\section{Further Research in the Nexus Agenda}

To give a final thought to cities in the context of the nexus, this research suggests looking further into the different scales of governance of urban flows. Considering a broader perspective of scales may help to understand the global nature of resources and the consequences of resource flows not only at the urban scale, where resources are consumed the most. Also, it might help to understand 
how urban resources have consequences on a global scale. Such a global scale is often the place where resources are produced, organised, and governed. Space and time in the urban and in the global may place uneven spatial and temporal consequences, but also opportunities, in the making of sustainable cities. Further understanding and matching of such uneven spatial and temporal dimensions between the local and the global would help to improve sustainability for global cities in modernity. Further research needs to understand, in-depth, the dynamics between the city, the regional, national, and ultimately the global scales (and their related processes and interfaceable actors) in the making of the nexus. Such an approach can be applied to the study of one particular food product (e.g. salmon, tomatoes, or oranges). This means, not exhaustively, movement and mobility to trace a particular food product and its networks dynamics through its provisioning in local markets to upstream dynamics at the regional and global scales. This would help to understand global and local implications of resource provisioning, through exploration of a particular food product. In a similar vein, the local-global widening can also be applied to identify the ideal scope of a nexus interface for specific urban contexts. In other words, research needs to study what the relevant actors, values, and goals are at (and from) the regional, national, and global levels for developing the urban. Or, what the contours or limits of an urban nexus interface are. While this research provided an overview of what pioneering and European cities are doing, in terms of city nexus practices, further research could include nexus practices in developing cities, beyond Europe (including relations between cities and regions in the Global North and South). Whilst this research mainly focused on switchers and programmers because of their key role in connecting and configuring networks, further research could focus instead, on 
Chapter 6. Conclusions

the role and practices of incumbent actors in translating and taking up emerging nexus projects. 


\section{References}

Adey, P. (2006). If Mobility is Everything Then it is Nothing: Towards a Relational Politics of (Im)mobilities. Mobilities, 1(1), 75-94. https://doi.org/10.1080/17450100500489080 AEB Amsterdam. (2014, June 18). Duurzaamheidsdag. Agnoletti, M., \& Serneri, S. N. (2014). The Basic Environmental History (Vol. 4). Springer.

Ajuntament de Barcelona. (2013). Alimentar la Ciutat. El Proveïment de Barcelona del Segle xiii al Segle $x x$. http://ajuntament.barcelona.cat/mercats/sites/default/ files/CastAlimentar\%20la\%20ciutat_cast-2013.pdf Ajuntament de Barcelona. (2014). Pla Estrategic Mercats de Barcelona 2015/ 2025. Ajuntament de Barcelona. (2018, January 22). History of the Markets: Mercats de Barcelona. http://ajuntament.barcelona.cat/mercats/en/canal/historia-delsmercats

Allouche, J., Middleton, C., \& Gyawali, D. (2015). Technical Veil, Hidden Politics: Interrogating the Power Linkages behind the Nexus. Water Alternatives, $8(1)$, 610-626.

Amsterdam Smart City. (n.d.). Amsterdam Smart City. Amsterdam Smart City. Retrieved 20 June 2017, from https:/ / amsterdamsmartcity.com/ Amsterdam Smart City. (2015, October 19). Last Mile Logistics: Foodlogica. Amsterdam Smart City.

http://amsterdamsmartcity.com/projects/detail/id/116/slug/last-milelogistics-foodlogica?lang $=\mathrm{nl}$ 
Anderies, J., Janssen, M., \& Ostrom, E. (2004). A Framework to Analyze the Robustness of Social-ecological Systems from an Institutional Perspective. Ecology and Society, 9(1). https://doi.org/10.5751/ES-00610-090118 Appadurai, A. (1996). Modernity at Large: Cultural Dimensions of Globalization. University of Mineapolis Press. Appadurai, A. (2001). Globalization. Duke University Press. Artioli, F., Acuto, M., \& McArthur, J. (2017). The Water-Energy-Food Nexus: An Integration Agenda and Implications for Urban Governance. Political Geography, 61, 215-223. https://doi.org/10.1016/j.polgeo.2017.08.009 Arts, B., \& Tatenhove, J. V. (2004). Policy and Power: A Conceptual Framework Between the 'Old' and 'New' Policy Idioms. Policy Sciences, 37(3), 339-356. https://doi.org/10.1007/s11077-005-0156-9

Barber, B. R. (2013). If Mayors Ruled the World. Yale University Press; JSTOR. www.jstor.org/stable/j.ctt5vksfr Bazilian, M., Rogner, H., Howells, M., Hermann, S., Arent, D., Gielen, D., Steduto, P., Mueller, A., Komor, P., Tol, R. S. J., \& Yumkella, K. K. (2011). Considering the Energy, Water and Food Nexus: Towards an Integrated Modelling Approach. Energy Policy, 39(12), 7896-7906. https://doi.org/10.1016/j.enpol.2011.09.039 Beck, M. B., \& Villarroel Walker, R. (2013). Nexus Security: Governance, Innovation and the Resilient City. Frontiers of Environmental Science \& Engineering, 7(5), 640-657. https://doi.org/10.1007/s11783-013-0549-5

Bhaduri, A., Ringler, C., Dombrowski, I., Mohtar, R., \& Scheumann, W. (2015). Sustainability in the Water-Energy-Food Nexus. Water International, 40(5-6), 723-732. https://doi.org/10.1080/02508060.2015.1096110 
Biggs, E. M., Bruce, E., Boruff, B., Duncan, J. M. A., Horsley, J., Pauli, N., McNeill, K., Neef, A., Van Ogtrop, F., Curnow, J., Haworth, B., Duce, S., \& Imanari, Y. (2015). Sustainable Development and the Water-Energy-Food Nexus: A Perspective on Livelihoods. Environmental Science \& Policy, 54, 389-397. https://doi.org/10.1016/j.envsci.2015.08.002 Binder, C. R. (2007a). From Material Flow Analysis to Material Flow Management Part I: Social Sciences Modeling Approaches Coupled to MFA. Journal of Cleaner Production, 15(17), 1596-1604. https://doi.org/10.1016/j.jclepro.2006.08.006 Binder, C. R. (2007b). From Material Flow Analysis to Material Flow Management Part II: The Role of Structural Agent Analysis. Journal of Cleaner Production, 15(17), 1605-1617. https://doi.org/10.1016/j.jclepro.2006.08.017 Binder, C. R., Hinkel, J., Bots, P. W. G., \& Pahl-Wostl, C. (2013). Comparison of Frameworks for Analyzing Social-ecological Systems. Ecology and Society, 18(4). http://www.jstor.org/stable/26269404

Bizikova, L., Roy, D., Swanson, D., Venema, D., \& McCandless, M. (2013). The Water-Energy-Food Security Nexus: Towards A Practical Planning and Decision Support Framework for Landscape Investment and Risk Management. http://www.iisd.org/pdf/2013/wef_nexus_2013.pdf Bloemhof, J. M., van der Vorst, J. G. A. J., Bastl, M., \& Allaoui, H. (2015). Sustainability Assessment of Food Chain Logistics. International Journal of Logistics Research and Applications, 18(2), 101-117. https://doi.org/10.1080/13675567.2015.1015508

Boas, I. (2019). Using Mobile Methods to Trace Networks and Connections: Environmental Migration in the Digital Age. 'SAGE Research Methods Cases Politics \& International Relations'. K. Figiel (eds). 
Boas, I., Biermann, F., \& Kanie, N. (2016). Cross-Sectoral Strategies in Global Sustainability Governance: Towards a Nexus Approach. International Environmental Agreements: Politics, Law and Economics, 16(3), 449-464. https://doi.org/10.1007/s10784-016-9321-1 Boas, I., Kloppenburg, S., van Leeuwen, J., \& Lamers, M. (2018). Environmental Mobilities: An Alternative Lens to Global Environmental Governance. Global Environmental Politics, 18(4), 107-126. WorldCat.org. https://doi.org/10.1162/glep_a_00482

Bogner, A., Littig, B., \& Menz, W. (Eds.). (2009). Interviewing Experts. Palgrave Macmillan UK. http://link.springer.com/10.1057/9780230244276 Born, B., \& Purcell, M. (2006). Avoiding the Local Trap: Scale and Food Systems in Planning Research. Journal of Planning Education and Research, 26(2), 195-207.

Boström, M., Jönsson, A. M., Lockie, S., Mol, A. P. J., \& Oosterveer, P. J. M. (2015). Sustainable and Responsible Supply Chain Governance: Challenges and Opportunities. Journal of Cleaner Production, 107, 1-7. https://doi.org/10.1016/j.jclepro.2014.11.050 Bouteligier, S. (2013). Cities, Networks, and Global Environmental Governance: Spaces of Innovation, Places of Leadership (Wageningen UR Library). Routledge.

Brand, C., Bricas, N., Conaré, D., Daviron, B., Debru, J., Michel, L., \& Soulard, C.-T. (2019). Designing Urban Food Policies: Concepts and Approaches. Springer Nature.

Bulkeley, H., \& Castán Broto, V. (2013a). Government by Experiment? Global Cities and the Governing of Climate Change. Transactions of the Institute of British Geographers, 38(3), 361-375. https://doi.org/10.1111/j.1475-5661.2012.00535.x 
Bulkeley, H., \& Castán Broto, V. (2013b). Government by Experiment? Global Cities and the Governing of Climate Change. Transactions of the Institute of British Geographers, 38. https://doi.org/10.1111/j.1475-5661.2012.00535.x

Büscher, M., \& Urry, J. (2009). Mobile Methods and the Empirical. European Journal of Social Theory, 12(1), 99-116.

https://doi.org/10.1177/1368431008099642

Bush, S. R., Oosterveer, P. J. M., Bailey, M., \& Mol, A. P. J. (2015).

Sustainability Governance of Chains and Networks: A Review and Future

Outlook. Journal of Cleaner Production, 107, 8-19.

https://doi.org/10.1016/j.jclepro.2014.10.019

C40 Cities. (2011, October 11). C40: The World's Largest Geothermal Heating System Saves up to 4M Tons CO2 Annually. C40. http://www.c40.org/case_studies/theworlds-largest-geothermal-heating-system-saves-up-to-4m-tons-co2-annually CAAB. (n.a.). Centro Agro Alimentare Bologna Scpa. Eataly World F.I.Co. Project... In Bologna, Italy. http:/ /www.caab.it/wp-content/uploads/Brochure-FICo.pdf Cairns, R., \& Krzywoszynska, A. (2016). Anatomy of a Buzzword: The Emergence of 'The Water-Energy-Food Nexus' in UK Natural Resource Debates. Environmental Science \& Policy, 64, 164-170. https://doi.org/10.1016/j.envsci.2016.07.007 Castán Broto, V., \& Bulkeley, H. (2013). Maintaining Climate Change Experiments: Urban Political Ecology and the Everyday Reconfiguration of Urban Infrastructure. International Journal of Urban and Regional Research, 37(6), 1934-1948. https://doi.org/10.1111/1468-2427.12050

Castells, M. (2009). Communication Power. Oxford University Press. Castells, M. (2010). The Rise of the Network Society (2nd ed., with a new pref). Wiley-Blackwell. 
Chan, A. (2015). Connecting Cities and their Environments: Harnessing the Water-Energy-Food Nexus for Sustainable Urban Development. Change and Adaptation in Socio-Ecological Systems, 2(1). https:// doi.org/10.1515/cass-20150017

Chen, S., \& Chen, B. (2016). Urban Energy-Water Nexus: A Network Perspective. Applied Energy. https://doi.org/10.1016/j.apenergy.2016.03.042 Childers, D., Cadenasso, M., Grove, J., Marshall, V., McGrath, B., \& Pickett, S. (2015). An Ecology for Cities: A Transformational Nexus of Design and Ecology to Advance Climate Change Resilience and Urban Sustainability. Sustainability, 7(4), 3774-3791. https://doi.org/10.3390/su7043774 Chirisa, I., \& Bandauko, E. (2015). African Cities and the Water-Food-ClimateEnergy Nexus: An Agenda for Sustainability and Resilience at a Local Level. Urban Forum, 26(4), 391-404. https://doi.org/10.1007/s12132-015-9256-6 Cidell, J. (2012). Flows and Pauses in the Urban Logistics Landscape: The Municipal Regulation of Shipping Container Mobilities. Mobilities, 7(2), 233-245. https://doi.org/10.1080/17450101.2012.654995

Circle Economy, TNO, \& Gemeente Amsterdam. (2016). Circular-Amsterdam a Vision and Action Agenda for the City and Metropolitan Area. http://www.circleeconomy.com/wp-content/uploads/2016/04/Circular-Amsterdam-EN-small210316.pdf

City of Bologna. (2016, October 18). City of Food is Bologna. http://www.cityoffood.it/en/about-us/ CityZen Smart City. (2017, February 21). Neighbourbood Bio Refinery: Producing Nutrients and Heat from W aste. City-Zen. http:/ / www.cityzensmartcity.eu/neighbourhood-bio-refinery-producing-nutrients-and-heat-fromwaste/ 
Costa, N., Mackay, M., Perez, O., Navarro, G., Partridge, A., Portinaro, A., \& Scheffler, N. (2015). Urban Markets: Heart, Soul and Motor of Cities. https://urbact.eu/sites/default/files/urbact_markets_handbook_250315.pdf Covarrubias, M. (2018). The Nexus Between Water, Energy and Food in Cities: Towards Conceptualizing Socio-Material Interconnections. Sustainability Science. https://doi.org/10.1007/s11625-018-0591-0

Covarrubias, M., Spaargaren, G., \& Boas, I. (2019). Network Governance and the Urban Nexus of Water, Energy, and Food: Lessons from Amsterdam. Energy, Sustainability and Society, 9(1), 14. https://doi.org/10.1186/s13705-0190196-1

Cresswell, T. (2006). On the Move: Mobility in the Modern Western World. Routledge. Crow-Miller, B., Webber, M., \& Molle, F. (2017). The (Re) Turn to Infrastructure for Water Management?

Czarniawska, B. (2014). Social science research: From field to desk. Sage.

Daher, B. T., \& Mohtar, R. H. (2015). Water-Energy-Food (WEF) Nexus Tool 2.0: Guiding Integrative Resource Planning and Decision-Making. Water International, 40(5-6), 748-771.

https://doi.org/10.1080/02508060.2015.1074148

DELVA Landscape Architects. (2014). Transitioning Amsterdam to a Circular City: Circular Buiksloterbam.

https://buiksloterham.nl/engine/download/blob/gebiedsplatform/69870/201 5/28/CircularBuiksloterham_ENG_FullReport_05_03_2015.pdf?app=gebieds platform\&class $=9096 \&$ id $=63 \&$ field $=69870$

DELVA Landscape Architects. (2016). Circular Cities. Designing Post-Industrial Amsterdam: The Case of Buiksloterham. 
Departament d'Estadísitca de la ciutat de Barcelona. (2018, January 22). Anuario Estadístico de la Ciudad de Barcelona 2017 [Data set] [Data set]. In Estadistica. http://www.bcn.cat/estadistica/castella/dades/anuari/index.htm Department of Physical Planning of Amsterdam. (2013). PLAN Amsterdam. Diputació Barcelona. (n.d.). Geografía Física-Parc Agrari. Retrieved 18 October 2018, from https://parcs.diba.cat/es/web/baixllobregat/geografia-fisica Doernberg, A., Zasada, I., Bruszewska, K., Skoczowski, B., \& Piorr, A. (2016). Potentials and Limitations of Regional Organic Food Supply: A Qualitative Analysis of Two Food Chain Types in the Berlin Metropolitan Region. Sustainability, 8(11), 1125. https://doi.org/10.3390/su8111125

Dubbeling, M. (2013). Cityfood: Linking Cities on Urban Agriculture and Urban Food Systems (p. 8).

EIP-SCC. (2013). European Innovation Partnership on Smart Cities and CommunitiesStrategic Implementation Plan. https://smartcities.at/assets/Uploads/sip-finalen.pdf

Endo, A., Tsurita, I., Burnett, K., \& Orencio, P. M. (2015). A Review of the Current State of Research on the Water, Energy, and Food Nexus. Journal of Hydrology: Regional Studies. https://doi.org/10.1016/j.ejrh.2015.11.010 European Commission (Ed.). (2011). Cities of Tomorrow: Challenges, Visions, Ways Forward (Oct. 2011). Publ. Office of the European Office.

Evans, B. (Ed.). (2005). Governing Sustainable Cities. Earthscan. Evans, J., Karvonen, A., \& Raven, R. (2016). The Experimental City: New Modes and Prospects of Urban Transformation. 10.

Fan, J.-L., Kong, L.-S., Wang, H., \& Zhang, X. (2019). A water-Energy Nexus Review from the Perspective of Urban Metabolism. Ecological Modelling, 392, 128-136. https://doi.org/10.1016/j.ecolmodel.2018.11.019 
FAO. (2017). Quality control of wastewater for irrigated crop production. FAO http://www.fao.org/docrep/w5367e/w5367e04.htm FAO. (2018). The Role of Cities in the Transformation of Food Systems: Sharing Lessons from Milan Pact Cities. http://www.fao.org/3/ca0912en/CA0912EN.pdf Faulconbridge, J., \& Hui, A. (2016). Traces of a Mobile Field: Ten Years of Mobilities Research. Mobilities, 11(1), 1-14.

FICO Eataly. (2015, October 26). FICO Eataly World Progetto Italia Sviluppo Immobiliare. Daily Real Estate S.R.L. http://www.ilqi.it/ebook/2 Fischer-Kowalski, M. (1998). Society's Metabolism. Journal of Industrial Ecology, 2(1), 61-78. https://doi.org/10.1162/jiec.1998.2.1.61 Foodlogica. (2015, October 19). Foodlogica: Duurzame Logistiek voor Lokale Merken en Horeca. http:/ / foodlogica.com/

Foran, T. (2015). Node and Regime: Interdisciplinary Analysis of Water-EnergyFood Nexus in the Mekong Region. Water Alternatives, 8(1). http://search.proquest.com/openview/a23c4e50ba1d4ebdee9f6cf5153612e8/1 ?pq-origsite $=$ gscholar Forster, T., Egal, F., Renting, H., \& Dubbeling, M. (2015). Milan Urban Food Policy Pact: Selected Good Practices from Cities. 125.

Fredriksson, A., \& Liljestrand, K. (2015). Capturing Food Logistics: A Literature Review and Research Agenda. International Journal of Logistics Research and Applications, 18(1), 16-34. https://doi.org/10.1080/13675567.2014.944887 Gain, A. K., Giupponi, C., \& Benson, D. (2015). The Water-Energy-Food (WEF) Security Nexus: The Policy Perspective of Bangladesh. Water International, 40(5-6), 895-910. https://doi.org/10.1080/02508060.2015.1087616 
Gemeente Amsterdam. (2016, March 29). A Green Metropole: Amsterdam Definitely Sustainable.

https://www.amsterdam.nl/publish/pages/502029/a_green_metropole_def.pd $\mathrm{f}$

Gemeente Amsterdam. (2009). Amsterdam in 2020. Sustainable Opportunities, Sustainable Future.

Gemeente Amsterdam. (2016, April 4). Economically Strong and Sustainable Structural Vision: Amsterdam 2040.

https://www.amsterdam.nl/publish/pages/419019/plan-01-2011-eng.pdf Gemeente Amsterdam. (2015). Sustainable Amsterdam: Agenda for Renewable Energy, Clear Air, a Circular Economy and a Climate-Resilient City.

Gemeente Amsterdam. (2016a, March 29). Food: I Amsterdam. http://www.iamsterdam.com/en/business/invest/your-industry/food Gemeente Amsterdam. (2016b). Watervisie Amsterdam 2040. https://issuu.com/gemeenteamsterdam/docs/watervisie_amsterdam_2040 Gemeente Amsterdam. (2016c, March 29). Plan Amsterdam. The Electric City. file:///Users/enp/Downloads/Plan\%2520Amsterdam\%2520The\%2520Electri c\%2520City-1.pdf

Gemeente Amsterdam. (2019a). Amsterdam Maakt Ruimte: Agenda Amsterdam Autoluw.

Gemeente Amsterdam. (2019b, November 13). Amsterdam's Cycling History | I amsterdam. https://www.iamsterdam.com/en/plan-your-trip/gettingaround/cycling/amsterdam-cycling-history Giezen, M. (2016). Sustainable Cities: Addressing the Challenges of Tomorrow. DisP - The Planning Review, 52(1), 92-93. https://doi.org/10.1080/02513625.2016.1171054 
Givoni, M., \& Banister, D. (Eds.). (2013). Moving Towards Low Carbon Mobility. Edward Elgar Publishing. https://EconPapers.repec.org/RePEc:elg:eebook:15004 Graham, S., \& Marvin, S. (2001). Splintering Urbanism: Networked Infrastructures, Technological Mobilities and the Urban Condition. Routledge.

Gregson, N. (2017). Logistics at Work: Trucks, Containers and the Friction of Circulation in the UK. Mobilities, 12(3), 343-364. https://doi.org/10.1080/17450101.2015.1087680

Guta, D. D., Jara, J., Adhikari, N. P., Chen, Q., Gaur, V., \& Mirzabaev, A. (2017). Assessment of the Successes and Failures of Decentralized Energy Solutions and Implications for the Water-Energy-Food Security Nexus: Case Studies from Developing Countries. Resources, 6(3), 24.

Guy, S., Marvin, S., Medd, W., \& Moss, T. (2011). Shaping Urban Infrastructures: Intermediaries and the Governance of Socio-technical Networks. Earthscan.

Halbe, J., Pahl-Wostl, C., Lange, M. A., \& Velonis, C. (2015). Governance of Transitions Towards Sustainable Development: The Water-Energy-Food Nexus in Cyprus. Water International, 40(5-6), 877-894.

https://doi.org/10.1080/02508060.2015.1070328

Harvey, M. (2014). The Food-Energy-Climate Change Trilemma: Toward a Socio-Economic Analysis. Theory, Culture \& Society, 31(5), 155-182. https://doi.org/10.1177/0263276414537317

Haysom, G. (2015). Food and the City: Urban Scale Food System Governance. Urban Forum, 26(3), 263-281. https://doi.org/10.1007/s12132-015-9255-7

Heard, B. R., Miller, S. A., Liang, S., \& Xu, M. (2017). Emerging Challenges and Opportunities for the Food-Energy-Water Nexus in Urban Systems. Current 
Opinion in Chemical Engineering, 17, 48-53.

https://doi.org/10.1016/j.coche.2017.06.006

Hellegers, P., Zilberman, D., Steduto, P., \& McCornick, P. (2008). Interactions

Between Water, Energy, Food and Environment: Evolving Perspectives and

Policy Issues. Water Policy, 10(S1), 1. https://doi.org/10.2166/wp.2008.048

Hodson, Michael, \& Marvin, S. (2017). Intensifying or Transforming Sustainable

Cities? Fragmented Logics of Urban Environmentalism. Local Environment,

22(sup1), 8-22. https://doi.org/10.1080/13549839.2017.1306498

Hodson, M., Marvin, S., Robinson, B., \& Swilling, M. (2012). Reshaping Urban

Infrastructure. Journal of Industrial Ecology, 16(6), 789-800.

https://doi.org/10.1111/j.1530-9290.2012.00559.x

Hoff, H. (2011). Understanding the Nexus. Background Paper for the Bonn 2011

Conference: The Water, Energy and Food Security Nexus.

Hopwood, B., \& Mellor, M. (2007). Visioning the Sustainable City. Capitalism Nature Socialism, 18(4), 75-89. https://doi.org/10.1080/10455750701705096

Howarth, C., \& Monasterolo, I. (2016). Understanding Barriers to Decision

Making in the UK Energy-Food-Water Nexus: The Added Value of Interdisciplinary Approaches. Environmental Science \& Policy, 61, 53-60.

https://doi.org/10.1016/j.envsci.2016.03.014

Howells, M., Hermann, S., Welsch, M., Bazilian, M., Segerstrom, R., Alfstad, T., Gielen, D., Rogner, H., Fischer, G., van Velthuizen, H., Wiberg, D., Young, C., Roehrl, R. A., Mueller, A., Steduto, P., \& Ramma, I. (2013). Integrated Analysis of Climate Change, Land-Use, Energy and Water Strategies. Nature Clim. Change, 3(7), 621-626.

Howells, M., \& Rogner, H.-H. (2014). Water-Energy Nexus: Assessing Integrated Systems. Nature Clim. Change, 4(4), 246-247. 
Hunt, D., Leach, J., Lee, S., Bouch, C., Braithwaite, P., \& Rogers, C. (2014). Material Flow Analysis (MFA) for Liveable Cities. Proceedings of The 4th World Sustainability Forum, f010. https://doi.org/10.3390/wsf-4-f010 I amsterdam. (2020, January 6). Facts \& Figures: I Amsterdam. https://www.iamsterdam.com/en/about-amsterdam/overview/facts-andfigures

Isenhour, C., McDonogh, G., \& Checker, M. (Eds.). (2015). Sustainability in the Global City: Myth and Practice. Cambridge University Press; Cambridge Core. https://doi.org/10.1017/CBO9781139923316 Janssen, M. A., Anderies, J. M., \& Ostrom, E. (2007). Robustness of SocialEcological Systems to Spatial and Temporal Variability. Society \& Natural Resources, 20(4), 307-322. https://doi.org/10.1080/08941920601161320 Karvonen, A., Evans, J., \& Heur, B. (2014). The Politics of Urban Experimentation: Radical Change or Business as Usual? In After Sustainable Cities (pp. 104-115).

Karvonen, A., \& Van Heur, B. (2014). Urban Laboratories: Experiments in Reworking Cities. International Journal of Urban and Regional Research, 38(2), 379392.

Keilmann-Gondhalekar, D., \& Ramsauer, T. (2017). Nexus City: Operationalizing the urban Water-Energy-Food Nexus for Climate Change Adaptation in Munich, Germany (Vol. 19). https://doi.org/10.1016/j.uclim.2016.11.004

Kenway, S. J., Lant, P. A., Priestley, A., \& Daniels, P. (2011). The Connection Between Water and Energy in Cities: A Review. Water Science and Technology, 63(9), 1983-1990. https://doi.org/10.2166/wst.2011.070 
Kenway, S. J., Lant, P., \& Priestley, T. (2011). Quantifying water-energy links and related carbon emissions in cities. Journal of Water and Climate Change, 2(4), 247-259. https://doi.org/10.2166/wcc.2011.005

Khan, S., \& Zaman, A. U. (2018). Future Cities: Conceptualizing the Future Based on a Critical Examination of Existing Notions of Cities. Cities, 72, 217225. https://doi.org/10.1016/j.cities.2017.08.022

Klimaatbureau Amsterdam. (2010). Amsterdam: A Different Energy 2040 Energy Strategy.

file://Users/enp/Downloads/energiestrategieamsterdam2040defengels.pdf Knoeri, C., K. Steinberger, J., \& Roelich, K. (2016). End-User Centred Infrastructure Operation: Towards Integrated End-Use Service Delivery. Journal of Cleaner Production, 132, 229-239.

https://doi.org/10.1016/j.jclepro.2015.08.079

Kuindersma, W., Arts, B., \& van der Zouwen, M. W. (2012). Power Faces in Regional Governance. Journal of Political Power, 5(3), 411-429.

https://doi.org/10.1080/2158379X.2012.735116

Kurian, M. (2017). The Water-Energy-Food Nexus: Trade-Offs, Thresholds and Transdisciplinary Approaches to Sustainable Development. Environmental Science \& Policy, 68(Supplement C), 97-106.

https://doi.org/10.1016/j.envsci.2016.11.006

Kurian, M., \& Ardakanian, R. (2015). Governing the Nexus Water, Soil and Waste Resources Considering Global Change. Springer.

http://download.springer.com.ezproxy.library.wur.nl/static/pdf/782/bok\%253 A978-3-319-05747-

7.pdf?originUrl=http $\% 3 \mathrm{~A} \% 2 \mathrm{~F} \% 2 \mathrm{Flink}$.springer.com $\% 2 \mathrm{Fbook} \% 2 \mathrm{~F} 10.1007 \% 2$ F978-3-319-05747- 
$7 \&$ token $2=\exp =1494841474 \sim$ acl $=\% 2 \mathrm{Fstatic} \% 2 \mathrm{Fpdf} \% 2 \mathrm{~F} 782 \% 2 \mathrm{Fbok} \% 25253$ A978-3-319-05747-

7.pdf $\% 3$ ForiginUrl $\% 3 \mathrm{Dhttp} \% 253 \mathrm{~A} \% 252 \mathrm{~F} \% 252$ Flink.springer.com $\% 252 \mathrm{Fbook}$ $\% 252 \mathrm{~F} 10.1007 \% 252 \mathrm{~F} 978-3-319-05747$ -

$7^{*} \sim \mathrm{hmac}=25 \mathrm{eae} 5 \mathrm{~d} 50 \mathrm{f} 29351 \mathrm{a} 8 \mathrm{~b} 5 \mathrm{f} 5 \mathrm{dcdfb} 1 \mathrm{bad} 84421 \mathrm{fccd} 9 \mathrm{ffb} 660 \mathrm{bf} 88 \mathrm{~b} 601 \mathrm{e} 9000$ $34 \mathrm{~b} 79$

Lafortune, G., Fuller, G., Schmidt, G., Zoetman, K., Mulder, R., \& Dagevos, J. (2019). The 2019 SDG Index and Dashboards Report for European Cities.

https://s3.amazonaws.com/sustainabledevelopment.report/2019/2019_sdg_in dex_euro_cities.pdf

Leung Pah Hang, M. Y., Martinez-Hernandez, E., Leach, M., \& Yang, A. (2016). Designing Integrated Local Production Systems: A Study on the Food-EnergyWater Nexus. Journal of Cleaner Production, 135, 1065-1084.

https://doi.org/10.1016/j.jclepro.2016.06.194

Levelt, M., Rademakers, K.-W., \& van Damme, D. (2017). Roadmap logistiek voor de foodsector in de metropoolregio Amsterdam.pdf.

file:///Users/enp/Downloads/roadmap-logistiek-voor-de-foodsector-in-demetropoolregio-amsterdam.pdf

Magagna, D., Hidalgo Gonzalez, I., Bidoglio, G., \& Peteves, S. (2019). WaterEnergy Nexus in Europe (EUR 29743 EN).

Mannan, M., Al-Ansari, T., Mackey, H. R., \& Al-Ghamdi, S. G. (2018).

Quantifying the energy, water and food nexus: A review of the latest developments based on life-cycle assessment. Journal of Cleaner Production, 193, 300-314. https://doi.org/10.1016/j.jclepro.2018.05.050

Martinez-Hernandez, E., Leach, M., \& Yang, A. (2017). Understanding WaterEnergy-Food and Ecosystem Interactions Using the Nexus Simulation Tool 
NexSym. Applied Energy, 206, 1009-1021.

https://doi.org/10.1016/j.apenergy.2017.09.022

Maye, D. (2019). 'Smart Food City': Conceptual Relations Between Smart City Planning, Urban Food Systems and Innovation Theory. City Food Governance, 16, 18-24. https://doi.org/10.1016/j.ccs.2017.12.001

McGinnis, M. D., \& Ostrom, E. (2014). Social-ecological system framework: Initial changes and continuing challenges. Ecology and Society, 19(2). https://doi.org/10.5751/ES-06387-190230 Menegaki, A. N., \& Tiwari, A. K. (2018). A global food-energy-water nexus with heterogeneity, non-stationarity and cross-sectional dependence. Quality \& Quantity. https://doi.org/10.1007/s11135-018-0690-0

Mguni, P., van Vliet, B., \& Spaargaren, G. (in press). What Could Go Wrong with Cooking? Exploring Vulnerability at the Water, Energy and Food Nexus in Kampala Through a Social Practices Lens. Global Environmental Change. Mijatovic, S. (2016, July 18). Circular Buiksloterham. Amsterdam Smart City. https://amsterdamsmartcity.com/projects/circulair-buiksloterham Mijatovic, S. (2017, July 18). Buiksloterbam- New Sanitation Raw Materials Station. Amsterdam Smart City.

https://amsterdamsmartcity.com/projects/buiksloterham-new-sanitation-rawmaterials-statio Milan Urban Food Policy Pact. (2015). Milan Urban Food Policy Pact. http://www.milanurbanfoodpolicypact.org/wpcontent/uploads/2016/06/Milan-Urban-Food-Policy-Pact-EN.pdf Mol, A. P. J., \& Dieu, T. T. M. (2006). Analysing and Governing Environmental Flows: The Case of Tra Co Tapioca Village Vietnam. NJAS - Wageningen Journal of Life Sciences, 53(3), 301-317. https://doi.org/10.1016/S1573-5214(06)80011-4 
Mol, A. P. J., \& Spaargaren, G. (2005). From Additions and Withdrawals to Environmental Flows Reframing Debates in the Environmental Social Sciences. Organization \& Environment, 18(1), 91-107. https://doi.org/10.1177/1086026604270459 Mol, A. P. J., \& Spaargaren, G. (2006a). Governing Environmental Flows: Global Challenges to Social Theory (Wageningen UR Library). MIT.

Mol, A. P. J., \& Spaargaren, G. (2006b). Towards a Sociology of Environmental Flows: A New Agenda for Twenty First Century Environmental Sociology. In Governing environmental flows: Global challenges to social theory (pp. 39-82). The MIT Press.

Morgan, K. (2009). Feeding the City: The Challenge of Urban Food Planning. International Planning Studies, 14(4), 341-348.

https://doi.org/10.1080/13563471003642852

Morganti, E., \& Gonzalez-Feliu, J. (2015). The Last Food Mile Concept as a City Logistics Solution for Perishable Products (pp. 202-207).

Moss, T., \& Marvin, S. (2001). Urban Infrastructure in Transition: Networks, Buildings and Plans. Earthscan.

Nair, S., George, B., Malano, H. M., Arora, M., \& Nawarathna, B. (2014).

Water-Energy-Greenhouse Gas Nexus of Urban Water Systems: Review of Concepts, State-of-Art and Methods. Resources, Conservation and Recycling, 89, $1-$ 10. https://doi.org/10.1016/j.resconrec.2014.05.007

National Energy Authority. (2016, October 12). Greenhouses: National Energy Authority of Iceland. http://www.nea.is/geothermal/directutilization/greenhouses/ Oosterveer, Peter J.M. (2005). Global Food Governance [S.n.]. https://edepot.wur.nl/41142 
Oosterveer, Peter J.M. (2015). Promoting sustainable palm oil: Viewed from a global networks and flows perspective. Journal of Cleaner Production, 107, 146-153. https://doi.org/10.1016/j.jclepro.2014.01.019

OR Orkuveita Reykjavikur. (n.d.). About | wnw.or.is. Retrieved 11 October 2016, from https://www.or.is/en/about

Ostrom, E. (2007). A diagnostic Approach for Going Beyond Panaceas.

Proceedings of the National Academy of Sciences, 104(39), 15181-15187.

Pahl-Wostl, C., Arthington, A., Bogardi, J., Bunn, S. E., Hoff, H., Lebel, L., Nikitina, E., Palmer, M., Poff, L. N., Richards, K., Schlüter, M., Schulze, R., StHilaire, A., Tharme, R., Tockner, K., \& Tsegai, D. (2013). Environmental Flows and Water Governance: Managing Sustainable Water Uses. Current Opinion in Environmental Sustainability, 5(3-4), 341-351.

https://doi.org/10.1016/j.cosust.2013.06.009

Ramaswami, A., Boyer, D., Nagpure, A. S., Fang, A., Bogra, S., Bakshi, B., Elliot Cohen, \& Rao-Ghorpade, A. (2017). An Urban Systems Framework to Assess the Trans-Boundary Food-Energy-Water Nexus: Implementation in Delhi, India. Environmental Research Letters, 12(2), 025008.

Reinstra, O. (2018). Waste water Treatment Biorefinery. http://www.cityzensmartcity.eu/wp-content/uploads/2016/01/cityzen-kif-wat-water-treatmentbiorefinery.pdf

Renting, H., \& Wiskerke, H. (2010). New Emerging Roles for Public Institutions and Civil Society in the Promotion of Sustainable Local Agro-Food Systems. 11.

Sassen, S. (2005). The Global City: Introducing a Concept. The Global City, 2, 18. Satterthwaite, D. (Ed.). (1999). The Earthscan Reader in Sustainable cities. Earthscan. Satterthwaite, D. (2010). The Role of Cities in Sustainable Development. 8. 
Schiller, F. (2009). Linking Material and Energy Flow Analyses and Social Theory. Ecological Economics, 68(6), 1676-1686.

https://doi.org/10.1016/j.ecolecon.2008.08.017

Schiller, F., Penn, A. S., \& Basson, L. (2014). Analyzing Networks in Industrial Ecology: A Review of Social-Material Network Analyses. Journal of Cleaner Production, 76, 1-11. https://doi.org/10.1016/j.jclepro.2014.03.029

Scott, C. A., Pierce, S. A., Pasqualetti, M. J., Jones, A. L., Montz, B. E., \& Hoover, J. H. (2011). Policy and institutional dimensions of the water-energy nexus. Energy Policy, 39(10), 6622-6630. https://doi.org/10.1016/j.enpol.2011.08.013

Serbanica, C., \& Constantin, D.-L. (2017). Sustainable Cities in Central and Eastern European Countries. Moving Towards Smart Specialization. Habitat International, 68, 55-63. https://doi.org/10.1016/j.habitatint.2017.03.005 Sheller, M. (2011). Mobility. Sociopedia.Isa. https://doi.org/10.1177/205684601163 Sheller, M., \& Urry, J. (2006). The New Mobilities Paradigm. Environment and Planning A, 38(2), 207-226. https://doi.org/10.1068/a37268 Sheller, M., \& Urry, J. (2016). Mobilizing the New Mobilities Paradigm. Applied Mobilities, 1(1), 10-25. https://doi.org/10.1080/23800127.2016.1151216 Smajgl, A., Ward, J., \& Pluschke, L. (2016). The Water-Food-Energy Nexus Realising a New Paradigm. Journal of Hydrology, 533, 533-540. https://doi.org/10.1016/j.jhydrol.2015.12.033 Smil, V. (2010). Energy Transitions: History, Requirements, Prospects. ABC-CLIO. Smil, V. (2019). Energy in World History. Routledge. 
Sonnino, R. (2009). Feeding the City: Towards a New Research and Planning Agenda. International Planning Studies, 14(4), 425-435.

https://doi.org/10.1080/13563471003642795

Sonnino, R. (2016). The New Geography of Food Security: Exploring the Potential of Urban Food Strategies. The Geographical Journal, 182(2), 190-200. https://doi.org/10.1111/geoj.12129

Sonnino, R., \& Moragues Faus, A. (2018). Introduction to Part VI: Feeding Hungry and Thirsty Cities.

Sonnino, R., Tegoni, C. L. S., \& De Cunto, A. (2019). The Challenge of Systemic Food Change: Insights From Cities. Cities, 85, 110-116. https://doi.org/10.1016/j.cities.2018.08.008 Sørensen, E., \& Torfing, J. (2009). Making Governance Networks Effective and Democratic Through Metagovernance. Public Administration, 87(2), 234-258. https://doi.org/10.1111/j.1467-9299.2009.01753.x

Spaargaren, G. (2003). Sustainable Consumption: A Theoretical and Environmental Policy Perspective. Society \&Natural Resources, 16(8), 687-701. https://doi.org/10.1080/08941920309192 Spaargaren, G., Oosterveer, P. J. M., \& Loeber, A. (2012). Food Practices in Transition: Changing Food Consumption, Retail and Production in the Age of Reflexive Modernity. Routledge.

Stojanovic, T., McNae, H. M., Tett, P., Potts, T. W., Reis, J., Smith, H. D., \& Dillingham, I. (2016). The "Social” Aspect of Social-Ecological Systems: A Critique of Analytical Frameworks and Findings from a Multisite Study of Coastal Sustainability. Ecology and Society, 21(3). https://doi.org/10.5751/ES08633-210315 
Tevar, A. D., Aelion, H. M., Stang, M. A., \& Mendlovic, J. (2016). The Need for Universal Metrics in the Energy-Water-Food Nexus. Journal of Environmental Studies and Sciences, 6(1), 225-230. https://doi.org/10.1007/s13412-016-0365-x The World Bank. (2013). Thirsty Energy: Securing Energy in a Water-Constrained World.

http://www.worldbank.org/en/topic/sustainabledevelopment/brief/waterenergy-nexus. World Bank.

http://www.worldbank.org/en/topic/sustainabledevelopment/brief/waterenergy-nexus

UN Habitat. (2017, May 19). Quick Facts - World Cities Report 2016. http://wcr.unhabitat.org/quick-facts/ UNDP. (2016, August 29). SDGs ..: Sustainable Development Knowledge Platform. https://sustainabledevelopment.un.org/sdgs United Nations. (1992). United Nations Conference on Environment \& Development Rio de Janerio, Brazil, 3 to 14 June 1992 Agenda 21. https://sustainabledevelopment.un.org/content/documents/Agenda21.pdf United Nations. (2016, June 29). Breaking 'Silo' Approach Key in Toppling Barriers to Merging Three Pillars of Sustainable Development, Speaker Tells High-level Political Forum | Meetings Coverage and Press Releases.

http://www.un.org/press/en/2015/ecosoc6705.doc.htm United Nations. (2015). Paris Agreement.

https://unfccc.int/files/essential_background/convention/application/pdf/en glish_paris_agreement.pdf United Nations. (2017). New Urban Agenda. https://sustainabledevelopment.un.org/content/documents/17761NUAEnglis h.pdf 
United Nations. (2018, May 16). 68\% of the World Population Projected to Live in Urban Areas by 2050, says UN. UN DESA | United Nations Department of Economic and Social Affairs.

https://www.un.org/development/desa/en/news/population/2018-revisionof-world-urbanization-prospects.html

Urban Centre Bologna. (2016). Bologna Resilient City. Sustainable energy and Climate Change Adaptation. http://www.caab.it/wp-content/uploads/16-05-24-PAES_IQuaderni-Bologna-citt $\%$ C3\%A0-resiliente.pdf

Urry, J. (2003). Global Complexity. Polity Press.

http:/ / www.polity.co.uk/book.asp?ref=0745628184

Urry, J. (2007). Mobilities. Polity Press.

Urry, J. (2012). Social networks, mobile lives and social inequalities. Journal of Transport Geography, 21, 24-30. https://doi.org/10.1016/j.jtrangeo.2011.10.003 Van Bets, L. K. J., Lamers, M. A. J., \& van Tatenhove, J. P. M. (2017).

Governing Cruise Tourism at Bonaire: A Networks and Flows Approach. Mobilities, 12(5), 778-793. https://doi.org/10.1080/17450101.2016.1229972 Van Bossum, J. (2017). Thesis: Amsterdam's Food Flows Carbon Footprint, Key Actors and Climate Policy. Wageningen University \& Research.

Van Der Hoek, J. P., Struker, A., \& Danschutter, J. E. M. (2013, November 5). Amsterdam as a Sustainable European Metropolis: Integration of Water, Energy and Material Flows. International Water Week, IWW Conference "Integrated Water Solutions for a Green Economy", Amsterdam, The Netherlands, 4-6 November 2013. http:// repository.tudelft.nl/view/ir/uuid\%3A310557b6-c673-4e8b-a452b0cdb9b1cef3/

Van Vliet, B., Chappels, H., \& Shove, E. (2005). Infrastructures of Consumption: Environmental Innovation in the Utility Industries. Earthscan. 
Van Vliet, B., Spaargaren, G., \& Oosterveer, P. J. M. (2011). Sanitation Under Challenge: Contributions from the Social Sciences. Water Policy, 13(6), 797-809. https://doi.org/10.2166/wp.2011.089

Van Wilden, W., Oskam, I., van den Buuse, D., Schrama, W., \& van Dijck, E.-J. (2016). Organising Smart City Projects. Amsterdam University of Applied Sciences. Villamayor-Tomas, S., Grundmann, P., Epstein, G., Evans, T., \& Kimmich, C. (2015). The Water-Energy-Food Security Nexus Through the Lenses of the Value Chain and the Institutional Analysis and Development Frameworks. Water Alternatives, 8(1), 735-755.

Villarroel Walker, R., Beck, M. B., Hall, J. W., Dawson, R. J., \& Heidrich, O. (2014). The Energy-Water-Food Nexus: Strategic Analysis of Technologies for Transforming the Urban Metabolism. Journal of Environmental Management, 141, 104-115. https://doi.org/10.1016/j.jenvman.2014.01.054

Vogt, C., Zimmermann, M., \& Brekke, K. (2014). Operationalizing the Urban Nexus: Towards Resource-Efficient and Integrated Cities and Metropolitan Regions. GIZ and ICLEI.

http://www.iclei.org/fileadmin/publications/Papers/Urban_Nexus_Publicatio n_ICLEI-GIZ_2014_web.pdf

Wallsten, B. (2015). Toward Social Material Flow Analysis: On the Usefulness of Boundary Objects in Urban Mining Research. Journal of Industrial Ecology, 19(5), 742-752. https://doi.org/10.1111/jiec.12361

Waternet. (2018, July 2016). Waternet: Who We Are. https://www.waternet.nl/en/about-us/who-we-are/

Webb, R., Bai, X., Smith, M. S., Costanza, R., Griggs, D., Moglia, M., Neuman, M., Newman, P., Newton, P., Norman, B., Ryan, C., Schandl, H., Steffen, W., Tapper, N., \& Thomson, G. (2018). Sustainable Urban Systems: Co-Design and 
Framing for Transformation. Ambio, 47(1), 57-77.

https://doi.org/10.1007/s13280-017-0934-6

Weitz, N., Strambo, C., Kemp-Benedict, E., \& Nilsson, M. (2017). Governance in the Water-Energy-Food Nexus: Gaps and Future Research Needs. Stockholm Environment Institute. https://www.sei-international.org/mediamanager/SEI2017-WP-Nexus-Governance-Weitz.pdf Wichelns, D. (2017). The Water-Energy-Food Nexus: Is the Increasing Attention Warranted, From Either a Research or Policy Perspective? Environmental Science \& Policy, 69, 113-123. https://doi.org/10.1016/j.envsci.2016.12.018 Williams, K. (2010). Sustainable cities: Research and Practice Challenges. International Journal of Urban Sustainable Development, 1(1-2), 128-132. https://doi.org/10.1080/19463131003654863 World Bank. (2007). Liveable Cities: The Benefits of Urban Environmental PlanningA Cities Alliance Study on Good Practices and Useful Tools. http://documents.worldbank.org/curated/en/944211468155698900/pdf/4709 70replacem1able0cities01 public1.pdf WWAP (World Water Assessment Programme). (2014). The United Nations World Water Development Report 2014. (Water and Energy). UNESCO. WWR. (2015). Towards a Food Policy. http://www.wrr.nl/fileadmin/en/publicaties/PDFsamenvattingen/Synopsis_WRR-report_93_Towards_a_Food_Policy.pdf Yumkella, K. K., \& Yillia, P. T. (2015). Framing the Water-energy Nexus for the Post-2015 Development Agenda. Aquatic Procedia, 5, 8-12. https://doi.org/10.1016/j.aqpro.2015.10.003 
Zhang, C., Chen, X., Li, Y., Ding, W., \& Fu, G. (2018). Water-Energy-Food Nexus: Concepts, Questions and Methodologies. Journal of Cleaner Production, 195, 625-639. https://doi.org/10.1016/j.jclepro.2018.05.194

Zhang, P., Zhang, L., Chang, Y., Xu, M., Hao, Y., Liang, S., Liu, G., Yang, Z., \& Wang, C. (2019). Food-Energy-Water (FEW) Nexus for Urban Sustainability: A Comprehensive Review. Resources, Conservation and Recycling, 142, 215-224. https://doi.org/10.1016/j.resconrec.2018.11.018 


\section{Summary}

This research elaborated in greater depth how the connectivity of WEF flows occurs and how their related governance networks reconfigure. This research argued that resource flows contain a social and a material dimension that interplay with one another in giving shape to resource provisioning systems and in connecting WEF. This research work contributed to the theorising of the urban nexus. It shed light on the socio-material interface of flows in shaping connections between WEF, and the actors facilitating these connections. Its main argument is that in the quest for understanding the WEF urban nexus, cities are crucial spaces in which environmental flows get configured and linked through governance networks. Some of the key actors to look at when identifying nexuses are switchers and programmers. These are actors that link and configure the socio-material flows of WEF facilitating the emergence of nexus governance networks. These actors play an important role on how nexus governance networks emerge, and how they connect and (re)configure WEF flows. This research focused on the interaction of structures, functions, and power dynamics of networks (re)connecting and (re)configuring WEF in higher or lesser nexus outcomes. This thesis proposed a set of concepts to analyse the nexus as exemplified through examples from geothermal energy in Reykjavik, a food centre showcase in Bologna, proximity food in Barcelona, the cases of the last mile of food and the car-regulated last time in Amsterdam (the experimental city). In the in-depth case study of Barcelona, this thesis argued that the sustainability of proximity food is not just determined by distance (between places of production and access) but by the specific ways in which food flows relate to 
connections with energy-and-water flows. We conclude that in Barcelona, proximity is developed as a concept to improve and gain on food sustainability and it has been employed as a crucial element in the re-coding of the urban food network and its food flows. However, such code and coding still deserve further developments in closing physical and social distances, not only within the food network (through its processes) but between the WEF dimensions at and through every process of food provisioning in Barcelona. In the in-depth case study of the car-regulated city of Amsterdam, this thesis unpacked the content and meaning of what occurs in distributing food in the proximity. The authors study the case of emergent e-transport alternatives distributing food in the last mile (following food flows on board of electric boats, electric vehicles, and electric bikes). The authors argued that a more sustainable last mile of food requires more than a shift toward greener modes of transport. It is also about the wider supporting urban infrastructure, including fuel shifts, alternative infrastructure provisioning (e.g. the use of canals as opposed to roads), and the socio-political infrastructure supporting or limiting the sustainable urban food transition (e.g. who supports or obstructs the transition). One of the final conclusions of this thesis suggests that governing the nexus requires a nexus interface which is mainly developed by switchers \& programmers with the help of incumbent actors. The thesis concluded on two tools that switchers, programmers, and incumbents used for steering nexus projects in cities. 1) Food proximity: learning from food short supply chains and practice, and 2) New social relations organising water, energy, and food: the open-code experimental city. between urban versus global governance, for proximity or for an experimental-city policy. After critically reflecting on the pros and cons of such tools, this research suggests that researching the urban requires to also study the continuum of urban flows on the 
move (socio-material), across urban and global scales, through resource networks. A final thought on actors making the nexus of governance networks is that new social relations as shown in cities do not always come along straightforwardly. WEF nexus thinking needs to be assisted by guiding principles, concepts, methodologies, and tools (as proximity and experimentation, but also many other ones) that can provide an initial direction towards pathways of further connectivity. In either way, from a closed-code fashion or from a more opensource code one. 


\section{WIMEK SENSE Education Certificate}

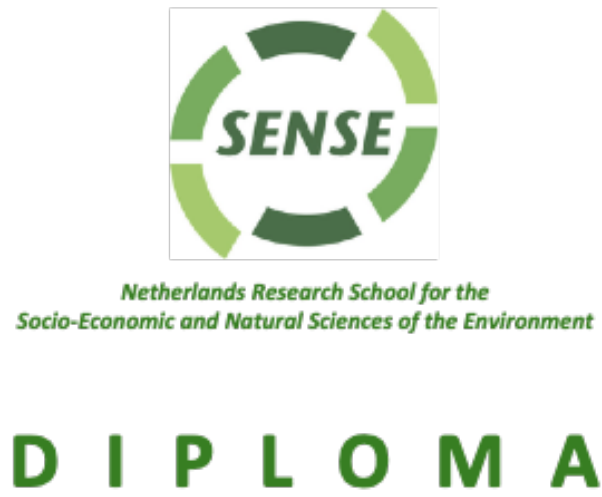

for specialised PhD training

The Netherlands research school for the Socio-Economic and Natural Sciences of the Environment (SENSE) declares that

\section{Moises Covarrubias Perez}

born on 4 August 1988 in Guadalajara, Mexico

has successfully fulfilled all requirements of the educational PhD programme of SENSE.

Wageningen, 5 November 2020
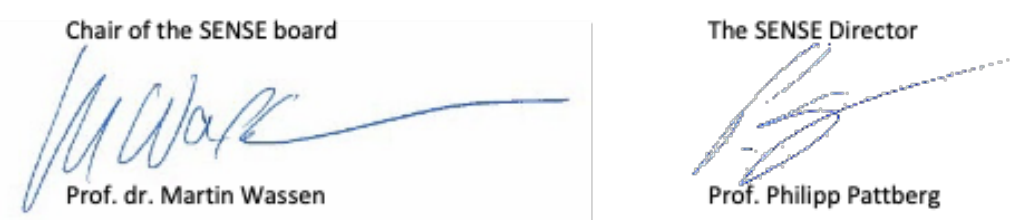

The SENSE Research School has been accredited by the Royal Netherlands Academy of Arts and Sciences (KNAW) 


\section{About the author}

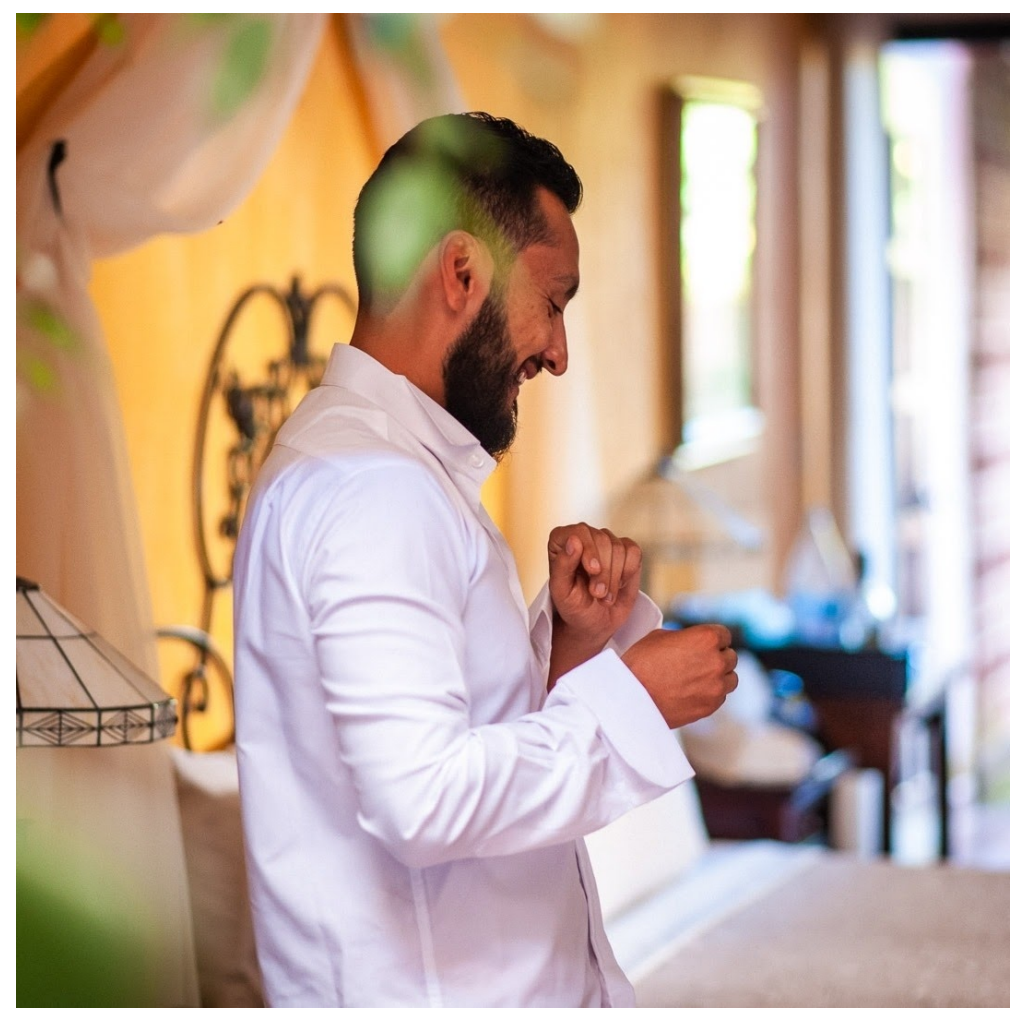

Moises Covarrubias was born on August 4th, 1988 in Guadalajara, Mexico. He studied a B.A. in Law and practiced as a Corporate and Tax Lawyer. Moises got an outstanding interest in environmental related topics after collaborating in urban management projects in Guadalajara. These facts inspired Moises to embark on his next journey in Wageningen where he studied a MSc in Urban Environmental Management (Wageningen University). During this training he developed a particular interest in the fields of Environmental Policy and Natural Resources Economics. He collaborated with the Energy Research Centre of the Netherlands (ECN) in researching 'Global Prospects for Fossil Fuels with special reference to resource rent effects and CCS' and 'Post-2020 Visions and National 
Plans for Sustainable Transport in Europe'. After these experiences he got a special interest in how society organises natural resources provisioning and then conducted further research in how 'Public-Private-Community-Partnerships for Energy Cooperatives in Amsterdam' emerge. During his Ph.D. training Moises discovered his fascination for cities. This fascination took him to explore the cities of Amsterdam, Barcelona, Bologna, Naples, and Reykjavik. New cities and new forms of governing them is what intrigues Moises the most. 
The research described in this thesis was financially supported by CONACYT

Cover illustration by Moises Covarrubias

Cover design by Moises Covarrubias

Printed by ProefschriftMaken 